\title{
Recent Advances in Nanoscale Metal-Organic Frameworks Towards Cancer Cell Cytotoxicity: An Overview
}

\author{
Pierre D. Harvey ${ }^{1}$ Jessica Plé ${ }^{1}$
}

Received: 29 January 2021 / Accepted: 19 April 2021 / Published online: 12 May 2021

(c) The Author(s), under exclusive licence to Springer Science+Business Media, LLC, part of Springer Nature 2021

\begin{abstract}
The fight against cancer has always been a prevalent research topic. Nanomaterials have the ability to directly penetrate cancer cells and potentially achieve minimally invasive, precise and efficient tumor annihilation. As such, nanoscale metal organic frameworks (nMOFs) are becoming increasingly attractive as potential therapeutic agents in the medical field due to their high structural variability, good biocompatibility, ease of surface functionalization as well as their porous morphologies with tunable cavity sizes. This overview addresses five different common strategies used to find cancer therapies, while summarizing the recent progress in using nMOFs as cytotoxic cancer cell agents largely through in vitro studies, although some in vivo investigations have also been reported. Chemo and targeted therapies rely on drug encapsulation and delivery inside the cell, whereas photothermal and photodynamic therapies depend on photosensitizers. Concurrently, immunotherapy actively induces the body to destroy the tumor by activating an immune response. By choosing the appropriate metal center, ligands and surface functionalization, nMOFs can be utilized in all five types of therapies. In the last section, the future prospects and challenges of nMOFs with respect to the various therapies will be presented and discussed.
\end{abstract}

\section{Graphic Abstract}

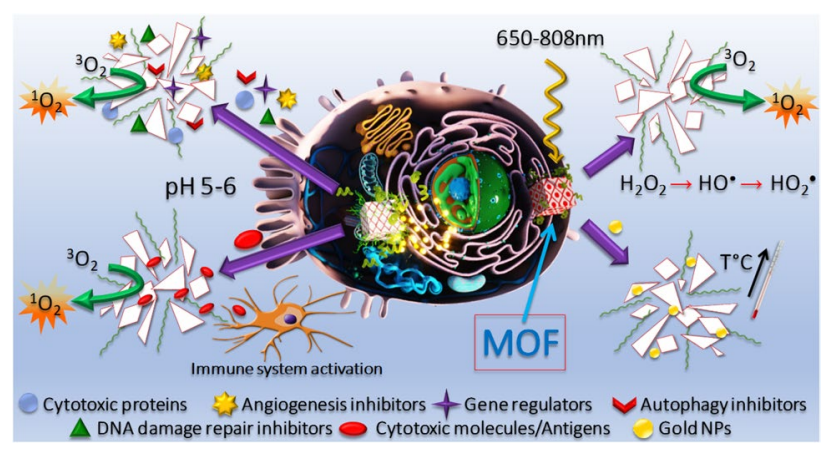

Pierre D. Harvey

Pierre.Harvey@USherbrooke.ca

1 Département de Chimie, Université de Sherbrooke, Sherbrooke, PQ J1K 2R1, Canada 


\section{Codes}

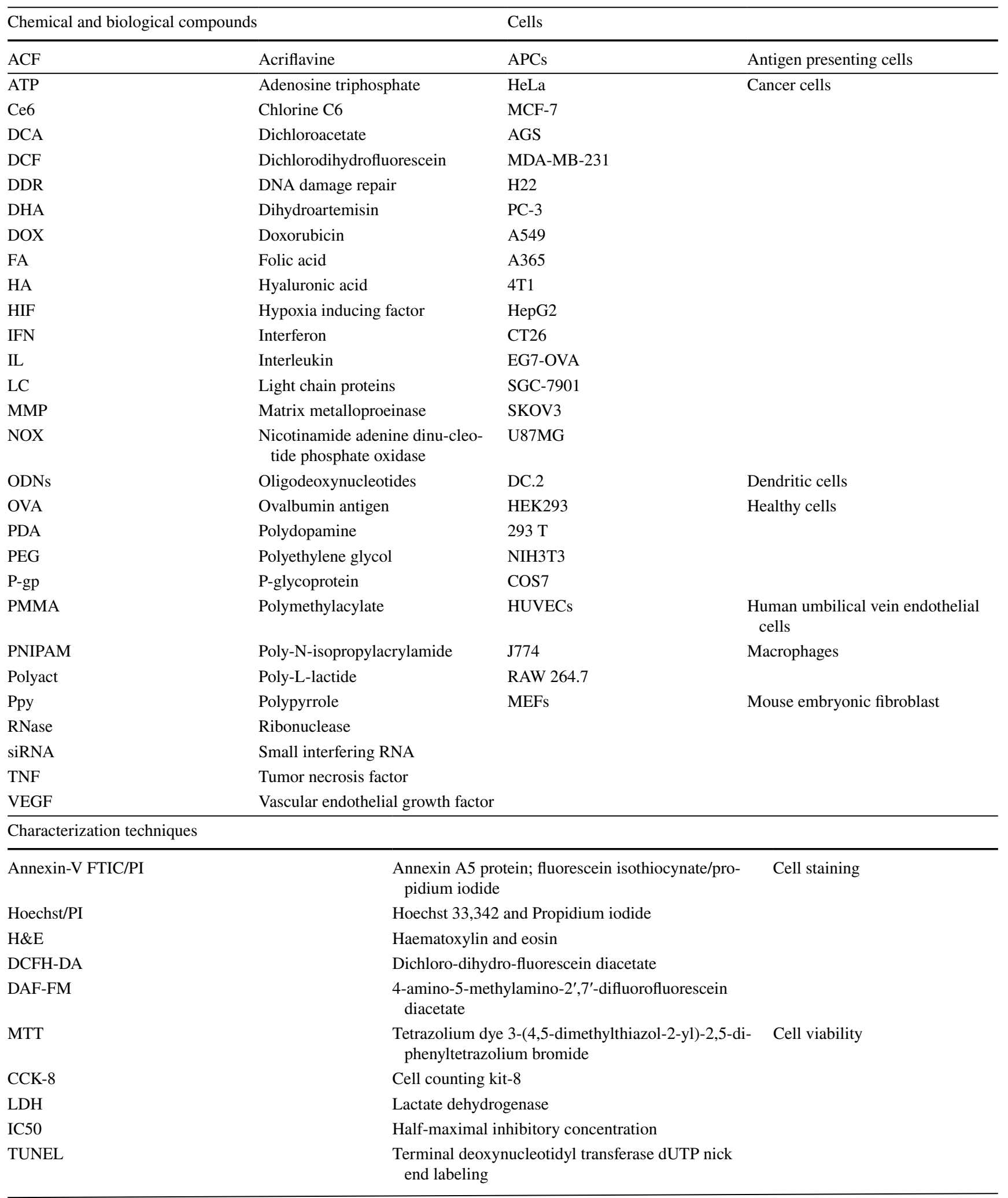


Characterization techniques

\begin{tabular}{|c|c|c|c|}
\hline FTIR & \multirow{2}{*}{\multicolumn{2}{|c|}{$\begin{array}{l}\text { Fourier transform infrared spectroscopy } \\
\text { (Powder) X ray diffraction }\end{array}$}} & MOF structure characterization \\
\hline (P)XRD & & & \\
\hline TEM/SEM & \multicolumn{2}{|c|}{ Transmission/Scanning electron microscopy } & \\
\hline TMB & \multicolumn{2}{|c|}{ 3,3',5,5'-tetramethylbenzidine } & ROS detection \\
\hline DCF & \multicolumn{2}{|c|}{ Dichlorofluorescein } & \\
\hline SOSG & \multicolumn{2}{|c|}{ Singlet oxygen sensor green } & \\
\hline DPBF & \multicolumn{2}{|c|}{ 1,3-Diphenylisobenzofuran } & \\
\hline \multicolumn{4}{|c|}{ General terms } \\
\hline FDA & Food and Drug Administration & nMOFs & Nanosized metal organic frameworks \\
\hline ICB & Immune checkpoint blockade & NPs & Nanoparticles \\
\hline JNPs & Janus nanoparticles & ROS & Reactive oxygen species \\
\hline MIL & Materials Institute Lavoisier & TNBC & Triple negative breast cancer \\
\hline MSNs & Mesoporous silica nanoparticles & $\mathrm{UiO}$ & University i Oslo \\
\hline NIR & Near-infrared & ZIF & Zeolitic imidazole frameworks \\
\hline
\end{tabular}

Fig. 1 Simplified reaction scheme of various nMOFs belonging to the ZIF, MIL and UiO families. Red: oxygen; grey: carbon; orange: iron; blue: nitrogen; turquoise: zirconium (Color figure online)
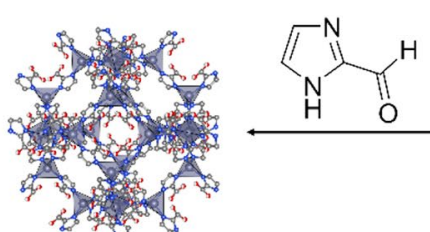

$\mathrm{Zn}\left(\mathrm{NO}_{3}\right)_{2} \cdot \mathrm{H}_{2} \mathrm{O}$<smiles>Cc1ncc[nH]1</smiles>

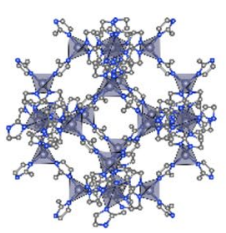

ZIF-90

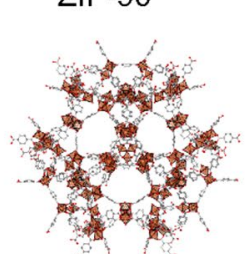<smiles>O=C(O)c1ccc(C(=O)O)cc1</smiles>

$\mathrm{FeCl}_{3} \cdot 6 \mathrm{H}_{2} \mathrm{O}$<smiles>O=C(O)c1cc(C(=O)O)cc(C(=O)O)c1</smiles>

MIL-101
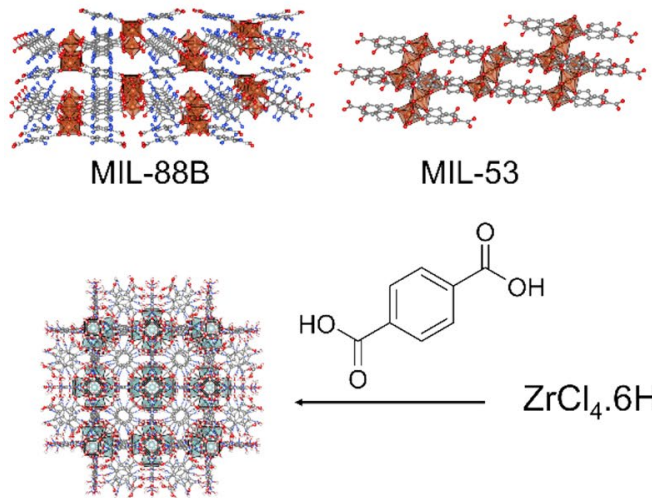<smiles>O=C(O)c1ccc(C(=O)O)cc1</smiles>

UiO-66
$\mathrm{ZrCl}_{4} \cdot 6 \mathrm{H}_{2} \mathrm{O}$<smiles>CC(C)(C)C(=O)O</smiles>

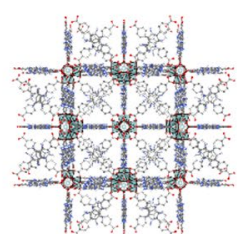

$\mathrm{UiO}-68$ 


\section{Introduction}

The second half of the twentieth century marked the rise of nanotechnology, biopharmaceutics and pharmacokinetics. Research turned to using nanoparticles (NPs) for medical applications such as drug and gene delivery, cancer therapy, biomolecule detection, tissue engineering, antimicrobial resistance and diagnosis [1-5]. Since 1995, the Food and Drug Administration (FDA) has approved close to thirty NP therapies, the first being lipid-based systems [6]. Owing to their size, NPs can easily penetrate the tissue system and be incorporated into cells for a targeted approach. Moreover, properties such as shape, charge, high surface to volume ratio, and surface chemistry can be modified to promote cellular uptake, biocompatibility, and stability in vivo. The two main classes of NPs used in medicine are organic and inorganic nanostructures. Organic nanostructures include liposomes/polymersomes, micelles and polymeric NPs; whereas inorganic materials are composed of nanoshells, silica/gold/iron oxide NPs and quantum dots [7]. Each type has specific properties that can be tuned to achieve optimal interaction with the human body.

Among the many existing nanocarriers, nanosized metal organic frameworks (nMOFs) are an attractive alternative for medical applications. The assembly of metal ions and organic linkers via coordination bonds results in a porous and tunable structures that can be further functionalized post-synthetically [8]. As potential therapeutic agents in vivo, MOFs are required to be non-toxic, stable and biocompatible in order to avoid immune system recognition. Current research investigates the use of nMOFs as bacteria inhibitors [9], wound healers [10] and diagnostic agents [11] but the most prevalent field remains cancer therapy. nMOFs have the advantage of offering synergetic therapies, which can improve cytotoxicity towards cancer cells. Thanks to their size and enhanced permeability and retention effect, MOF NPs can accumulate in tumor tissues through passive targeting, relying on the leaky vasculature, $\mathrm{pH} /$ temperature difference and absence of efficient lymphatic drainage systems of tumors. MOFs typically used for cancer treatments are porphyrine-based MOFs, zeolitic imidazole frameworks (ZIFs), Materials Institute Lavoisier (MILs) and University i Oslo (UiO) MOFs. MIL, UiO and ZIFs MOFs are, respectively, iron carboxylate, zirconium and zinc-based NPs (Fig. 1), all demonstrating significant biocompatibility [12-14].

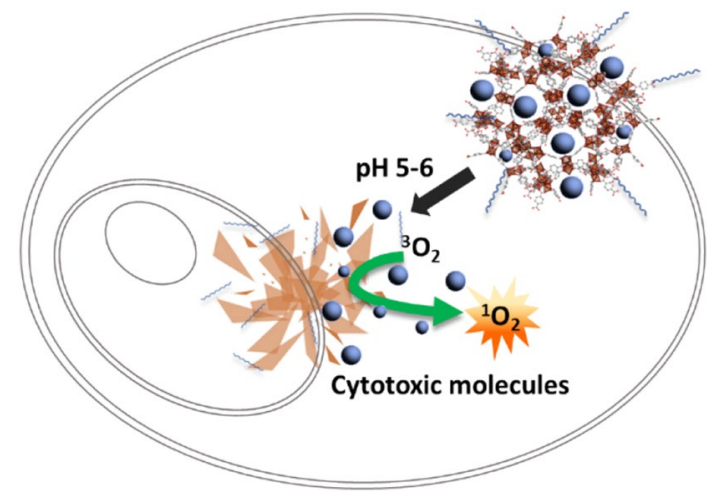

Fig. 2 Schematic illustration of nMOF-mediated chemotherapy inside a cancer cell (Color figure online)

This review focuses on the recent progress of nMOFs in triggering a cytotoxic attack on cancerous cells through photothermal, photodynamic, chemo, targeted and immuno therapies. Upon penetrating the tumor cells, nMOFs can induce cell apoptosis through different mechanisms. Photothermal and photodynamic therapies typically rely on the interactions between the nMOF structure or its surface functionalization and light, which results in the production of heat and reactive oxygen species, respectively. The release of cytotoxic molecules trapped inside nMOFs, via structural disintegration is the very basis for chemotherapy. However, as these molecules cannot differentiate normal cells from cancer cells, targeted therapies have been developed in order to limit harmful side effects of ordinary chemotherapy. As the name suggests, targeted therapies use molecules or proteins capable of disrupting specific intracellular mechanisms of cancer cells. Finally, immunotherapy uses nMOFs to increase the immune response towards cancer cells via antigen presentation, immune checkpoint blockade or vaccines. Of course, all these therapies can be combined to achieve optimal cytotoxic results.

\section{Chemotherapy}

Chemotherapy is the use of chemicals or drugs to effectively induce cancer cell death (apoptosis) through different mechanisms depending on the types of drugs. Alkylating 


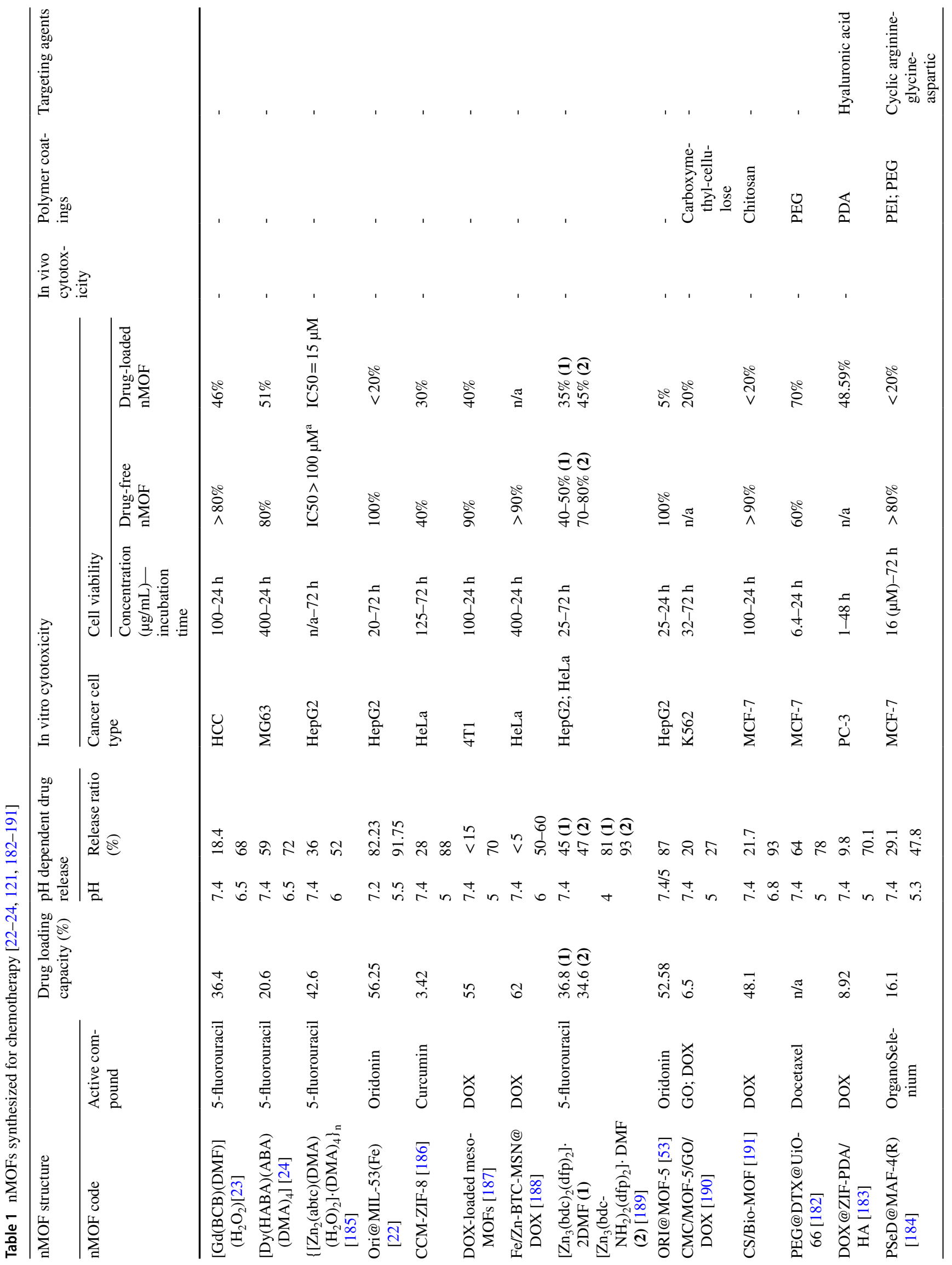


agents damage the cell's DNA, while anti-metabolites, such as 5-fluoroucil [Appendix 1 (entry 2)], substitute the DNA and RNA nucleotides. Antibiotics, namely Doxorubicin [DOX, Appendix 1. (entry 1)], prevents DNA replication and topoisomerase inhibitors block specific enzymes that separate DNA strands during replication and transcription. Finally mitotic inhibitors impede mitosis and cell division [Docetaxel, Appendix 1 (entry 4)] [15]. Other drugs mentioned in the section below include curcumin [Appendix 1 (entry 3)], which interferes with enzymes, transcription and growth factors, inflammatory cytokines and pro/antiapoptotic proteins of cancer cells [16]; as well as oridonin [Appendix 1 (entry 5)], that targets nucleolin and HSP70 proteins [17].

Metal organic frameworks have been used to improve the specificity of chemotherapy drugs, which cannot naturally distinguish healthy cells from tumors. Due to their high surface area, stimuli-responsive structure and surface functionalization properties (through post-synthesis), they are ideal candidates for targeted drug delivery. Cancer cell cytotoxicity occurs after drug release, which is achieved through the cleavage of internal covalent bonds or the shedding of surface functionalization (Fig. 2).

\subsection{Triggered Drug Delivery}

$\mathrm{pH}$ triggered drug delivery is widely used to release active molecules into cancer cells [18]. It relies on the stability of the MOF, which is usually lower in acidic conditions, resembling that of tumor environments. By regulating the secretion of lactic acid, tumor cells actively maintain low $\mathrm{pH}$, which has been shown to suppress anticancer immune responses [19]. Alavijeh et al. investigated this behavior by synthesizing a pH-responsive MIL-101(Fe) (Appendix 2 (entry a), which is a MOF loaded with curcumin via a solvothermal method [20]. The drug loading content ${ }^{1}$ was estimated to be $48.7 \%$ based on the calibration curve of curcumin [Appendix 1 (entry 3)] in ethanol using UV-vis spectroscopy titration. Powder X-ray diffraction (PXRD), FTIR spectroscopy, dinitrogen adsorption and electronic microscope images (SEM/TEM) confirmed the presence of curcumin inside the nMOF carrier. The drug release was monitored for 22 days at $\mathrm{pH} 7.4$ and 5, which reached $26 \pm 2 \%$ and $64.7 \pm 2.9 \%$, respectively. Furthermore, in vitro cytotoxicity studies were carried out on HeLa (cancer) and HEK293 (normal) cells using an MTT assay [21]. The results showed that the unloaded MIL-101(Fe) had no noticeable effects on cells even for concentrations as high as $400 \mu \mathrm{g} / \mathrm{mL}$. Upon loading with $500 \mu \mathrm{g} / \mathrm{mL}$ of curcumin, the HeLa cell viability dropped to $20 \%$ after $48 \mathrm{~h}$ of incubation, indicating an inhibition of cellular growth, while concurrently HEK293

Drug loading content $=\frac{\text { Amount of loaded drug }}{\text { Amout of drug loaded NPs }} * 100$ 
Fig. 3 Structures of MIL-53(Fe) (a), $[\mathrm{Gd}(\mathrm{BCB})(\mathrm{DMF})]\left(\mathrm{H}_{2} \mathrm{O}_{2}\right)$ (b) and $[\mathrm{Dy}(\mathrm{HABA})(\mathrm{ABA})$ $\left.(\mathrm{DMA})_{4}\right]$ (c). Red: oxygen; grey: carbon; orange: iron; turquoise: gadolinium $(\mathbf{b})$ and dysprosium (c) (Color figure online)

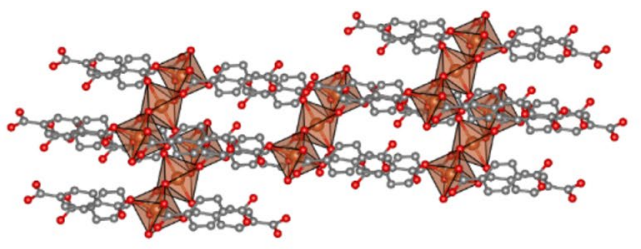

(a)

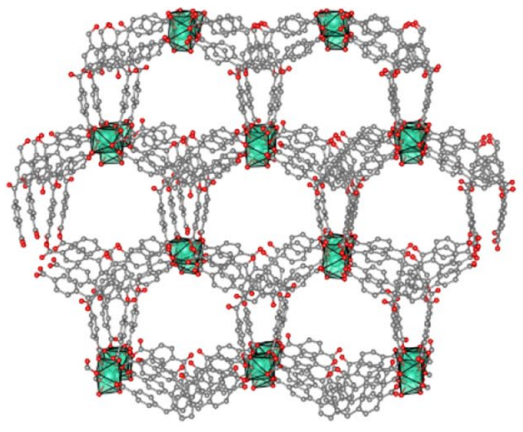

(b)

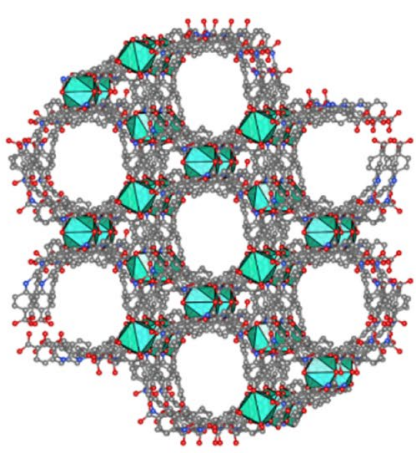

(c)

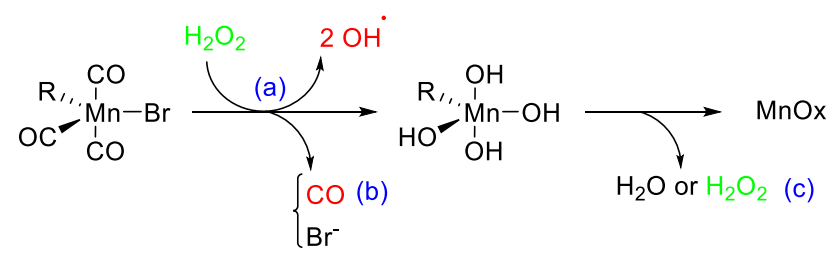

Fig. 4 Scheme illustrating how MnCO@Ti-MOF releases CO in the presence of $\mathrm{H}_{2} \mathrm{O}_{2}:$ a $\mathrm{H}_{2} \mathrm{O}_{2}$ decomposes into $\mathrm{OH}^{\bullet}$ radicals through a Fenton-like reaction; b the $\mathrm{OH}^{\bullet}$ radicals replace the $\mathrm{Br}$ and $\mathrm{CO}$ ligands causing $\mathrm{CO}$ release; $\mathbf{c}$ manganese hydroxyl decomposes into MnCOx via the removal of $\mathrm{H}_{2} \mathrm{O}_{2}$ and $\mathrm{H}_{2} \mathrm{O}$ [28] (Color figure online)

exhibited low cytotoxicity. Many other pH-responsive MOFs have been investigated (Table 1) but it appears that those belonging to the MIL family allow for enhanced cytotoxicity towards cancer cells. Indeed, they are characterized by significant drug loading capacities and are conveniently highly unstable in acidic conditions. As indicated in Table 1, the curcumin-loaded MIL-101 and oridonin-loaded MIL-53(Fe) MOFs (Fig. 3a) have drug loading capacities of about $56 \%$ $[20,22]$ whereas those of lanthanide-based MOFs [23, 24] (Fig. 3b, c) do not exceed 40\%. Combining these results with those of the drug release ratios (around 70\% compared to $>90 \%$ at $\mathrm{pH}<7$ ), the lower cytotoxicity levels of lanthanide-based MOFs are unsurprising.

Besides $\mathrm{pH}$, redox-responsive nanocarriers can be also used for drug delivery purposes. Ren et al. developed a dual triggered system in which DOX was loaded inside a $\mathrm{pH}$ responsive ZIF-8 framework [Appendix 2 (entry c)] and then encapsulated in a redox-responsive organosilica shell (ZIF-8@DOX@organosilica, denoted ZDOS), containing disulfide linkages [25]. Such bonds are stable in the cell plasma but are known to break down in the presence of high concentrations of tripeptide glutathione [Appendix 1 (entry 18)], which is characteristically present in cancer cells. After proving the efficient loading of DOX inside the ZDOS NPs using UV-vis and FTIR spectroscopy, TEM, SEM and $\mathrm{XRD}$, drug release profiles showed that, in the presence of $10 \mathrm{mM}$ of tripeptide glutathione and at $\mathrm{pH} \mathrm{5}$, the release of DOX reached $75 \%$ after $48 \mathrm{~h}$, compared to $39 \%$ without tripeptide glutathione. In vitro and in vivo MTT assays were then carried out in HeLa, MCF-7 and 293 T cells to evaluate cytotoxicity. Cell viability in vitro remained at $80 \%$ in the presence of blank NPs but decreased for increasing amounts of DOX. Moreover, Annexin-V FTIC/PI apoptosis detection assay [26] showed that apoptosis induced by ZDOS NPs was higher than that of the free DOX (84.29\% against $70 \%)$. Finally, mice bearing Hela tumors and injected with ZDOS, were monitored for 15 days: ZDOS exhibited an inhibition rate of $89.4 \%$ compared to $71.2 \%$ for free DOX. Histological studies [27] of the major organs also showed negligible pathological changes, thus confirming good biocompatibility of the system.

Jin et al. put forward yet another type of triggered drug delivery, that of hydrogen peroxide. The authors synthesized a titanium-based MOF using 4,4'-bipyridine as the linker and coordinated it to a manganese carbonyl prodrug (MnCO@ Ti-MOF, Fig. 11a) [28]. In the presence of $\mathrm{H}_{2} \mathrm{O}_{2}$, which is typically overexpressed in tumors, the system releases carbon monoxide, capable of inducing cancer cell apoptosis, via a Fenton-like reaction (Fig. 4). Moreover, this release is accompanied by a "turn-off" of the cyanine fluorescence, used as an internal probe, thus enabling the monitoring of the intracellular carbon monoxide distribution. 


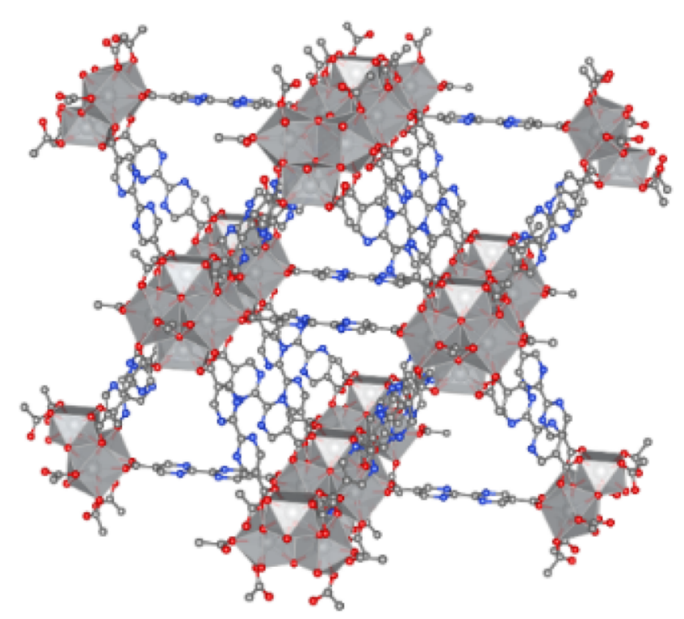

(a)

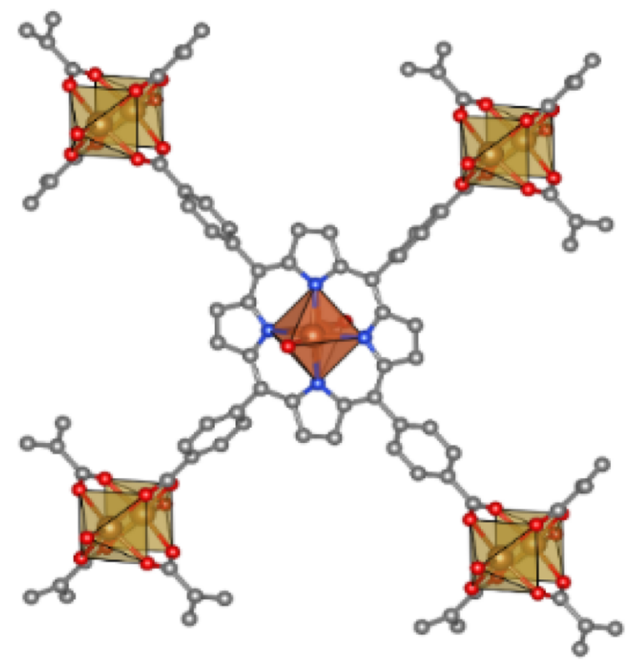

(c)

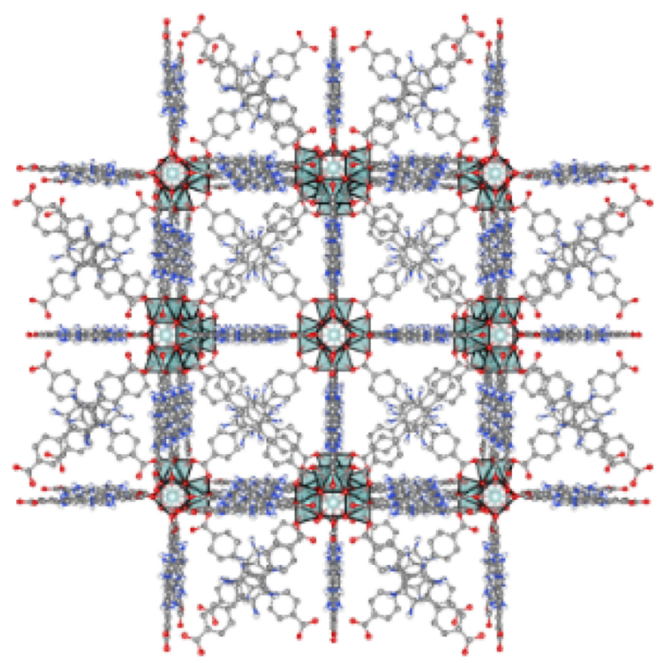

(b)

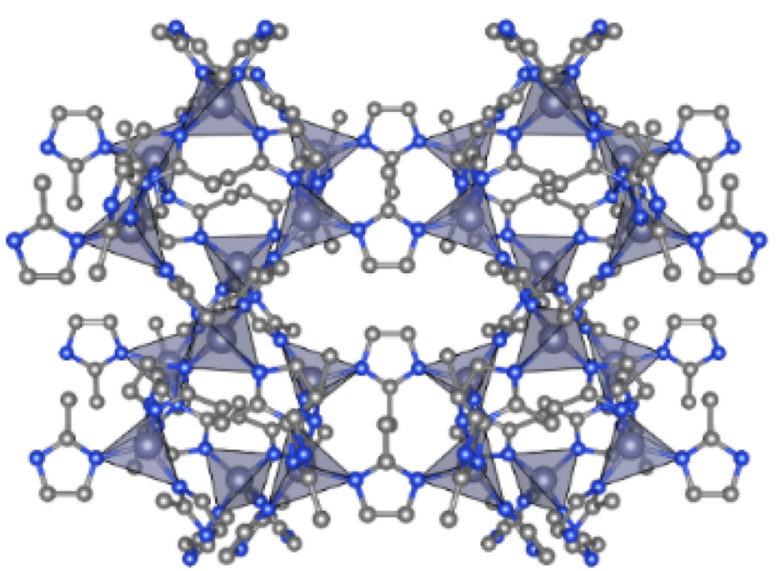

(d)

Fig. 5 a Ti-MOF structure. b UiO-68 MOF structure. c Cu-TCPP(Fe) nMOF nanosheets structure. d ZIF-L MOF structure. Red: oxygen; grey: carbon; blue: nitrogen; purple: titanium (a) or zinc (d); green: zirconium; orange: iron; yellow: copper (Color figure online)

In vitro fluorescence imaging was carried out on $\mathrm{HeLa}$ breast cancer cells. In the presence of $\mathrm{MnCO} @ \mathrm{Ti}-\mathrm{MOF}$, cell morphology gradually changed, possibly attributed to cell apoptosis. CCK-8 assays performed on HeLa and AGS cancer cells revealed that the nanocarriers caused an $80 \%$ reduction in AGS cell viability at $200 \mu \mathrm{g} / \mathrm{mL}$ loading, which is superior to that of HeLa cells (50\%) due to the higher $\mathrm{H}_{2} \mathrm{O}_{2}$ concentration. In comparison, Ti-MOFs maintained excellent cell viability and showed good biocompatibility.

nMOFs are far from being the only stimuli-responsive drug delivery systems available, but they exhibit certain advantages over mesoporous silica nanoparticles (MSNs) and dendrimers for example. Firstly, they have a higher drug loading capacity. For instance, the BET surface of nMOFs ranges from 1000 to $7000 \mathrm{~m}^{2} / \mathrm{g}(1419.6,1465.9$ and 968 $\mathrm{m}^{2} / \mathrm{g}$ for MIL-101(Fe) [20], ZDOS [25] and Ti-MOF [28], respectively) while that of the MSNs ranges from 700 to $1200 \mathrm{~m}^{2} / \mathrm{g}$. Furthermore, dendrimers and MSNs can only encapsulate hydrophobic substances whereas nMOFs are amphiphilic, thanks to the variety of available organic linkers [29]. Even though MSN and dendrimers can be used as chemotherapy agents and achieve cytotoxicity through triggered release [30, 31], the results cannot easily be compared as they simultaneously depend on the drug type, the drug diffusion rate, the nature of host-guest interactions and degradation kinetics [29]. Nevertheless, it should be noted that the nMOFs have the distinct advantage of being highly tailorable, meaning they can be designed to accommodate various drugs, depending on the type of tumor targeted. 
Fig. 6 a Synthesis of the nucleic acid-functionalized $\mathrm{MOF}(3)$. b Preparation of the dye/drugloaded $\mathrm{MOF}(3)$ capped by the (3)/(4) duplex and the subsequent $\mathrm{pH}$-induced unlocking via the reconfiguration into intercalated-motif structures. c Preparation of the dye/drugloaded $\mathrm{MOF}(3)$ capped by the (3)/(5) duplex and the subsequent $\mathrm{pH}$-induced unlocking via the reconfiguration into intercalated-motif structures. d Drug/ dye release from $\operatorname{MOF}(6 / 7)$ through the cleavage of the capping units by $\mathrm{Mg}^{2+}$ ions that activate the $\mathrm{Mg}^{2+}$-dependent DNAzymes. e Drug/dye release from $\mathrm{MOF}(6 / 8)$ through the cleavage of the capping units by $\mathrm{Pb}^{2+}$ ions that activate the $\mathrm{Pb}^{2+}$-dependent DNAzymes. f Drug/dye release from $\operatorname{MOF}(6 / 9)$ via the unlocking of the capping units via the cooperative cleavage of the lock, in the presence of ATP and $\mathrm{Mg}^{2+}$ ions [33]. Published by The Royal Society of Chemistry (Color figure online)

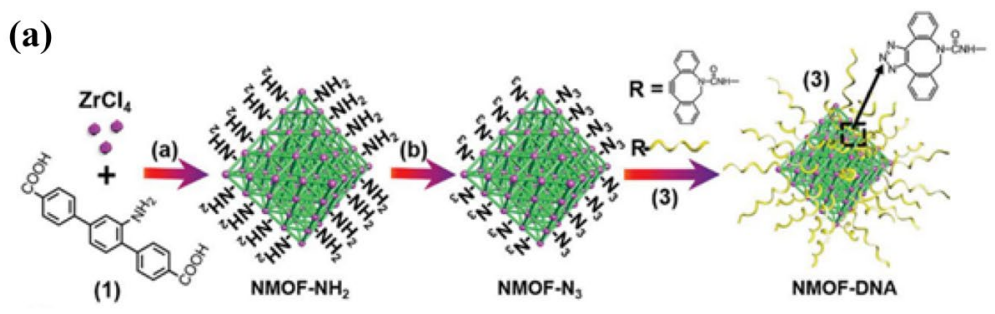

(b)

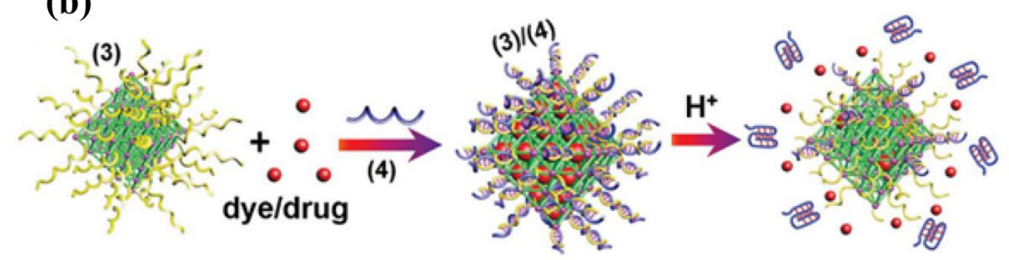

(c)

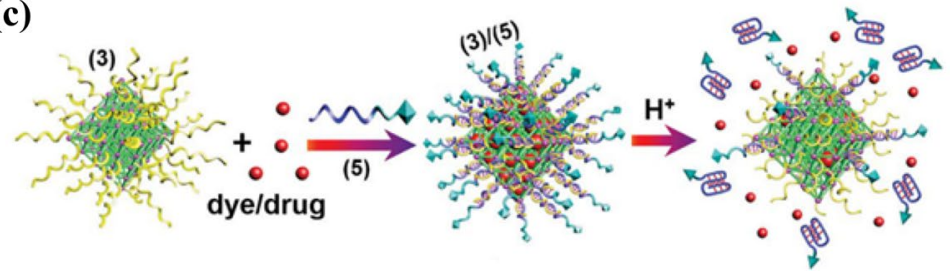

(d)

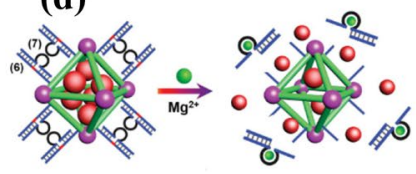

(e)

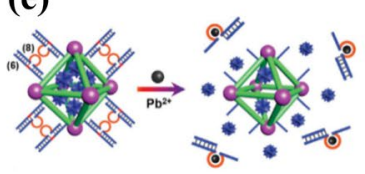

(f)

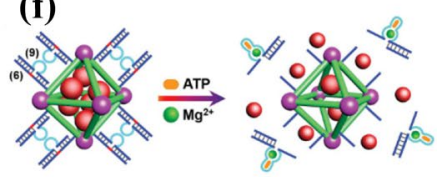

\subsection{Nucleic Acids and Polymer Coating of MOFs}

Post-synthetic modifications of nMOFs have been widely investigated as they improve biocompatibility, stability and dispersion; while allowing the nanocarriers to cross biological barriers and avoid immune system recognition in order to deliver the drugs. The functional groups of organic ligands $\left(-\mathrm{NH}_{2},-\mathrm{OH},-\mathrm{Cl},-\mathrm{Br}\right)$ or the unsaturated metal centers act as anchoring sites for Lewis acid-base interactions. Postsynthetic modifications of MSNs, on the other hand, are limited to silanol chemistry using alkosilanes and halosilanes to form $\mathrm{Si}-\mathrm{O}-\mathrm{Si}$ bonds via condensation reactions [32]. No such limitations exist for nMOFs as can be observed from the following examples. In 2017, Chen et al. designed a nucleic acid functionalized zirconium-based MOF (denoted MOF(3), Fig. 5a) using $\mathrm{NH}_{2}$-triphenyl carboxylic acid [Appendix 1. (entry 35)] as linker [33]. Two sets of nanocarriers were then developed depending on the selected DNA capping. The first set included the $\mathrm{pH}$-responsive $\mathrm{MOF}(3) /$ (4) (Fig. 5b), which was capped with nucleic acid strands containing a cytosine (C)-rich sequence that reconfigures into an intercalated-motif structure in acidic conditions. Concurrently, MOF(3)/(5) (Fig. 5c) was designed by adding a AS1411 aptamer as a cancer cell targeting agent to
MOF(3). When loaded with DOX, both nanostructures exhibited cytotoxicity towards MDA-MB-231 breast cancer cells. After five days, cell death reached $45 \%$ and $50 \%$ in the presence of $\operatorname{MOF}(3) /(4)$ and (3)/(5), respectively. The second set of nMOFs was designed by attaching metalion-dependent catalytic nucleic acids (DNAzymes), such as $\mathrm{Mg}^{2+}$ or $\mathrm{Pb}^{2+}$-containing DNAzyme, onto the $\mathrm{Zr}-\mathrm{MOF}$, resulting in $\mathrm{MOF}(6) /(7)$ (Fig. 5d) and (6)/(8) (Fig. 5e) where (6) is a nucleic acid acting as a substrate for the DNAzymes. $\operatorname{MOF}(6) /(7)$ was further functionalized with an adenosine triphosphate [ATP, Appendix 1 (entry 22)] aptamer resulting in $\operatorname{MOF}(6) /(9)$ (Fig. 5f). DOX-loaded $\operatorname{MOF}(6) /(7)$ and (6)/ (9) were then injected into MDA-MB-231 cells. Cell death reached $30 \%$ for $\mathrm{MOF}(6) /(9)$ versus $15 \%$ for $\mathrm{MOF}(6) /(7)$ due to the ATP aptamer.

More recently, Cao et al. investigated a similar stimuliresponsive DNA-functionalized ZIF-8 structure [Appendix 2. (entry c)] [34]. The main difference with the previous investigation is the choice of the metal-ion-dependent catalytic nucleic acid ( $\mathrm{K}^{+}$ions) and the use of rhodamine $6 \mathrm{G}$ as a drug model. NIH3T3 cells incubated with the rhodamine loaded ZIF-8 s showed an intense green fluorescence after $60 \mathrm{~min}$ of incubation, proving the effective $\mathrm{K}^{+}$-stimuli-responsive release of the dye. If the rhodamine 
Fig. 7 a Schematic loading and unlocking of $\operatorname{MOF}(1) /(2)$ through the formation of the VEGF/aptamer complex, where (2) is a nucleic acid containing the anti-VEGF aptamer. b Schematic loading and unlocking of $\mathrm{MOF}(1) /(3)$ through the formation of the VEGF/aptamer complex, where (3) includes the anti-VEGF aptamer conjugated to the AS1411 aptamer [38]. Reproduced with permission from The Royal Society of Chemistry (Color figure online)

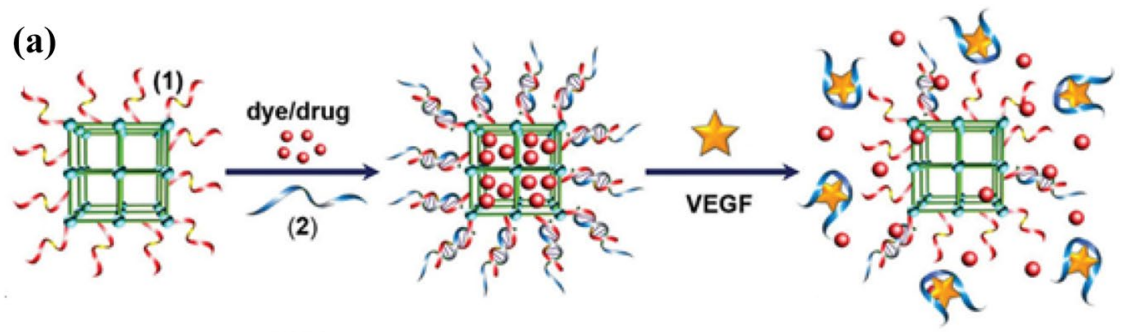

(b)

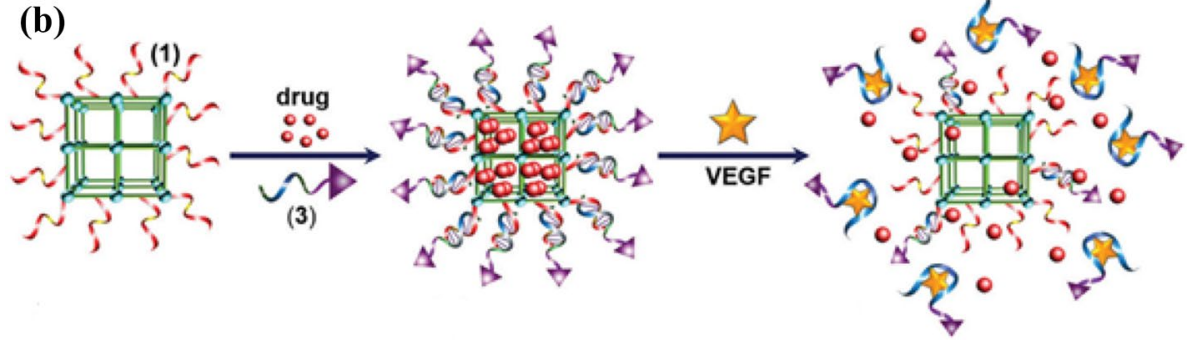

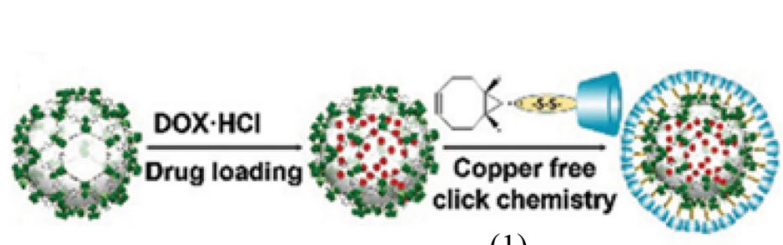

(1)

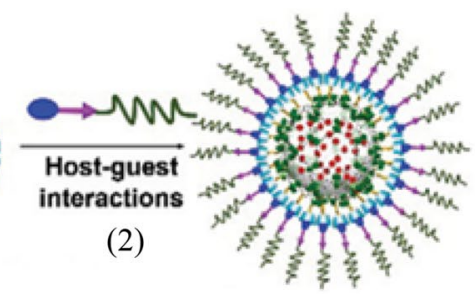

Fig. 8 Schematic illustration of drug loading and post-synthetic surface functionalization. (1) Functionalization with bicyclononyne functionalized $\beta$-cyclodextrin derivatives attached to PEG1900 poly-

dye were to be substituted with a chemotherapy drug, the synthesized nanocarrier could indeed become a significant therapeutic agent.

MicroRNAs (miRNAs) and vascular endothelial growth factor (VEGF) are other types of nucleic acid unlocking system. miRNA-functionalized silica NPs [35] and carbon quantum dots [36] have been investigated as drug carriers but because of the need for high miRNAs concentrations for drug release, Chen et al. decided to synthesize a miRNAresponsive, DOX loaded, UiO-68 MOF instead (Fig. 11b) [37]. The drug release occurred via a dual unlocking mechanism using miRNA-21, a specific biomarker of MCF-7 breast cancer cells, and miRNA-221 for OVCAR-3 ovarian cancer cells. An exonuclease-stimulated regeneration of both miRNAs solved the miRNA concentration issue, resulting in an enhanced drug release from the MOF. As expected, the miRNA-21-responsive DOX-loaded nMOFs decreased the in vitro cell viability of MCF-7 cells to $60 \%$ after $36 \mathrm{~h}$, compared to $85 \%$ for normal MCF-10A cells and OVCAR-3 cells. Comparatively, miRNA-221-responsive DOX-loaded MOFs caused the OVCAR-3 cell viability to drop to $60 \%$, while that of MCF-7 and MCF-10A cells remained above $90 \%$ after $36 \mathrm{~h}$. The advantage of the miRNA-responsive mers. (2) Functionalization with $\alpha_{v} \beta_{3}$ integrins [41]. Reproduced with permission from The Royal Society of Chemistry (Color figure online)

nanocarriers over other types of drug delivery systems rests on the selectivity of the miRNA strands towards specific cancer cells as can be seen from Chen et al.'s results.

Since cancer cells are also defined by high levels of VEGF, Chen et al. also developed a DOX-loaded Zr-based MOF functionalized with a nucleic acid containing the antiVEGF aptamer (denoted MOF(1)/(2), Fig. 6a) [38]. In the presence of VEGF, VEGF-aptamer complexes are formed, which triggers the unlocking of the MOF pores. $\mathrm{MOF}(1) /(3)$ (Fig. 6b) was further post-modified by attaching the cancer targeting aptamer AS1411 to the VEGF aptamer. The two types of nMOFs were incubated with normal MCF-10A cells and MDA-MB-231 cancer cells. Both nMOFs were non-toxic towards normal cells because of insufficient cell permeation and the low concentrations of VEGF. Besides, upon increasing cancer cell permeation, the presence of the targeting aptamer enhanced MDA-MB-231 cell death. Indeed, $40 \%, 60 \%$ and $79 \%$ cell death was observed respectively after one, two and three days of incubation, compared to $25 \%, 40 \%$ and $50 \%$ for $\mathrm{MOF}(1) /(2)$.

Besides the use of various nucleic acids, polymer coatings on nMOFs have also attracted significant attention recently [39]. Polyethylene glycol (PEG) is one of the most 
Fig. 9 ROS generation via the reaction between ferric ions and DHA [44, 45] (Color figure online)

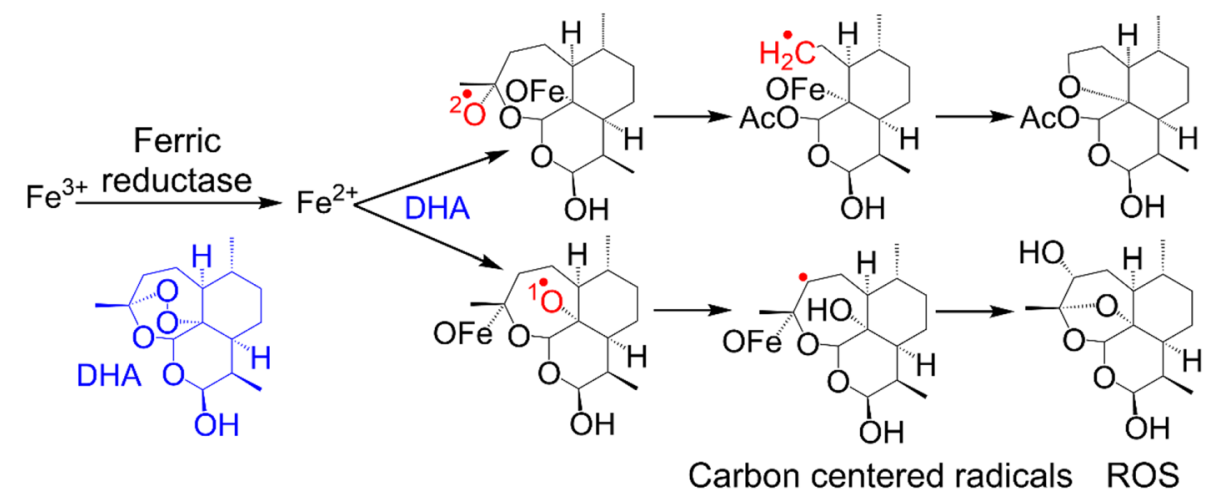

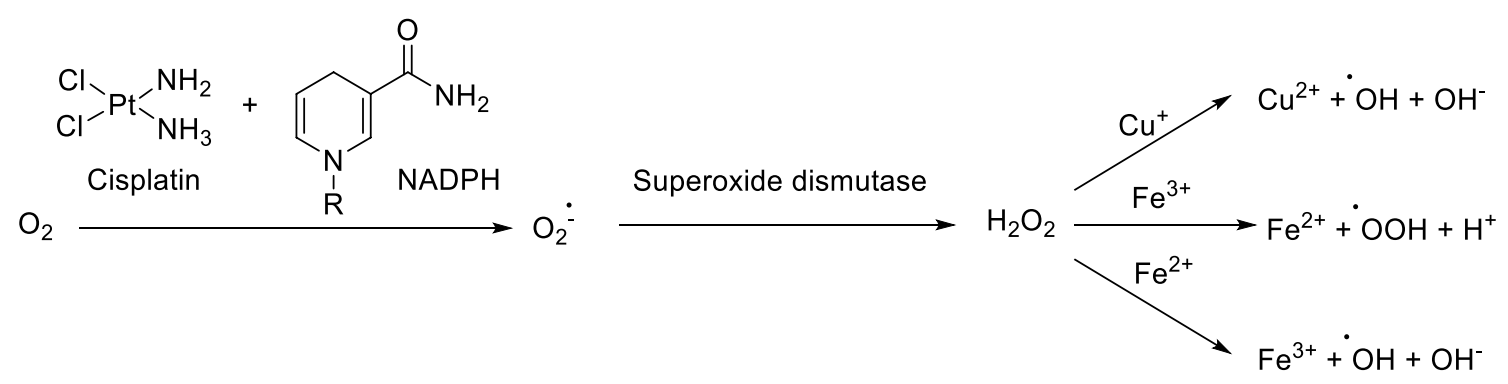

Fig. 10 Activation of NOX by Cisplatin and formation of superoxide anions and $\mathrm{H}_{2} \mathrm{O}_{2}$ from $\mathrm{O}_{2}$ followed by Fenton reactions [44]

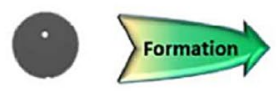

$\mathrm{Fe}_{3} \mathrm{O}_{4} \mathrm{NPS}$

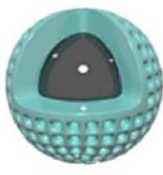

$\mathrm{Fe}_{3} \mathrm{O}_{4} @ \mathrm{MSN}$
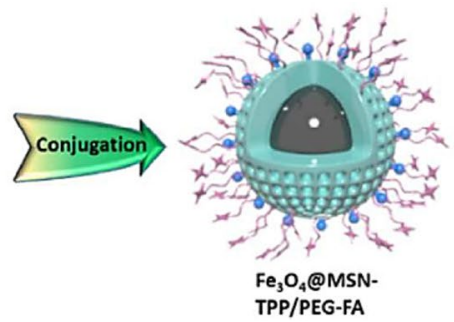

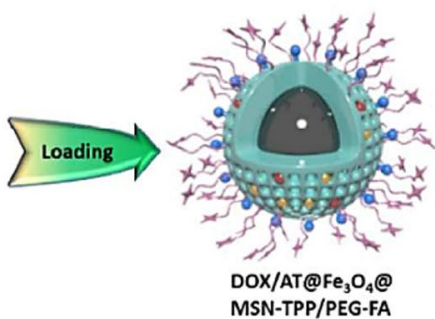

Fig. 11 Schematic synthesis of DOX/3-amino-1,2,4-triazole-loaded $\mathrm{Fe}_{3} \mathrm{O}_{4} @ \mathrm{MSN}$, further conjugated to folate/triphenylphosphonium [48]. Reproduced with permission from The Royal Society of Chemistry (Color figure online)

commonly used polymers, as it extends the nMOF lifetime through the blood stream, and offers increased stability and solubility while protecting the nanostructure from the immune system[40]. Wang et al. designed a DOX-loaded MIL-101(Fe) modified with a bicyclononyne functionalized $\beta$-cyclodextrin derivative attached to a PEG1900 polymer (Fig. 7). It was also functionalized with an $\alpha_{v} \beta_{3}$ integrin (abnormally expressed in cancer cells) hence targeting the peptides through host-guest interactions ((K(ad)RGDSPEG1900) [41]. The benzoic imine bond existing between the K(ad)RGDS motif and the PEG chains can break in acidic conditions, leaving the targeting peptide exposed, thus allowing cellular uptake in tumors. Dithiothreitol [Appendix 1. (entry 17)] and tripeptide glutathione can also cleave the disulfide bond linking the $\beta$-cyclodextrin unit to the nanostructure, thus releasing the drugs by a successive layer removal mechanism. The presence of dithiothreitol significantly increased the drug release, with a cumulative value of $78 \%(10 \mathrm{mM})$ versus $16 \%$ without dithiothreitol after $140 \mathrm{~h}$. The HeLa cell viability reached $62 \%$ and $29 \%$ at $\mathrm{pH} 7.4$ and 5, respectively, compared to $77 \%$ at $\mathrm{pH} 7.4$ for $\operatorname{COS} 7$ normal cells. In addition, the MOF surface modification effectively increased the biocompatibility of DOX-loaded and DOX free MIL-101(Fe), cell viability remaining over $80 \%$. In vivo experiments performed on mice bearing $\mathrm{H} 22$ tumors, showed an efficient inhibition of the tumor growth for the synthesized MOF after 12 days of treatment and no side effects were observed after hematoxylin and eosin (H\&E) staining [27].

Polydopamine [PDA, Appendix 1. (entry 14)] is another particularly biocompatible polymer. Miao et al. coated polymethylacrylate [Appendix 1. (entry 15)] and polydopamine 
unto a MIL-100(Fe) MOF, loaded with DOX, via a layer by layer method (PMAA BACy $_{0}(\mathrm{MOF})_{10} @$ PDA) [Appendix 2. (entry b)] [42]. Afterward, tripeptide glutathione was used to trigger the rupture of the disulfide bond in $\mathrm{PMMA}_{\mathrm{BACy}}$, destroying the MOF structure, thus releasing DOX and $\mathrm{Fe}^{3+}$, which leads to intracellular $\mathrm{H}_{2} \mathrm{O}_{2}$ decomposition in the reactive oxygen species $\mathrm{HO}^{\circ}$. Combining $\mathrm{H}_{2} \mathrm{O}_{2}$ and tripeptide glutathione improved drug delivery significantly. The nMOF responded first to $50 \mu \mathrm{M} \mathrm{H}_{2} \mathrm{O}_{2}$ dosage and then to $\mathrm{pH} 5$ with $10 \mathrm{mM} \mathrm{GSH}$, which resulted in a $78.52 \%$ cumulative DOX release after $50 \mathrm{~h}$. The PDA coating, while improving biocompatibility, hindered drug release because some of the pores remain blocked. The cell viability of PC- 3 cancer cells remained at $90 \%$ for the DOX-free MOFs after $24 \mathrm{~h}$, while decreasing to $10 \%$ when incubated with $9.6 \mu \mathrm{g} / \mathrm{mL}$ of DOX-loaded MOFs. Other types of polymer coatings are presented in Table 1.

\subsection{ROS Generation}

Cancer cells naturally have higher levels of reactive oxygen species (ROS) compared to normal cells because of their role in tumor development. However, tumors also show high levels of antioxidant proteins that keep the ROS generation in check. For this reason, inducing the production of additional ROS using chemotherapy can disrupt the metabolism of the cancer cells (mitochondrial dysfunction), resulting in apoptosis.

Wang et al. developed a MIL-100(Fe) MOF in which cell death occurs through the reaction between the encapsulated magnetic iron oxide NPs and dihydroartemisin [DHA, Appendix 1. (entry 6)] [43]. The acidic conditions induce decomposition of the prepared MOFs DHA- $\mathrm{Fe}_{3} \mathrm{O}_{4} @ \mathrm{C} @$ MIL-100(Fe) (DHA-FCM) and consequently of the drug release (Appendix 2. (entry b). The Fe(III) ions are reduced to $\mathrm{Fe}$ (II) ions by ferric reductase, which can then react with DHA, hence supplying ROS and inducing cell death (Fig. 8) $[44,45]$. HeLa cells were used for in vitro ROS and MTT assays. The fluorescence intensity of dichlorodihydro-fluorescein [DCF, Appendix 1. (entry 24)] almost quadrupled in cells injected with DHA-FCM after $48 \mathrm{~h}$ indicating a significant increase in ROS generation. Concurrently, DHA-FCM was found to maintain the cell viability at around $80 \%$ for a concentration as high as $100 \mu \mathrm{g} / \mathrm{mL}$, which indicates an insufficient degradation of the MOF structure. When injected into mice bearing the HeLa tumors, DHA-FCM exhibited a higher tumor inhibition rate than that of free DHA. Optimal results were obtained when the MOFs were coupled with a magnet capable of concentrating the MOFs in the tumors, thanks to the magnetic properties of the iron oxide NPs. H\&E staining confirmed these results, while proving that no major organs suffered inflammation or lesions after 25 days of treatment.

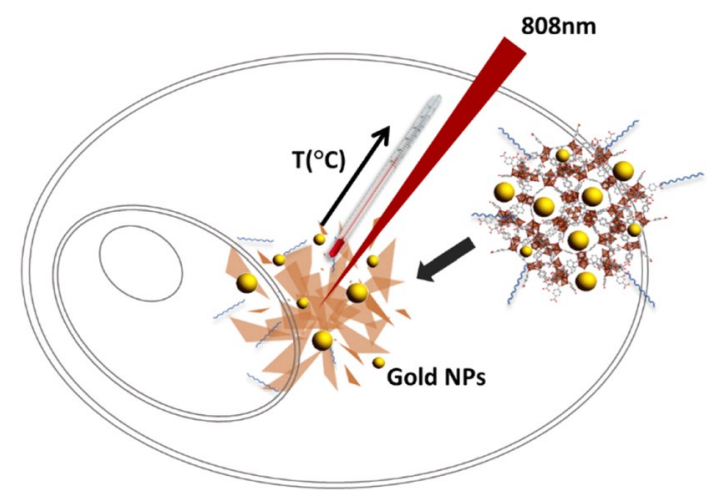

Fig. 12 Schematic illustration of nMOF-mediated photothermal therapy (Color figure online)

Cisplatin (cis-diamminedichloridoplatinum(II)) is a commercial anti-cancer drug able to activate nicotinamide adenine dinucleotide phosphate oxidase (NOX) which transforms $\mathrm{O}_{2}$ into superoxide anions, subsequently converted into $\mathrm{H}_{2} \mathrm{O}_{2}$ by superoxide dismutase. Ferric or cupric ions then catalyze $\mathrm{H}_{2} \mathrm{O}_{2}$ to ROS through a Fenton reaction (Fig. 9) [46]. Li et al. fabricated copper-porphyrin MOF nanosheets $(\mathrm{Cu}-\mathrm{TCPP}(\mathrm{Fe})$, Fig. 11c) coordinated with $4.8 \%$ Cisplatin [47]. Upon exposure to the nanosheets, A549 cancer cells underwent a $96.86 \%$ inhibition after $48 \mathrm{~h}$ of incubation at $50 \mu \mathrm{g} / \mathrm{mL}$. The presence of Cisplatin highly increased the green fluorescence intensity of dichlorodihydrofluorescein diacetate [DCFH-DA, Appendix 1. (entry 25)] sixfold through intracellular ROS (compared to the free Cisplatin system). Inside the cells, DCFH-DA is hydrolyzed into a DCFH carboxylate anion, which can then be deprotonated into DCF.

In comparison, iron oxide core-shell MSNs, conjugated with folate/triphenyl-phosphonium and loaded with DOX/3amino-1,2,4-triazole, were synthesized by Sun et al.(Fig. 10) [48]. Like Cisplatin, DOX activates NOX, which leads to the generation of toxic ROS. When incubated with MCF-7 cancer cells, the NPs showed an effective inhibition rate of $92.25 \%$. As the MSNs are functionalized with both a tumor targeting agent and a mitochondrial binding fragment, the cellular uptake was facilitated, which could explain the remarkable inhibition rate value of $92.25 \%$ compared to that of $\mathrm{Cu}-\mathrm{TCPP}(\mathrm{Fe}) \mathrm{MOF}(96.86 \%)$.

To further improve the biocompatibility and the cellular uptake of ROS generating MOFs, Prabhu et al. synthesized a methyl gallate encapsulated ZIF-L MOF using marine algae (MG@ZIF-L, Fig. 11d)[49]. As such, ZIF-L exhibited minimal cytotoxicity towards A549 cells, but when loaded with MG, the cell viability decreased to $20 \%$ at $100 \mu \mathrm{g} /$ $\mathrm{mL}$. The cells incubated with MG@ZIF-L also showed an increase of the concentration dependence in lactate dehydrogenase (LDH) leakage [50] and enhanced ROS levels. 


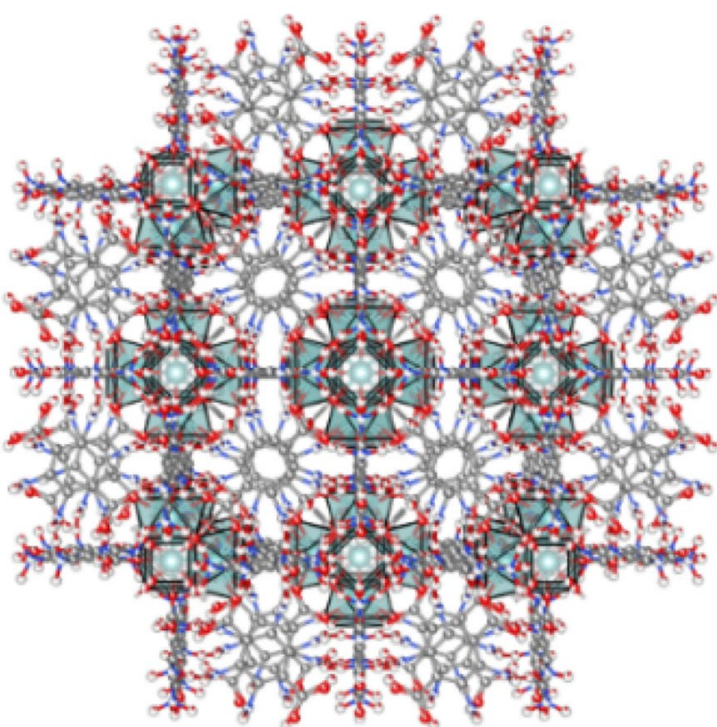

(a)

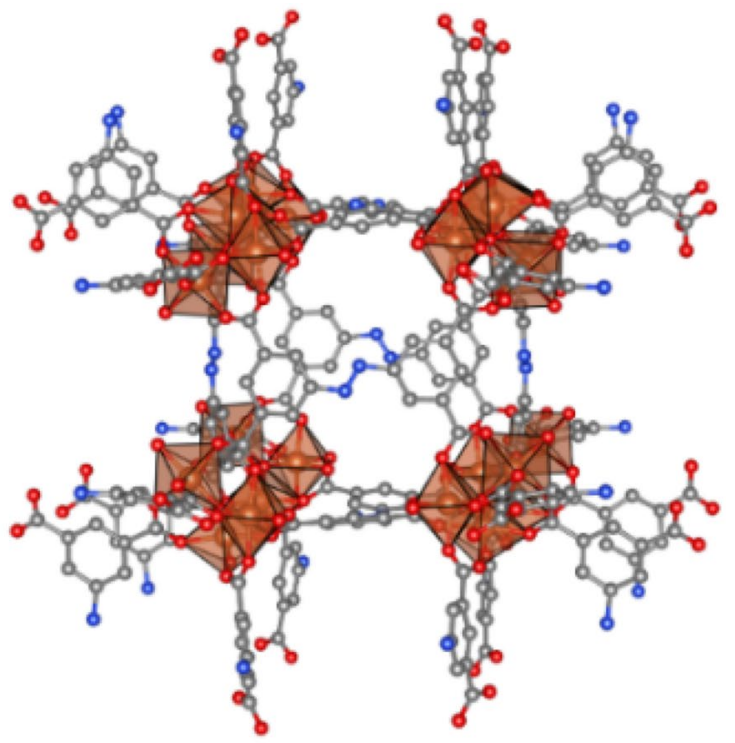

(b)

Fig. 13 a UiO-66 MOF structure. b Fe-soc-MOF structure. Red: oxygen; grey: carbon; blue: nitrogen; green: zirconium; orange: iron (Color figure online)

The fluorescence of DCFH-DA dyed A549 cells was six times higher when treated with MG@ZIF-L compared to ZIF-L. This result confirmed that the mitochondrial membrane damage and overall apoptosis were linked to the ROS mediated oxidative stress in the cells. Apoptotic cell death was estimated to be around $64.6 \%$ against $7.5 \%$ for the control group. The techniques used to evaluate cell apoptosis included mithrocondria specific lipophilic fluorescence to assess the mitochondria transmembrane potential [51], comet assay [26] to examine DNA damage, and Annexin V-FITC/PI staining using flow cytometry [52] to confirm the percentage of the apoptotic cell death. In vivo tests were also carried out on healthy zebra fish. Both embryos and adult fish treated with MG@ZIF-L showed no malformations proving the non-toxic and biocompatible properties of the designed MOF.

To briefly summarize, cytotoxicity of cancer cells using drug-encapsulated nMOFs is mainly achieved through the structural decomposition of the nanocarrier in acidic conditions. Between pH 4 and 6, all nMOFs in Table 1 release $50 \%$ to $95 \%$ of their drug loads. Cell apoptosis then occurs either directly via drug-DNA damage or indirectly with the generation of ROS. pH-responsive nMOFs seem to be the most popular chemotherapy agents but attention has also turned towards nucleic acid gated nanostructures [33-38]. The biological nature and specificity of the nucleic acids improve the nMOFs' biocompatibility and drug release in specific cancer cells. Concurrently, redox-responsive nanocarriers are still rare and should be investigated further as they appear to be very effective. This situation is not formally addressed thoroughly the literature, but the design redox-responsive nano-devices are often difficult to apply and limited in biological systems. Indeed, Ren et al.'s ZDOS NPs showed one of the highest in vitro cytotoxicity levels. Indeed, the MCF-7 cell viability decreased below $10 \%$ at $20 \mu \mathrm{g} / \mathrm{mL}$ after $24 \mathrm{~h}$ of incubation [25]. Among all other nMOFs mentioned in this section, only Chen et al. managed to achieve similar cytotoxicity results [53]. The synthesized oridonin-loaded MOF-5 released the drug via molecular diffusion and skeleton erosion, causing the HepG2 cell viability to drop to $5 \%$ after $24 \mathrm{~h}$ of incubation at $25 \mu \mathrm{g} / \mathrm{mL}$. Further research should focus on the incubation of these nMOFs with different cancer cell lines in order to evaluate their specificity and differential cytotoxicity. Ren et al.'s work has the added value of presenting in vivo results. Notably, from previous examples and Table 1, very few in vivo studies have been carried out, calling into question the therapeutic potential of nMOFs in live subjects.

\section{Photothermal Therapy}

Photothermal therapy consists of locally heating a tumor above $40{ }^{\circ} \mathrm{C}$ in order to induce cell apoptosis (Fig. 12). It usually relies on materials able to efficiently convert light into heat when irradiated with a near-infrared (NIR) laser [54]. The NIR region is ideal, as wavelengths between 650 
and $1350 \mathrm{~nm}$ (optimally at $800 \mathrm{~nm}$ ), have maximum depth of penetration in tissue.

\subsection{Core-Shell Nanostructures}

Gold is an attractive material for medical purposes due to its biocompatibility, NIR light responsive behavior and surface functionalization properties. Intricate core-shell nanoplateforms can be developed using gold coatings, NPs and nanorods for photothermal therapy. As NPs, gold exhibits important surface plasmon resonance and unique photothermal conversion efficiency [55] $]^{2}(22-103 \%)$ depending on size, shape and aggregation state [56]. Majidi et al. synthesized gold coated silica NPs, which they injected into A365 tumor cells [57]. A four-minute irradiation $(808 \mathrm{~nm}, 0.9 \mathrm{~W} /$ $\mathrm{cm}^{2}$ ) caused cell viability to drop to $31 \%$ [58]. Other reports on core-shell gold structures show similar in vitro cytotoxicity results, where $\mathrm{KB}$ cancer cell death reached $60 \%$ after irradiation $\left(755-808 \mathrm{~nm} ; 6-40 \mathrm{~W} / \mathrm{cm}^{2}\right)[59,60]$.

However, NIR absorbing gold nanostructures lack photothermal stability when irradiated with high power lasers [61]. Combining them with MOFs as core-shell structures could circumvent this problem and thereby improve their antitumor activity. With this in mind, Liu et al. synthesized an amino functionalized UiO-66 MOF loaded with platinum nanoenzymes and coated in a porous gold shell (PAU, Fig. 14a) [62].

The use of photodynamic therapy was also made by encapsulating chlorine $\mathrm{C} 6$ as a photosensitizer (PAU-Ce6). Chlorines [Appendix 1. (entry 11)] are reduced versions of porphyrins. PAU-containing aqueous solutions irradiated with an $808 \mathrm{~nm}$ laser for 5 min showed that the temperature variation was dependent upon both the nanoparticles' concentration and the laser power density. Irradiated PAU nanoparticles at a concentration of $60 \mu \mathrm{g} / \mathrm{mL}$ induced a temperature increase of $28{ }^{\circ} \mathrm{C}$ at $1.0 \mathrm{~W} / \mathrm{cm}^{2}$. When increasing the power density to $2.0 \mathrm{~W} / \mathrm{cm}^{2}$, the solution temperature drastically evolved from 24.2 to $71.1{ }^{\circ} \mathrm{C}$. A total of ten on/ off laser irradiation cycles ( $808 \mathrm{~nm} ; 60 \mu \mathrm{g} / \mathrm{mL} ; 1.0 \mathrm{~W} / \mathrm{cm}^{2}$ ) confirmed the photothermal stability of the PAU nanoparticles. The photothermal conversion efficiency was estimated to be $58.65 \%$. An MTT assay confirmed the non-toxic nature of the NPs. Indeed, when incubated with MCF-7 cancer cells, cell viability remaining at $97 \%$. Effective cytotoxicity

Photothermal conversion efficiency $: \eta=\frac{h A\left(\Delta T-\Delta T_{\max , H_{2} O}\right)}{I\left(1-10^{-A_{\lambda}}\right)}$

$h$ : heat transfer coefficient $-A$ : container surface $-I$ : laser power $A_{\lambda}$ : NP absorbance at $808 \mathrm{~nm}$ in aqueous solution $-\Delta T$ : temperature variation between the solution and the surrounding $-\Delta T_{\max , H 2 O}$ : temperature variation of the water at the maximum steady-state temperature
( $15 \%$ cell viability) was achieved after laser irradiation at 808 and $670 \mathrm{~nm}$ of the PAU-Ce6 nanoparticles $(100 \mu \mathrm{L}$; $5 \mathrm{~min})$. Mice bearing MCF-7 tumors were then injected with PAU-Ce6 nanoparticles. After 16 days, successful elimination of all tumors was obtained for mice having undergone photothermal and photodynamic therapy, although among the photothermally treated mice, three out of five were able to completely eliminate their tumors while the others saw a slight regrowth after day 10 .

Another example of a photothermal active core-shell MOF structure was put forward by Zhang et al. who developed PVP stabilized gold nanostars (AuNS) encapsulated in MIL-101- $\mathrm{NH}_{2}(\mathrm{Fe})$ [Appendix 2. (entry a)] nMOFs (Fig. 13) [63]. The nMOF surface was functionalized with N-hydroxysuccinimide polyethylene glycol and triple negative breast cancer (TNBC) targeting peptides (ZD2). ZD2 specifically targets extradomain-B fibronectin [64], typically overexpressed in TNBC MDA-MB-231 cancer cells. The AuNS allow for significant NIR absorption at $800 \mathrm{~nm}$, exhibiting excellent photothermal stability. The photothermal conversion efficiency was calculated to be $40.5 \%$. After a 5 -min irradiation at $808 \mathrm{~nm}\left(1.2 \mathrm{~W} / \mathrm{cm}^{2}, 100 \mu \mathrm{g} / \mathrm{mL}\right)$, the AuNs@ MOF-ZD2 exhibited a significant temperature increase of $30^{\circ} \mathrm{C}$. An in vitro MTT assay revealed cell viability to be at 90\% for AuNs@MOF-ZD2 incubated with MDA-MB-231 cells which dropped to $17 \%$ after laser irradiation. Mice bearing TNBC tumors also underwent photothermal therapy and the tumors were successfully eliminated, while they tripled in size for the control group on day 15. After a 40-day post-treatment, the MOF-injected mice remained alive and H\&E staining showed no major organ damage.

Table 2 presents other examples of core-shell structures using graphene oxide, bimetallic nanoparticles or gold nanorods. Chen et al. developed yet another type of core-shell MOF with which hyperthermia was conveniently induced via an alternating magnetic field as an alternative method to the NIR light irradiation treatment [65]. Magnetic hyperthermia is based on the ability of ferromagnetic materials to transform electromagnetic energy, produced by an alternating magnetic field, into heat [66]. Chen et al. synthesized iron oxide NPs coated with polydopamine, encapsulated inside ZIF-90 MOFs $\left(\mathrm{Fe}_{3} \mathrm{O}_{4} @\right.$ PDA@ZIF-90, Appendix 2, entry d) [62]. Under an alternating magnetic field, for a $\mathrm{Fe}_{3} \mathrm{O}_{4} @$ PDA@ZIF-90 NPs concentration of $5 \mathrm{mg} / \mathrm{mL}$, an impressive $45.6{ }^{\circ} \mathrm{C}$ temperature increase was noted. When incubated with HeLa cells for $24 \mathrm{~h}$, the cell viability remained close to $100 \%$. However, after two rounds of alternating magnetic fields, the nanoMOFs caused cell viability to drop to $40 \%$, and $10 \%$ when loaded with DOX). 


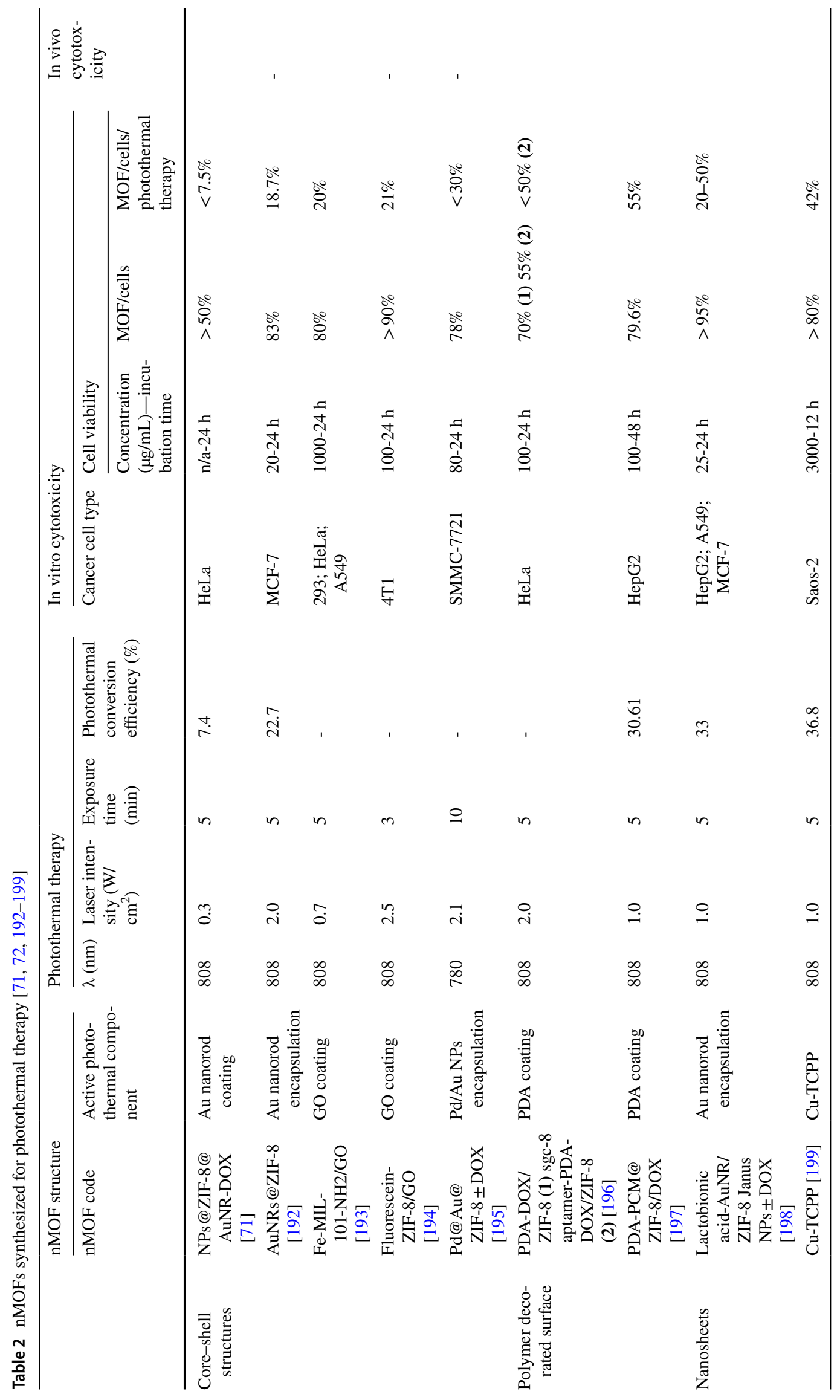



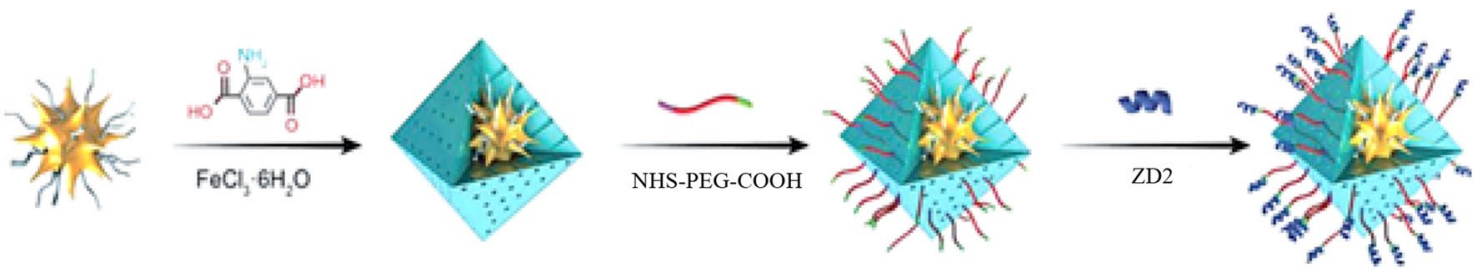

Fig. 14 Schematic synthesis of AuNS@MOF-ZD2 nMOFs. Reproduced with permission from WILEY (Color figure online)
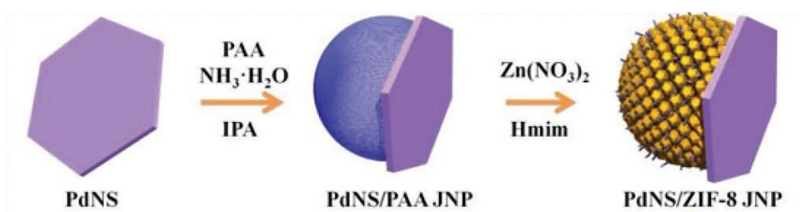

PdNS/PAAJNP
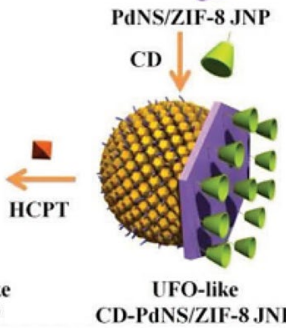

CD-PdNS/ZIF-8.JNP

Fig. 15 Schematic preparation of UFO-like CD-PdNS/ZIF-8 JNPs. Reproduced with permission from WILEY (Color figure online)

\subsection{Polymer Coated MOFs}

Certain polymers are known for their effective light-to-heat conversion in the NIR region such as polypyrrole [PPy, Appendix 1. (entry 13)], PDA and polyaniline [Appendix 1. (entry 16)]. PPy and PDA generate particular interest due to their excellent biocompatibility [67]. PPy NPs, synthesized by Zha et al. caused a $25.6{ }^{\circ} \mathrm{C}$ temperature elevation upon irradiation with a $808 \mathrm{~nm}$ laser $\left(10 \mathrm{~min} ; 2.0 \mathrm{~W} / \mathrm{cm}^{2} ; 16 \mu \mathrm{g} /\right.$ $\mathrm{mL}$ ), which was higher than that of a gold nanorod solution $\left(14.6{ }^{\circ} \mathrm{C}\right)$ [68]. The PPy NPs proved to be an effective in vitro PTT agent, for concentrations higher than $200 \mu \mathrm{g} /$ $\mathrm{mL}$, towards HeLa cells where between 5 and $30 \%$ of cell viability has been observed after a five-minute irradiation.

Since nMOFs have high surface areas, a higher amount of photothermal polymers can be introduced inside cancer cells. Cai et al. prepared a Fe-soc-MOF, functionalized with PPy for dual MRI imaging and photothermal therapy (Fig. 14b) [69]. Fe-soc-MOF is an isostructural analogue of In-soc-MOF, built from oxygen centered iron carboxylate trimermolecular building blocks and the ligand 3,3',5,5'-azobenzenetetracarboxylic acid [Appendix 1 (entry 32)]. Depending on the concentration, the polymer-coated materials showed temperature variations of the solution reaching $72.4{ }^{\circ} \mathrm{C}$ after irradiation at $808 \mathrm{~nm}$ for $10 \mathrm{~min}$ $\left(500 \mu \mathrm{g} / \mathrm{mL} ; 0.8 \mathrm{~W} / \mathrm{cm}^{2}\right)$. The photothermal conversion efficiency was evaluated to be $13.9 \%$. In the absence of NIR light, the 4T1 cancer cells were unaffected by Fe-socMOF@PPy, even at high concentrations. Conversely, the cell viability decreased to $40 \%$ at $500 \mu \mathrm{g} / \mathrm{mL}$ after irradiation. The in vivo studies consisted of injecting Fe-soc-MOF@PPy into mice bearing 4T1 tumors. The NIR irradiation inhibited tumor growth and the inhibition rate increased with elevated concentrations of Fe-soc-MOF@PPy. Specific markers such as aspartate amino-transferase and alanine aminotransferase, and kidney function indicators (namely blood urea nitrogen, creatinine) were within normal ranges, which indicated that the nMOFs did not cause tissue damage.

\subsection{Functionalized Nanosheets}

Janus nanoparticles (JNPs, i.e. double-component NPs) are specifically designed so that each side of the nanoparticle has specific properties. Among the various examples of functionalized nanosheets (Table 2), Zhang et al. synthesized a metallic 2D palladium nanosheet, modified with cyclodextrin on one side and ZIF-8 MOFs on the other, thus creating CD-PdNS/ZIF-8 JNPs (Fig. 15) [70]. Both sides of the nanoparticles allow drug encapsulation such as DOX or 10-hydroxycamptothecin. The dual drug loaded material was then used for photothermal therapy and chemotherapy in the

Fig. 16 Schematic illustration of nMOF-mediated immunotherapy by releasing antigens to APCs (dendritic cells in this case) (Color figure online)

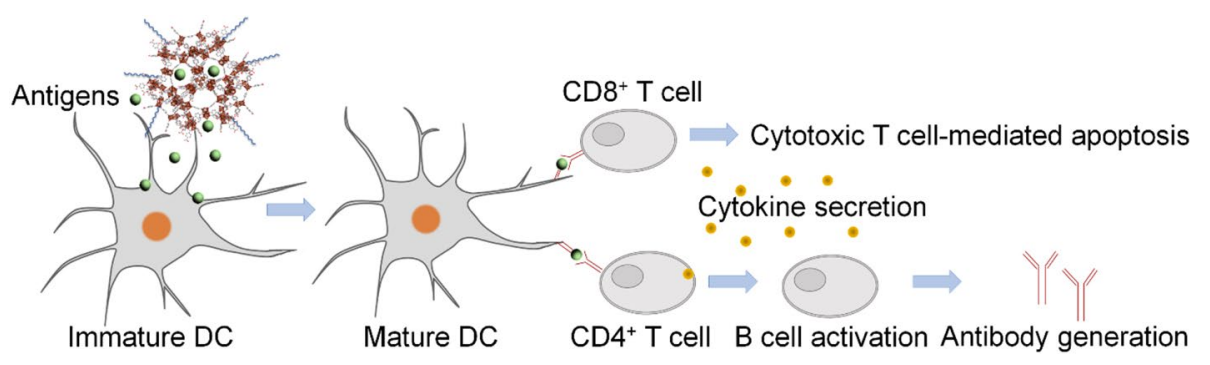




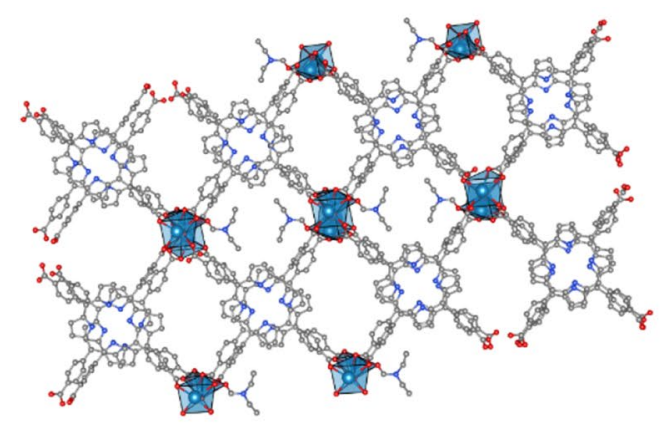

(a)

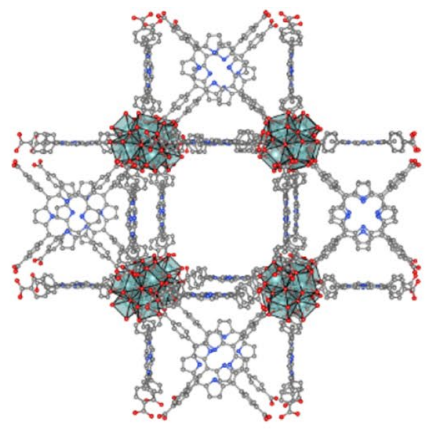

(b)

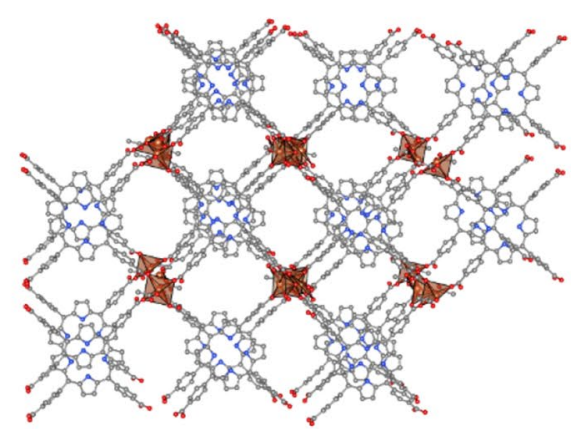

(c)

Fig. 17 a W-TBP MOF structure. b PCN MOF structure. c Fe-TBP MOF structure. Red: oxygen; grey: carbon; blue: nitrogen; green: zirconium; orange: iron; turquoise: tungsten (Color figure online)

NIR-II bio-window (1000-1350 nm), which offers deeper tissue penetration. When irradiating a CD-PdNS/ZIF-8 JNPs solution at $1064 \mathrm{~nm}\left(1 \mathrm{~W} / \mathrm{cm}^{2} ; 10 \mathrm{~min}\right)$ a $23{ }^{\circ} \mathrm{C}$ temperature increase was recorded, and four on/off cycles confirmed photothermal stability. Tissue penetration was evaluated by injecting the CD-PdNS/ZIF-8 JNPs into pig muscle slabs of various thicknesses and irradiating them at $1 \mathrm{~W} / \mathrm{cm}^{2}$ for 5 min. Biocompatibility was examined through CCK-8 and hemolysis assays. Results showed that the calculated hemolysis ratio $^{3)}$ was less than $5 \%$ even for a concentration of $1000 \mu \mathrm{g} / \mathrm{mL}$; while the cell viability of HepG2, A549 and MCF-7 cells remained over $90 \%$ in the absence of NIR light. This value decreased to the 10 to $50 \%$ range depending on the cell type. Finally, CD-PdNS/ZIF-8 JNPs were injected into mice bearing $\mathrm{H} 22$ tumors and incubated for $24 \mathrm{~h}$ before being irradiated. The tumor growth was effectively inhibited while no tissue damage, lesions or inflammation were observed in major organs.

Table 2 provides an overview of the nMOFs synthesized for PTT in the last five years. Most of the synthesized nanocarriers have a photothermal conversion efficiency ranging between 20 and $40 \%$ with some exceptions. The most notable examples are the nMOFs synthesized by Liu et al. [59] and Zhang et al. [71] with photothermal conversion efficiencies of $58.65 \%$ and $7.4 \%$, respectively. This significant difference could, in fact, be related to the nMOF structure. While Liu et al.'s MOF was homogeneously encapsulated in a porous gold nanoshell, Zhang et al. simply attached gold nanorods to the MOF's surface through electrostatic interactions. Despite this low value, the cancer cell in vitro cytotoxicity was superior to that of Liu et al. In general, photothermal therapy achieved a maximum cancer cell

3 Hemolysis $(\%)=\left(A_{\text {sample }(-)}-A_{\text {control(-) }}\right) /\left(A_{\text {sample }(+)}-A_{\text {control }(+)}\right)$

A: UV-vis absorbance. cytotoxicity of around $20 \%$ to $50 \%$ and effectively inhibited tumor growth in vivo. Complete irradiation of the tumor was rarely achieved, indicating that this type of therapy is not efficient enough to be used on its own. As shown in Table 2, researchers usually combined photothermal therapy with chemotherapy in order to improve the performance. However, photothermal therapy holds promise for clinical trials as it exhibits far more in vivo testing than chemotherapy, for example. The versatility of photothermal materials allows the synthesis of finely tuned nMOFs for both enhanced biocompatibility and anticancer activity.

\section{Immunotherapy}

Immunotherapy consists of using the body's own defense system to fight against cancer cells. The first line of defense consists of the innate immune cells, such as neutrophils, dendritic cells (DCs), macrophages and natural killer cells, produced in the bone marrow or lymph nodes. When tumor cells undergo apoptosis or necrosis, they release antigens that can be ingested by antigen presenting cells (APCs). nMOFs can also be used to bring the necessary antigens to APCs, which then present the new antigen to $\mathrm{B}$ and $\mathrm{T}$ cells (lymphocytes) in order to activate a humoral and cellular response. Activated $\mathrm{B}$ cells start multiplying and release antibodies, able to neutralize or agglutinate the foreign threat, marking them for death. T cells, on the other hand, are divided into two subclasses, CD4 and CD8 T cells, which upregulate the immune response. Helper CD4 T cells release proinflammatory cytokines, activate macrophages and B cells and cause $\mathrm{T}$ cell multiplication. Cytotoxic CD8 T cells roam the body to detect cells marked for death and trigger apoptosis by releasing enzymes into the threats (Fig. 16) [72].

Since cancer cells have the ability to "hide" from the immune system by displaying abnormal proteins on their surface, different types of immunotherapies have been 
developed. Immune checkpoint blockade (ICB) relies on monoclonal antibodies to inhibit immune checkpoints, which naturally stop the immune system from attacking healthy cells. Checkpoint inhibitors (PD-1/PD-L1; CTLA4) block the activity of abnormal cancer surface proteins ensuring immune system activation. Chimeric antigen receptor T-cell therapy involves modifying $\mathrm{T}$ cells with a specific cancer receptor so that they can easily recognize and destroy cancer cells. Finally, cancer vaccines expose the body to an antigen, which triggers an immune response, while memory $\mathrm{B}$ cells store the antigen for further use [73].

\subsection{Immune System Activation}

CpG Oligodeoxynucleotide [ODNs, Appendix 1. (entry 23)] are short synthetic DNA strands, used as a model for pathogen-associated molecular patterns. When these molecules are recognized by host toll-like receptors (TLRs), specifically TLR9 in the case of CpG ODNs, an adaptive immune response is triggered [74]. The CpG ODNs activate the NKs, macrophages, B cells, and DCs to up regulate antigen interactions with the major histocompatibility complexes (MHC I and II) and co-stimulatory molecules (CD80, CD86). They also stimulate the APCs to secrete cytokines such as interleukins (IL), tumor necrosis factors (TNF) and interferons (IFN) [75]. In order to increase the magnitude of induced immunity, Zhang et al. encapsulated CpG ODNs into ZIF-8 MOFs (Appendix 2. (entry c) [76]. When free, the $\mathrm{CpG}$ ODNs typically enter cells by inefficient passive diffusion, combining them with MOFs, and significantly increasing the cellular uptake by the RAW264.7 macrophages. This process was confirmed by the appearance of a strong green fluorescence of carboxyfluorescein-labeled CpG ODNs, recorded in confocal laser scanning microscopy images. A CCK-8 assay further demonstrated the excellent biocompatibility of the MOFs. In addition, the immunostimulatory activity was assessed by measuring the in vitro secreted cytokine levels (IL-6, TNF- $\alpha$ ). These levels were found to be significantly higher for the ZIF-8/CpG ODNs than that of the free $\mathrm{CpG}$ ODNS. Identical results were also obtained when measuring the serum level of cytokines in mice.

The immune system response against cancer cells can only occur if the tumor associated antigens are interacting with the T cells by APCs in the lymph nodes. To promote the antigen interactions, $\mathrm{Ni}$ et al. combined a photosensitive cationic porphyrinic W-based MOF (W-TBP(+), Fig. 17a) with CpG ODNs [77]. Photodynamic therapy can then facilitate an immune response by causing the release of tumor debris in the tumor micro-environment, which is subsequently ingested by APCs. Photodynamic therapy caused the TUBO in vitro cell viability to drop below $30 \%$ for concentrations of W-TBP(+) above $20 \mu \mathrm{g} / \mathrm{mL}$. Concurrently, the W-TBP/ $\mathrm{CpG}(+) \mathrm{s}$ were incubated with DCs and elevated cytokine levels (IL-6, IFN- $\alpha$ ) were recorded, hence demonstrating DC maturation. The combined effects of the photodynamic therapy $\left(650 \mathrm{~nm}, 45 \mathrm{~J} / \mathrm{cm}^{2}\right)$ and $\mathrm{CpG}$ stimulation were investigated by injecting the nMOFs into mice bearing TUBO tumors. The treatment led to a $96.6 \%$ tumor regression after 22 days and the flow cytometry results showed an increase in macrophages and DCs in the tumor micro-environment compared to the control group. Furthermore, the abscopal effect (i.e. tumor regression at a distant site occurs concurrently with that of the primary tumor) of combined antigen interactions and ICB was investigated by treating a primary tumor with photodynamic therapy mediated by W-TBP/CpG(+), and leaving a distant tumor untreated. A subsequent injection of $\alpha$-PD-L1 antibody led to a $>97 \%$ regression of both tumors. The significant increase of $\mathrm{T}$ cells $(\mathrm{CD} 4+$ and $\mathrm{CD} 8+$ ) in splenocytes (primary and distant tumors) proved that W-TBP/CpG/ $\alpha$-PD-L1(+) enhanced anti-tumor immunity via immune activation and infiltration of cytotoxic $\mathrm{T}$ cells.

The effectiveness of photodynamic therapy as an immunogenic agent is hindered by tumor hypoxia. Hypoxic conditions lead to tumor growth via the release of the hypoxia inducing factor (HIF-1 $\alpha$ ) gene. To counter this phenomenon, Cai et al. [78] developed a similar photosensitive MOF (denoted PCN-ACF-CpG@HA, Fig. 17b) to that of Ni et al. Instead of simply coating it with $\mathrm{CpG}$ ODNs, acriflavine [ACF, Appendix 1. (entry 8)] was also encapsulated inside the nMOF. ACF is known to inhibit the dimerization of HIF- $1 \alpha$ with HIF- $1 \beta$ to block tumor transcription activity. The MOF itself was a zirconium porphyrinic based-MOF functionalized with both CpG ODNs and hyaluronic acid [HA, Appendix 1. (entry 21)] as a targeting agent. Compared to ACF-free MOFs, PCN-ACF-CpG@HA effectively inhibited the HIF- $1 \alpha$ signaling in $\mathrm{H} 22$ cancer cells after photodynamic therapy $\left(670 \mathrm{~nm} ; 1.0 \mathrm{~W} / \mathrm{cm}^{2}\right)$. This procedure improved the cytotoxicity results after photodynamic therapy. Indeed, the cell viability dropped below $20 \%$ for both PCN-ACF-CpG@HA and PCN-ACF@HA at $32 \mu \mathrm{g} /$ $\mathrm{mL}$, which turned out to be lower than that put forward by $\mathrm{Ni}$ et al. On the other hand, the immunotherapy data of PCNACF-CpG@HA showed similar results, with an increase in DC maturation (70.68\%), linked to the high values of CD80/ CD86 surface markers and cytokine secretion (IL-12p70, IFN- $\Upsilon$, TNF- $\alpha$ ), in $\mathrm{H} 22$ cells after photodynamic therapy. Mice bearing $\mathrm{H} 22$ cancer cells, treated with PCN-ACFCpG@HA and subsequently irradiated, also showed the most impressive tumor growth inhibition due to an elevated number of infiltrating T cells.

\subsection{Immune Checkpoint Blockade (ICB)}

In some cancers, ICB is ineffective due to adaptive and intrinsic resistance, where cancer cells either change their 


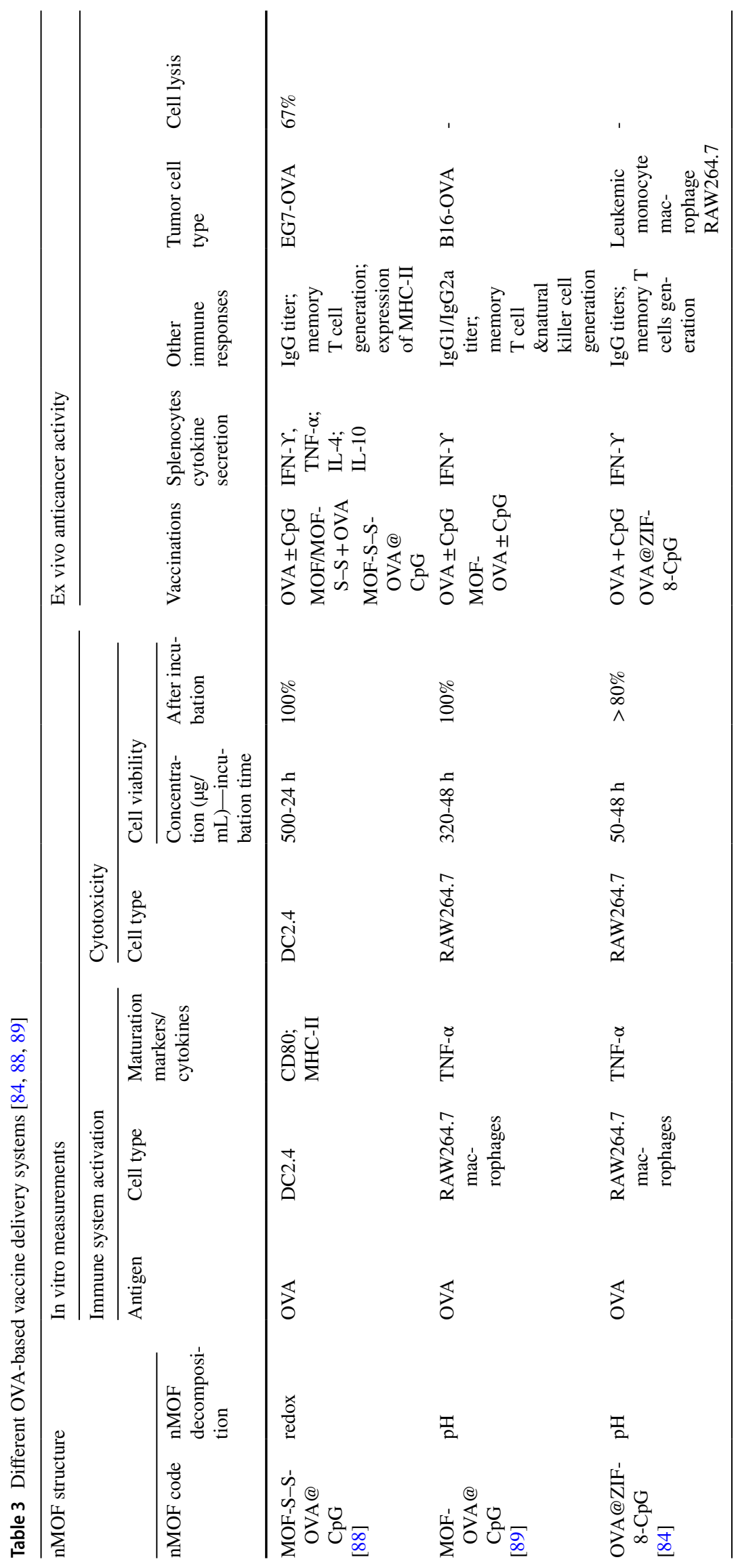




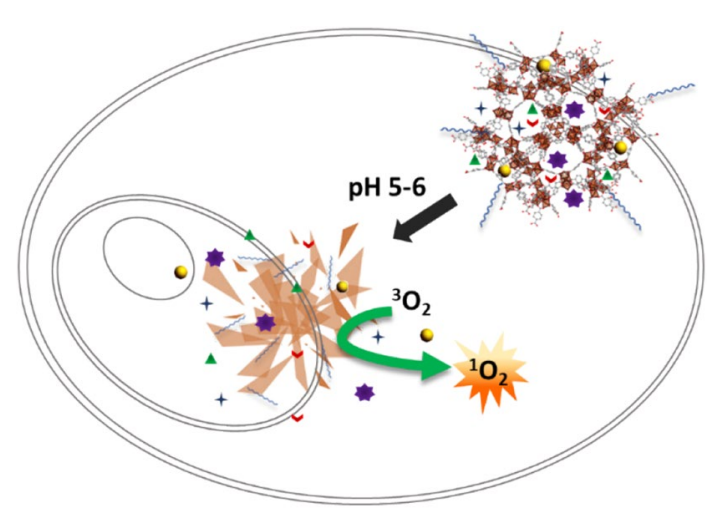

Fig. 18 Schematic illustration of nMOF-mediated targeted therapies. Violet star Cytotoxic proteins; red down arrow Gene regulators; green triangle DNA damage repair inhibitors; yellow circle Angiogenesis inhibitors; blue plus Autophagy inhibitors (Color figure online)

phenotypes or actually react to ICB by accelerating their replication [79]. However, photodynamic therapy could enhance ICB as it causes significant inflammatory responses in the tumor micro-environment. Lan et al. synthesized an iron porphyrinic based-MOF (Fe-TBP, Fig. 17c) designed to improve $\alpha$-PD-L1 ICB [80]. Hypoxia was minimized, due to the $\mathrm{Fe}_{3} \mathrm{O}$ clusters that react with intracellular $\mathrm{H}_{2} \mathrm{O}_{2}$ to produce $\mathrm{O}_{2}$ via a Fenton-like reaction. This was confirmed by the low fluorescence intensity of HIF- $1 \alpha$ in Fe-TBP-treated CT26 cancer cells. After irradiation, the cells underwent severe apoptosis/necrosis $(81.2 \%)$. The abscopal effect was investigated by first injecting and irradiating the FeTBP MOFs in mice bearing CT26 primary tumors followed by an $\alpha$-PD-L1 treatment, while the distant tumor was left untreated. Both tumors showed a $90 \%$ regression, confirming enhanced ICB. Indeed, Fe-TBP/ $\alpha-P D-L 1$ caused an increase in the number of CD4 +/CD8 + tumor infiltrating T cells, B cells and DCs in both primary and distant tumors.

\subsection{Cancer Vaccines}

Contrary to ordinary vaccines that prevent a disease from developing, cancer vaccines get the immune system to attack the disease by delivering antigens to APCs. The efficiency of protein-based vaccines can be increased by adding $\mathrm{CpG}$ ODNs to the mix, which accelerates the induction of antibodies and the generation of more persistent antibody titers such as IgG. However, the antigen delivery depends on the size, shape and surface charge of the synthesized nanocarriers. Particles between 5 and $100 \mathrm{~nm}$ seem to have the longest circulation times and can be efficiently delivered to the lymph nodes [81]. Reddy et al. showed that $25 \mathrm{~nm}$ NPs successfully targeted half of the DCs in the draining lymph nodes whereas the $100 \mathrm{~nm}$ NPs were $10 \%$ only as efficient [82]. Positively charged NPs with rod, prism, star, disc and shapes are also more likely to generate a higher immune response, as they have longer blood circulation times and higher tumor penetration capacities [80]. Since nMOF structures can be tuned to achieve specific properties, depending on the choice of raw materials and surface functionalization, they represent optimal antigen delivery vehicles. Zhong et al. developed a vaccine delivery system by encapsulating both an ovalbumin antigen (OVA) and an aluminum adjuvant in a CpG ODN coated ZIF-8 MOF (denoted ZANPs, Appendix 2, entry c) [83]. The particle size reached $80.4 \pm 1.24 \mathrm{~nm}$ and the in vitro cytotoxicity of ZANPs proved to be negligible at concentrations as high as $1000 \mu \mathrm{g} / \mathrm{mL}$. The nMOF uptake by APCs was evaluated by incubating the nanocarriers with bone marrow derived

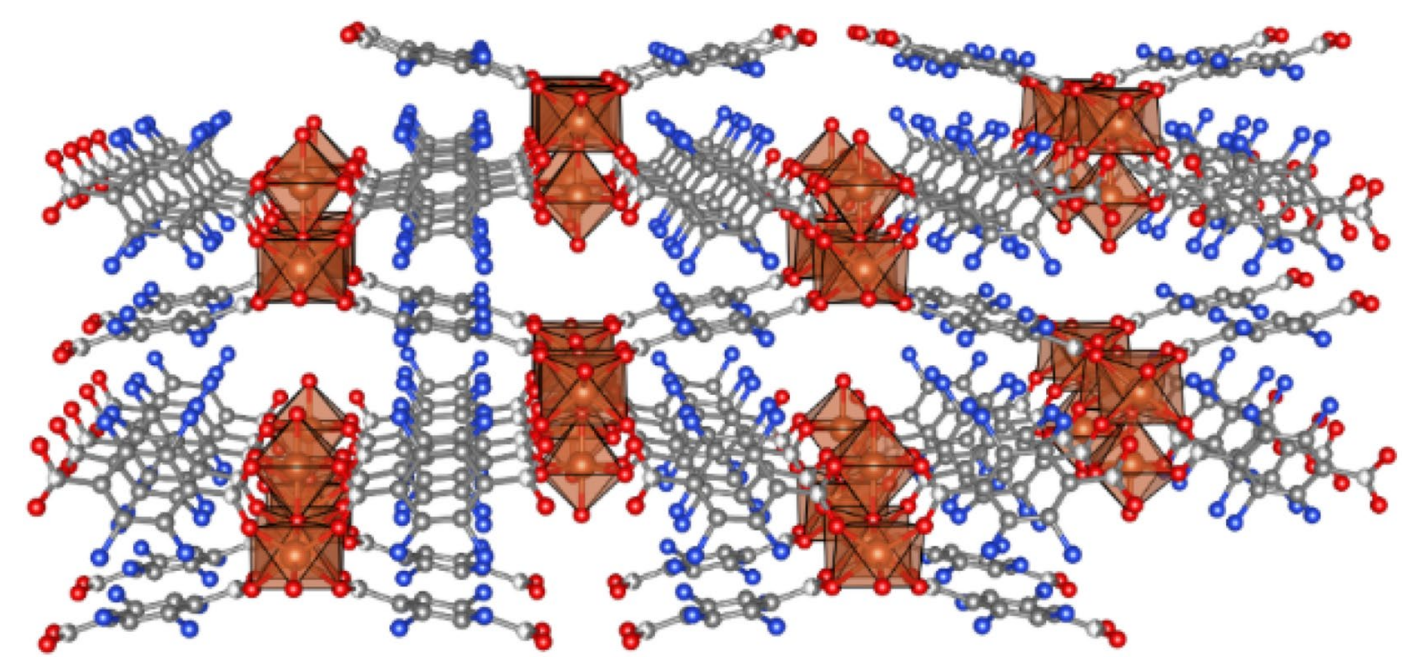

Fig. 19 Structure of rMOF (MIL-88B). Red: O; grey: C; blue: N; orange: Fe (Color figure online) 


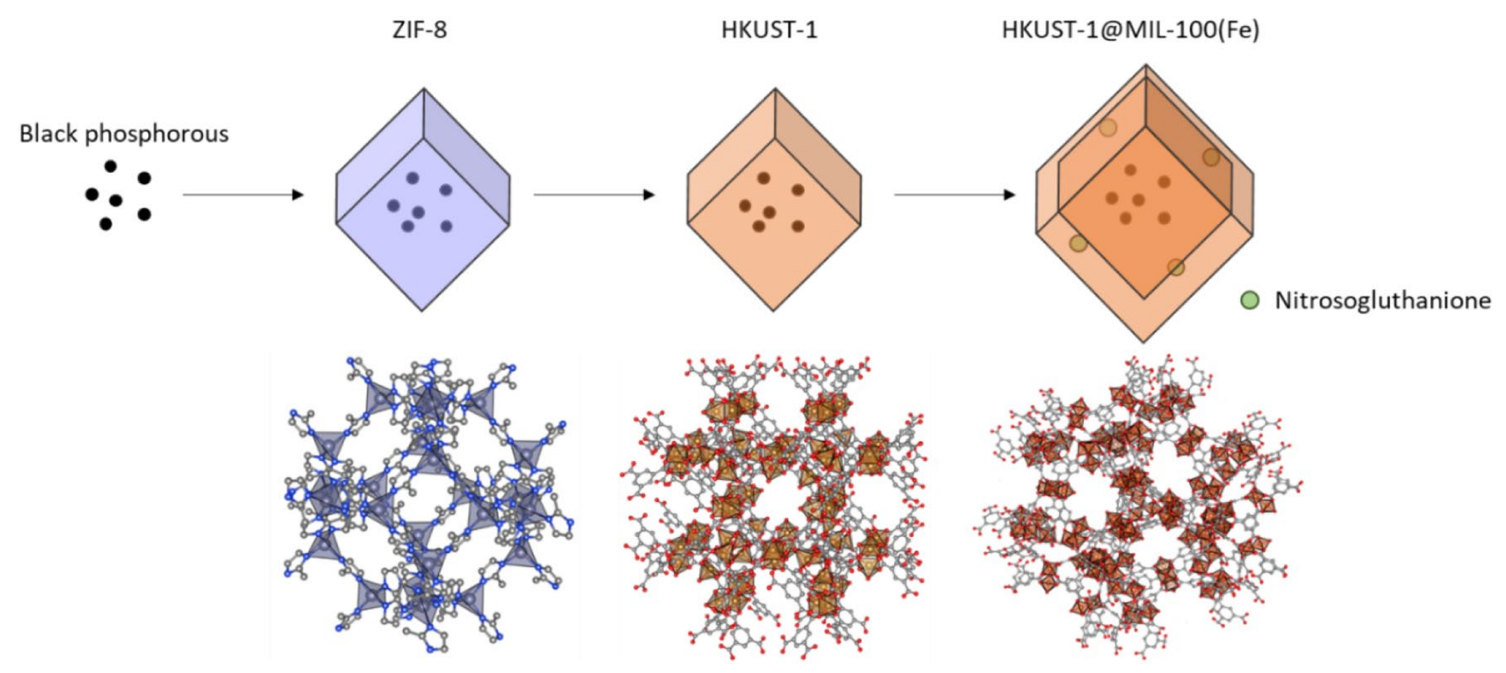

Fig. 20 Schematic diagram illustrating the consecutive encapsulations of black phosphorous quantum dots to form G-BHM nMOFs (Color figure online)

DCs. The flow cytometry results showed that the percentage of OVA-positive DCs incubated with ZANPs was 3.44 times higher than that of free OVA. Moreover, DCs matured successfully after MOF internalization, as both the up-regulation in CD40 and CD86 surface markers and cytokines (IFN-Y, IL-12p70) attest. The mean fluorescence intensity of the surface markers almost doubled for DCs incubated with ZANPs compared to that of the free OVA. The IFN- $Y$ and IL-12p70 cytokines levels also showed how the CpG ODNs significantly enhance the cytokine secretion, compared to naked ZANPs. However, both the CpG ODNs and adjuvant need to be co-delivered to the same APCs for an effective immune response. Flow cytometry confirmed that the co-localization of both substances was indeed higher after incubation with the CpG/ZANPs in DCs and in macrophages, which represent 5.32-fold and 4.98-fold increases, respectively, compared to that of $\mathrm{OVA}+\mathrm{CpG}$. The in vivo $\mathrm{CpG} / \mathrm{ZANP}$ vaccinations in mice triggered a rise in $\mathrm{IgG} 2$ antibodies (i.e. 2.2 -fold increase), IFN- $\Upsilon$ producing $T$ cells and TFN- $\alpha$ producing splenocytes, compared to that of the $\mathrm{OVA}+\mathrm{CpG}$ treated mice, confirming the efficient cellular and humoral immune response. The specific cytotoxic $\mathrm{T}$ lymphocyte response was also 1.4 times higher than that of $\mathrm{OVA}+\mathrm{CpG}$, after immunization with CpG/ZANPs. Meanwhile, mice bearing EG7-OVA tumors underwent an $85 \%$ OVA-specific lysis and had lowest tumor volumes after three separate vaccinations $\left(<1000 \mathrm{~mm}^{3}\right.$ compared to $>1500 \mathrm{~mm}^{3}$ for $\mathrm{OVA}+\mathrm{CpG})$.

Other OVA-vaccine delivery systems are presented in Table 3. In all cases, the synthesized nMOFs generally enhance the immune response, whether they are iron-based, zinc-based or lanthanide-based. It is impossible to state which MOF is the best vaccine delivery system since the type of immune cell, cancer cell, maturation markers and cytokines under observation are different. Nevertheless, all OVA-containing nMOFs allowed DC or macrophage maturation, due to efficient antigen release via $\mathrm{pH}-[80,84-89]$ or redox-responsive [86] behavior. All cytokine levels recorded in vitro (DCs, macrophages) and ex-vivo (splenocytes), were higher for cells incubated with the nMOFs than for those simply incubated with free OVA. Free OVA seems to have difficulty penetrating the cell membranes as demonstrated by the flow cytometry results and confocal scanning microscopy images.

\section{Targeted Therapy}

Targeted therapy uses substances that block the growth and metastasis of tumors by interacting with molecular targets that are essential to the tumor's development. Contrary to chemotherapy, which cannot differentiate cancer cells from normal cells, the targeted therapies are designed to interfere with specific proteins, genes, metabolic pathways, etc. [87]. Thanks to the ease with which they penetrate cellular membranes, nMOFs have recently attracted significant attention for various targeted therapies including apoptosis inducers, gene/protein modulators, autophagy and angiogenesis inhibitors (Fig. 18).

\subsection{Apoptosis Inducers}

\subsubsection{ROS Generation}

As mentioned in Sect. 1.3., cancer cells are characterized by elevated levels of ROS, which are typically produced in 
mitochondria, from the partial reduction of $\mathrm{O}_{2}$ and are made up of superoxide anion radicals $\left(\mathrm{O}_{2}{ }^{\bullet-}\right)$, singlet oxygen $\left({ }^{1} \mathrm{O}_{2}\right)$ and hydroxyl radicals $\left(\mathrm{OH}^{\bullet}\right)$. ROS are signalizing agents, crucial for cellular survival, but need to be regulated by antioxidants. If the ROS levels suddenly increase, oxidative stress occurs, leading to apoptosis through the damage of lipids, proteins and DNA [90]. One way to cause oxidative stresses is by targeting the overexpressed intracellular $\mathrm{H}_{2} \mathrm{O}_{2}$ in cancer cells. When introducing iron ions, like iron oxide NPs for example, $\mathrm{H}_{2} \mathrm{O}_{2}$ is transformed into $\mathrm{OH}^{\bullet}$ radicals through Fenton-like reactions [91].

Taking advantage of the high stability and biocompatibility of iron-based MOFs, Ranji-Burachaloo et al. developed a $\mathrm{NH}_{2}$-MIL-88B(Fe) MOF (Fig. 19) conjugated with folic acid (Appendix 1, entry 20, rMOF-FA), able to transform the endogenous $\mathrm{H}_{2} \mathrm{O}_{2}$ of cancer cells into $\mathrm{OH}^{\bullet}$ radicals via the release of $\mathrm{Fe}(\mathrm{II} / \mathrm{III})$ ions in acidic conditions [92]. Several techniques were used to quantify the amount of generated ROS. Firstly, the measurement of the terephtalic acid probe (Appendix 1, entry 33) assessed the $\mathrm{OH}^{\bullet}$ production following a Fenton reaction, via the production of the fluorescent 2-hydroxy terephthalic acid (Appendix 1, entry 31). In the presence of rMOF-FA, the fluorescence intensity (at $435 \mathrm{~nm}$ ) significantly increased. The $\mathrm{OH}^{\bullet}$ generation can further be investigated by using 3,3',5,5'-tetramethylbenzidine (TMB, Appendix 1, entry 27). The produced $\mathrm{OH}^{\bullet}$ easily oxidizes TMB into a blue ox-TMB product. As the rMOF- FA concentration increased, so did the absorbance intensity of ox-TMB at 370 and $652 \mathrm{~nm}$, which suggested an elevation in $\mathrm{OH}^{\circ}$. Finally, HeLa cancer cells and NIH3T3 normal cells were incubated with DCFH-DA for $12 \mathrm{~h}$ before adding the rMOF-FA. The fluorescence of DCF, which is directly proportional to the amount of generated ROS, was recorded by confocal laser scanning microscopy. Only a weak fluorescence was recorded for rMOF-FA incubated with normal NIH3T3 cells, while HeLa cells exhibited an intense green fluorescence. A CCK-8 assay showed that the in vitro cell viability of NIH3T3 cells remained over $90 \%$ for concentrations of rMOF-FA below $40 \mu \mathrm{g} / \mathrm{mL}$. However, in HeLa cells, the viability immediately decreased to $70 \%$ and $54 \%$ for concentrations of 20 and $40 \mu \mathrm{g} / \mathrm{mL}$, respectively. The generated $\mathrm{OH}^{\bullet}$ effectively broke down the DNA chains, proteins and lipids in the cell membranes.

The generation of nitrogen reactive species, such as nitric oxide, can also be an indication of cell health [93]. Du et al. synthesized a core-shell structure (Fig. 20) by first encapsulating black phosphorus quantum dots into ZIF-8 MOFs, subsequently degraded and replaced by a HKUST-1 matrix. A MIL-100(Fe) outer shell was added and nitrosogluthanione [Appendix 1. (entry 19)] was loaded into the pores to form HKUST-1 @ MIL-100(Fe) nMOFs (denoted G-BHM) [94]. In the presence of $\mathrm{H}_{2} \mathrm{O}_{2}$, copper ions released from the HKUST-1 internal framework can trigger the decomposition of nitrosogluthanione into nitric oxide, which, along with ROS generation of ferric ions, leads to cancer cell apoptosis.

Cytotoxicity of SGC-7901 cancer cells reached $45 \%$ after being incubated with G-BHM NPs at $200 \mu \mathrm{g} / \mathrm{mL}$ indicating a synergic action of nitric oxide and $\mathrm{OH}^{\bullet}$. Their formation was further increased with NIR irradiation $(808 \mathrm{~nm}$; $1 \mathrm{~W} /$ $\mathrm{cm}^{2}$ ), leading to $85 \%$ cytotoxicity. DCFH-DA and DAF-FM (4-amino-5-methylamino-2',7'-difluorofluorescein diacetate, [Appendix 1. (entry 26)] staining revealed that maximum concentrations of $\mathrm{OH}^{\bullet}$ and $\mathrm{NO}$, proportionally linked to the fluorescence intensity, were achieved between three and seven hours of incubation. Mice bearing SGC-7901 cancer cells were injected with the nMOFs and irradiated for three hours after injection. After 24 days, the tumor weights of G-BHM treated mice, with and without laser, were 0.13 and $1.21 \mathrm{~g}$, respectively, compared to $2.21 \mathrm{~g}$ for the control group.

Besides iron, silver ions are also a potential ROS source [95]. Song et al. synthesized a silver(I)-erlotinib complex $\left[\left\{\mathrm{Ag}_{18}\left(\mathrm{CF}_{3} \mathrm{COO}^{-}\right)_{18}\left(\mathrm{H}_{2} \mathrm{O}\right)_{2}\right\}\left\{\mathrm{Ag}_{4}(\text { erlotinib })_{4}\right\}\right]$ n. $7 n \mathrm{CH}_{3} \mathrm{OH} .3 n \mathrm{H}_{2} \mathrm{O}(\underline{1})$ [96]. The nMOF could both generate ROS via the silver metal centers and inhibit the epidermal growth factor receptor via the erlotinib [Appendix 1. (entry 34)] ligands [97]. The anticancer activity was first assessed by incubating (1) with A549 cancer cells in vitro. After $12 \mathrm{~h}$, the cell viability decreased to $39 \%$, compared to $69 \%$ for the free erlotinib $(1 \mu \mathrm{g} / \mathrm{mL})$, which confirms the role of the silver ions in cell cytotoxicity. Concentrations over $5 \mu \mathrm{g} / \mathrm{mL}$ caused the cell viability to fall below $10 \%$. The ROS generation was observed via DCFH-DA staining where the green fluorescence intensity of DCF in cancer cells was significantly increased in the case of (1) $)$, compared to that of the free erlotinib. In order to stay viable, an increase in ROS must be accompanied by an increase in antioxidant tripeptide gluthanione. However, the relative concentration of tripeptide gluthanione in A549 cells incubated with (1) was lower than that of free erlotinib, suggesting that the silver ions coordinate with tripeptide gluthanione, causing cellular imbalance and eventual apoptosis.

Fenton-based therapy can be coupled with cancer starvation therapy in order to improve the overall tumor killing efficiency. Cancer starvation therapy relies on the consumption of essential nutrients, such as oxygen and D-glucose, to inhibit cell growth. Glucose oxidase is an enzyme capable of oxidizing D-glucose into gluconic acid via the release of $\mathrm{H}_{2} \mathrm{O}_{2}$ [98]. The latter is subsequently used for ROS generation. With this in mind, Ranji-Burachaloo et al. encapsulated iron-rich hemoglobin [Appendix 1. (entry 7)] and glucose oxidase in a pH-responsive ZIF-8 MOF (denoted GOx\&Hb@ZIF-8) (Appendix 2. (entry c) to combine with the Fenton-cancer starvation therapy [99]. When using physiological concentrations of D-glucose (5-20 mM) in an acetic acid buffer solution, the synthesized MOF generated 


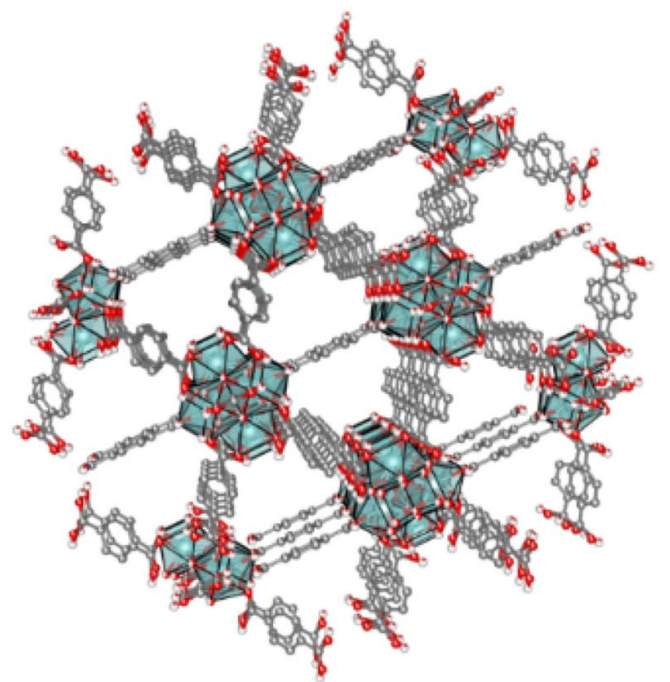

(a)

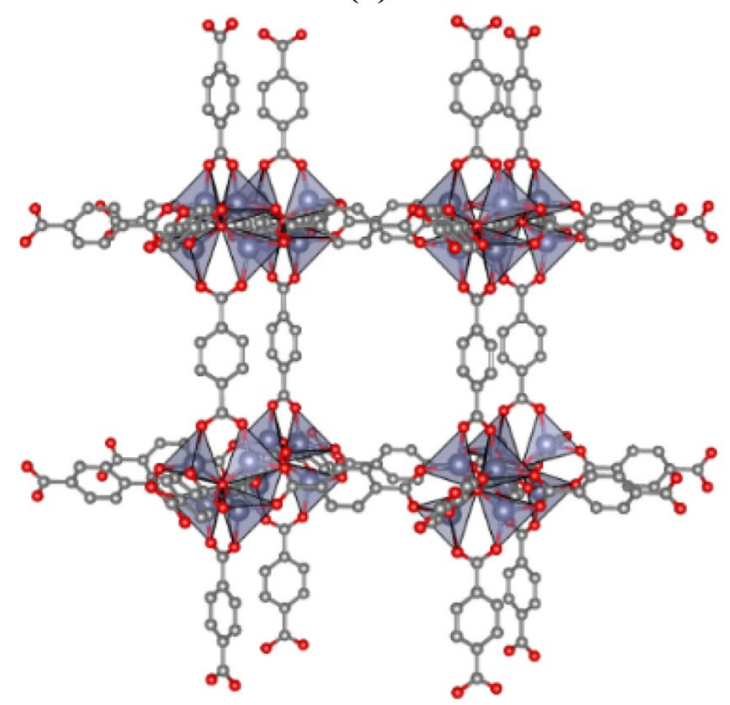

(c)

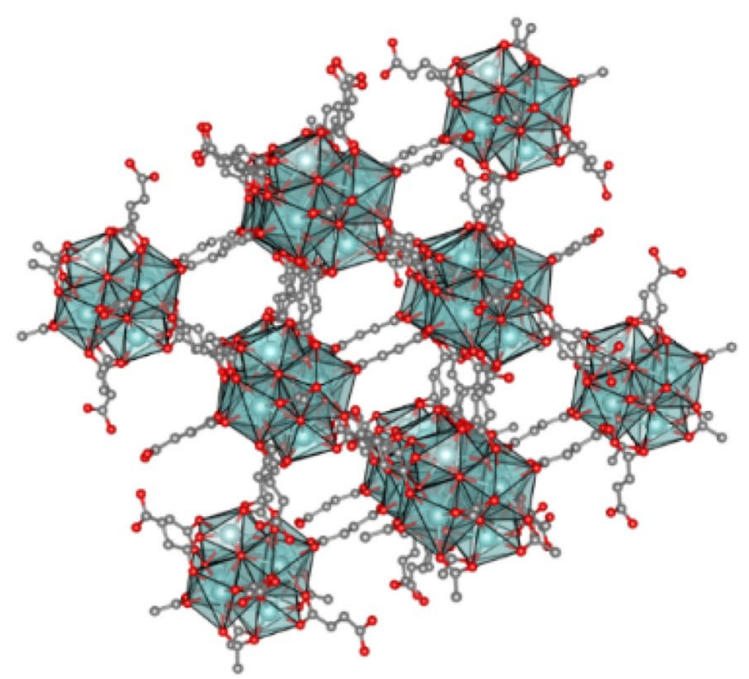

(b)

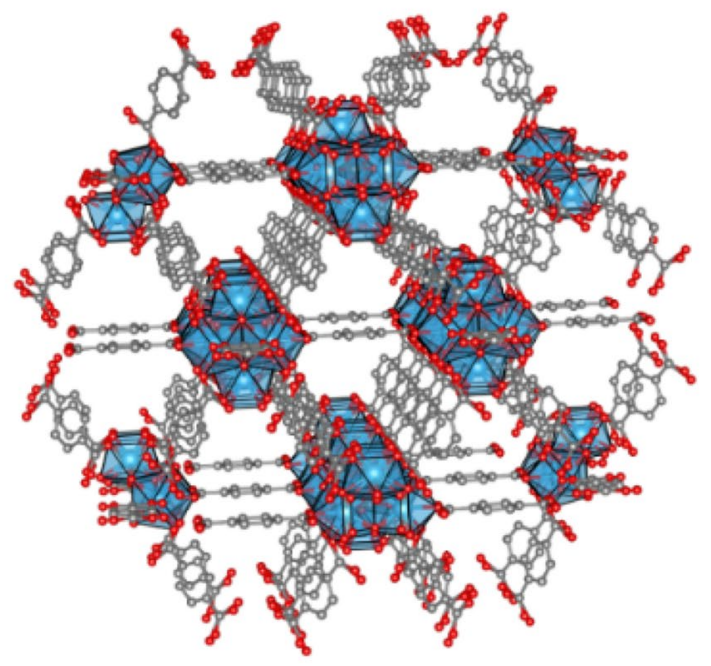

(d)

Fig. 21 a UiO-66 MOF structure. b Zr-Fum MOF structure. c IRMOF-3 structure. d Hf-BDC MOF structure. Red: oxygen; grey: carbon; purple: zinc; green: zirconium; blue: hafnium (Color figure online)

high levels of $\mathrm{OH}^{\bullet}$ after 40 min at $\mathrm{pH} 5$, based on the monitoring of the TMB absorbance at $652 \mathrm{~nm}$. In addition, the dissolved oxygen concentration (measured using a Unisense oxygen microelectrode) dropped to 4.4, 2.2 and $0.8 \mathrm{mg} / \mathrm{L}$ in the presence of 5,10 and $20 \mathrm{mM}$ of D-glucose, respectively, after $30 \mathrm{~min}$. Concurrently, HeLa and MCF-7 cancer cells and normal NIH3T3 cells were also used for in vitro studies. The ROS generation was again assessed by DCFH-DA staining and the cancer cells exhibited bright green DCF fluorescence, which was not the case for the healthy NIH3T3 cells. Quantitatively, the flow cytometry analysis showed that the ROS levels generated inside the HeLa and MCF-7 cells after $2 \mathrm{~h}$ were 8.1 and 3.7 times higher than that of the untreated cells. After $24 \mathrm{~h}$ of incubation, the NIH3T3 cell viability remained over $90 \%$ for concentrations of GOx\&Hb@ZIF-8 lower than $4 \mu \mathrm{g} / \mathrm{mL}$. However, the cancer cell viability decreased to $62 \%$ and $32 \%$ for HeLa and MCF-7 cells, respectively, at $2 \mu \mathrm{g} / \mathrm{mL}$. Moreover, the flow cytometry results based on Annexin V-FITC/PI staining showed that $63.1 \%$ of HeLa cells and $89.4 \%$ of MCF-7 cells were necrotic or apoptotic after $24 \mathrm{~h}$ at $4 \mu \mathrm{g} / \mathrm{mL}$ (compared to $7 \%$ for NIH3T3 cells). Compared to the rA-MOF, much lower concentrations of GOx\&Hb@ZIF-8 were needed to effectively kill cancer cells in vitro.

Again, nMOFs are appropriate candidates for Fentonbased therapy as they naturally carry metal ions. Their ease of decomposition in acidic environments allows them to release these active ions, resulting in the production of 


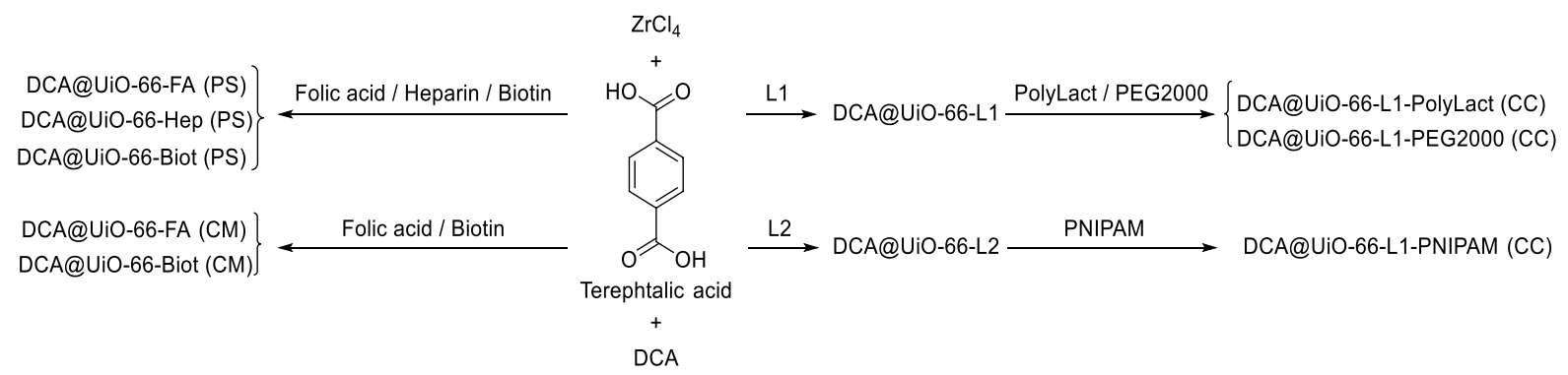

Fig. 22 Synthesis of DCA-loaded, surface functionalized UiO-66 MOFs through coordination modulation (CM), post-synthetic surface ligand exchange (PS) and click chemistry (CC) [103]

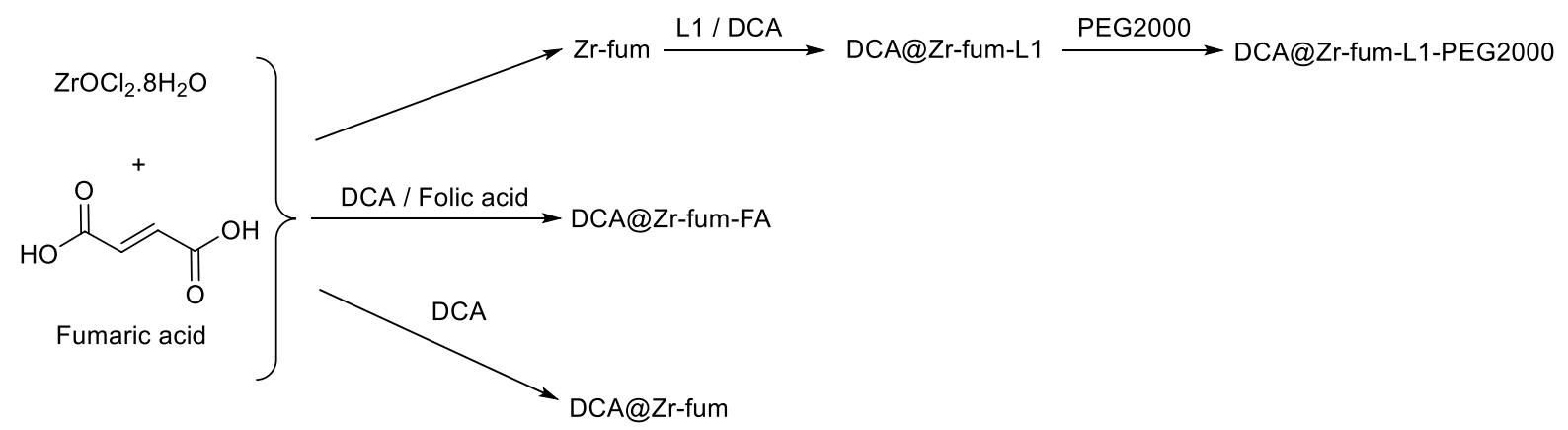

Fig. 23 Synthesis of DCA-loaded MOFs, surface functionalized Zr-fum MOFs [104]

ROS through various mechanisms, as described above. The in vitro cancer cell viabilities successfully decreased due to ROS generation. Despite the high levels of cell apoptosis and necrosis, in vitro cytotoxicity studies are as yet insufficient in assessing the clinical potential of the nMOFs. Indeed, apart from Du et al., no in vivo studies were carried out.

\subsubsection{Cytotoxic Protein Delivery}

Proteins plays an essential role in regulating cell metabolism and survival. The ribonucleases (RNases), for example, are enzymes capable of degrading RNA molecules. Indeed, in the case where the process renders the RNA strands illegible, the RNA cleavage can then lead to the inhibition of protein synthesis and to the overall cellular apoptosis. When the RNase is introduced directly into the cytosol, the cytotoxicity is 1000 times more effective than on the surface of the cell [100].

However, proteins are known for their poor cell permeability and alternatively nMOFs are attractive vehicles for active proteins, due to their tunable structure and efficient cell permeability. As such, Yang et al. encapsulated the cytotoxic RNase A-NBC protein in a ZIF-90 MOF [Appendix 2. (entry d)] for cytosolic delivery [101]. The nMOF decomposition occurs in the presence of high concentration of ATP, i.e. in the cytosol, as a result of the competitive coordination between ATP and the zinc metal centers. Compared to the free RNase A-NBC, ZIF-90/RNase A-NBC exhibited an enhanced cytotoxicity against HeLa cancer cells. Indeed, for a concentration of $135 \mu \mathrm{g} / \mathrm{mL}$, the cell viability fell to an impressive $15 \%$ while that of free RNase A-NBC remained constant at $85 \%$. Concurrently, Jia et al. synthesized an RNase A loaded ZIF-8 (RNase A@ZIF-8) [Appendix 2. (entry c)] and the results from the MTT assay showed that their NPs reduced the A549 cell viability to $52.2 \%$ at an RNase A concentration of $10 \mu \mathrm{g} / \mathrm{mL}$, after $48 \mathrm{~h}$ of incubation [102]. However, since the type of cancer cells is different from one investigation to another, and the concentration of RNase A inside the MOF differs as well, no reliable cytotoxic comparison can be drawn between both nMOFs. Jia et al. carried out further tests to assess the cytotoxic behavior of their nanocarriers. The cell survival rate was evaluated through Live/Dead staining assay where live cells exhibited green fluorescence, using calcein AM dye, while dead cells appeared red upon ethidium homodimer staining. Notably, the characteristic red fluorescence was barely visible for cells treated with free RNase A, as opposed to that of RNase A@ZIF-8 NPs. Finally, an LDH assay coupled with a TUNEL staining assay [26], revealed the nMOFs capacity for inducing cell apoptosis (i.e. $31.3 \%$ cell death compared to $25 \%$ for free RNase A). 


\subsection{Gene and Protein Modulators}

\subsubsection{Glycolysis Inhibition}

Consisting of a series of ten enzyme catalyzed reactions, the glycolysis metabolic pathway converts glucose into pyruvate and hydrogen ions. The energy released during the process triggers the formation of high energy molecules (ATP for example), which are necessary for the survival of the cells [103]. In cancer cells, pyruvate is transformed into lactate instead of acetyl-coenzymeA by pyruvate dehydrogenase kinase, which allows for the tumor to grow under hypoxic conditions [104]. Dichloroacetate [DCA, Appendix 1. (entry 12)] is a pyruvate dehydrogenase kinase inhibitor and has the ability to reverse the glycolysis process back to glucose oxidation, thus effectively prohibiting cancer cell apoptotic resistance [105]. However, since DCA is a hydrophilic molecule, it has difficulty crossing cell membranes. Abanades Lazaro et al. thus decided to encapsulate this molecule inside a Zr-MOF UiO-66 (Fig. 21a) to improve the cellular uptake and thereby cytotoxicity.

Recently, this group reported a first investigation describing the effect of different MOF surface coatings on the anticancer activity [106]. Cancer targeting biomolecules such as folic acid, biotin and heparin were attached to the MOF through coordination modulation or post-synthetic surface ligand exchange, while polyethylene glycol (PEG2000), poly-L-lactide (polylact) and poly- $\mathrm{N}$-isopropylacrylamide (PNIPAM) were covalently bonded by click-chemistry. All MOF codes are summarized in Fig. 22, where L1 and L2 refer to p-azidomethylbenzoic acid and p-propargyloxybenzoic acid, respectively. The in vitro cytotoxicity of the different synthesized MOFs was investigated against HeLa and MCF-7 cancer cells, and HEK293 normal cells. When incubated with empty MOFs for $72 \mathrm{~h}$, only PNIPAM coated MOFs were cytotoxic for concentrations over $0.25 \mathrm{mg} / \mathrm{mL}$. Unsurprisingly, the encapsulation of DCA in UiO-66-FA led to a 300-fold enhancement in cytotoxicity, compared to free DCA. The nMOFs prepared through coordination modulation have a higher folate content, which explains the observed decrease in cell viability to $14 \%$ compared to $>100 \%$ for the post-synthetically modified nMOFs at $0.25 \mathrm{mg} / \mathrm{mL}$, since the folate conjugate has cancer cell targeting abilities. In addition, since the HeLa cells have increased folate receptor overexpression, the cytotoxicity was higher than that of MCF-7 and HEK293 cells. DCA@ UiO-66-L1-polylact and DCA@UiO-66-L2-PNIPAM were also more cytotoxic towards HeLa cells, resulting in $100 \%$ cell death at $1 \mathrm{mg} / \mathrm{mL}$ and $0.25 \mathrm{mg} / \mathrm{mL}$, respectively. It is noteworthy that no cytotoxicity was observed for heparin and biotin coated MOFs due to inefficient cellular uptake and instability. Further tests were also carried out on DCA@ UiO-66-L1-PEG2000, which showed similar cytotoxicity results for both MCF-7 and HeLa cells $(32 \pm 3 \%$ and $50 \pm 3 \%$, respectively).

However, this latter MOF also induced cytotoxicity of healthy HEK293 cells ( $42 \pm 6 \%$ cell viability) at $1 \mathrm{mg} / \mathrm{mL}$. When incubated with macrophages (J774 cell line) and peripheral blood lymphocytes, DCA@UiO-66-L1-polylact and DCA@UiO-66-L2-PNIPAM killed almost all cells, the latter generating ROS in J774 cells. The authors concluded that the most effective DCA carrier was the UiO-66 MOF functionalized with folate via coordination modulation. As PEG- and folate-coated DCA-loaded UiO-66 MOFs showed the most promising results more research took place using this approach. Indeed, Abanades Lazaro et al. synthesized similar MOFs by replacing the terephthalic acid ligand for fumarate [107]. The DCA-encapsulated nMOFs were post-functionalized with p-azidomethylbenzoic acid (L1) and through coordination modulation with folic acid, to yield DCA@Zr-fum-L1 and DCA@Zr-fum-FA (b). The azide functionality of $\mathbf{L 1}$ was also used to covalently bond PEG2000 chains to form DCA@Zr-fum-L1-PEG2000. All MOF codes are summarized in Fig. 23.

Drug-free MOFs and DCA@Zr-fum-FA (constructed through coordination modulation) did not affect the HeLa cell viability even at high concentrations, whereas DCA@ Zr-fum-L1-PEG2000 exhibited a high cytotoxic behavior ( $<20 \%$ cell viability) for concentrations over $0.5 \mathrm{mg} / \mathrm{mL}$. This result suggests that $\mathrm{Zr}$-fum is a more effective drug delivery system than PEG-coated DCA@UiO-66, possib ly due to the difference in particle size. UiO-66 MOFs, synthesized with $\mathrm{ZrCl}_{4}$, were typically around $150 \mathrm{~nm}$ in size while $\mathrm{Zr}$-fum MOFs, synthesized with $\mathrm{ZrOCl}_{2} \cdot 8 \mathrm{H}_{2} \mathrm{O}$, were closer to $20 \mathrm{~nm}$ in size. The cellular uptake, usually achieved through endocytosis pathways for NPs larger than $20 \mathrm{~nm}$, was increased through passive diffusion [108]. The selectivity of cytotoxicity was assessed by incubating the NPs with MCF-7 and HEK293 cells. Both DCA@Zr-fumFA and DCA@Zr-fum-L1-PEG2000 showed similar results towards MCF-7 cells, where the viability dropped below $45 \%$ at $1 \mathrm{mg} / \mathrm{mL}$. However, DCA@Zr-fum-L1-PEG2000 also decreased the HEK293 cell viability to $50 \%$ for concentrations above $0.75 \mathrm{mg} / \mathrm{mL}$, which is similar to that of DCA@UiO-66-L1-PEG2000, thus questioning its potential for in vivo applications. Finally, J774 macrophages and peripheral blood lymphocytes were nearly unaffected by the NPs, which was not the case of DCA@UiO-66-L1PEG2000, where the cell viability fell below $75 \%$. All in all, comparing both investigations, the DCA@Zr-fum-FA $\mathrm{nMOF}$ synthesized via coordination modulation is seemingly the most effective nanocarrier of DCA for the inhibition of cancer cell glycolysis. 


\subsubsection{Gene Dysregulation}

In cancer cells, the internal disruption of cellular building blocks, such as proteins, genes and microtubules, can lead to apoptosis if properly targeted. When left unchecked, tumors can develop multi-drug resistance by overexpressing certain genes or proteins. For example, P-glycoprotein (P-gp) is known to reduce intracellular drug accumulation [109] while class III beta-tubulin regulates microtubule formation [110], polymers of tubulin that maintain cell viability and morphology. By down-regulating P-gp expression and disrupting microtubules, cancer cell growth could be effectively inhibited. To that effect, Chen et al. encapsulated small interfering RNA (siRNA) and selenium/ruthenium NPs in a MIL-101 MOF (denoted Se/Ru@MIL-101-siRNA, Appendix 2, entry a) [111]. siRNAs are able to silence genes and disrupt the microtubule dynamics, while selenium or ruthenium-based composites show anticancer activity $[112,113]$. Indeed, MTT assays showed that the MCF-7 cell viability fell below $35 \%$ after incubation with Se/Ru@ MIL-101 MOFs at $20 \mu \mathrm{g} /$ $\mathrm{mL}$. In order to evaluate the gene silencing properties, $\mathrm{Se} /$ Ru@MIL-101-siRNA was incubated with MCF-7 and MCF-7 Taxol resistant (MCF-7/T) cancer cells. P-gp and vascular endothelial growth factor (VEGF) expression was measured by immunofluorescence [114] and western blotting [115]. The presence of PsiRNA (pooled siRNA) and VsiRNA (VEGF siRNA) inside the MOFs effectively downregulated both P-gp and VEGF expression. The gene expression levels dropped below 40\% when using Se/Ru@ MIL101-(V+P)siRNA, compared to Se/Ru@MIL-101 MOFs, which left the protein levels unaffected in the MCF-7/T cells. Moreover, Se/Ru@MIL-101-(V+P)siRNA induced apoptosis by affecting the signaling pathways of phosphorylation of p53, MAPK and PI3K/Akt for example $[116,117]$. The AFM images confirmed that Se/Ru@MIL-101-(V+P) siRNA caused cell shrinkage and morphology destruction after $24 \mathrm{~h}$ of incubation due to microtubule and actin cytoskeleton damage. In addition, Se/Ru@ MIL-101-(V+P) siRNA caused an arrest of the cycle cell at the G0/G1 phase [118], with cell arrest proportions ranging from 53.58 to 57.99 and 43.86 to $53.83 \%$ for Se @ MIL-101-(V+P)siRNA and Ru@MIL-101-(V+P)siRNA, respectively. The authors speculated that the microtubule dynamic disruption led to the disorder of chromosome segregation and disorderly cell division, inducing apoptosis. The in vivo studies on mice bearing MCF-7 tumors and treated with Se/Ru@MIL101-(V+ P)siRNA showed a tumor inhibition rate of up to $79.4 \%$ compared to the untreated group. H\&E staining images of tumor tissues showed shrinkage, nuclei fragmentation and chromosome condensation, proving high levels of apoptosis.

Again, curcumin induces antitumor, antioxidant and antiproliferative effects, which can further be classified as a targeted therapy drug. Indeed, Ramachandran et al. showed curcumin's ability to up-regulate 22 genes while downregulating 17 others at both 25 and $50 \mu \mathrm{g} / \mathrm{mL}$ levels in MCF-7 cells [119]. However, the cellular uptake is limited due to limited absorption, rapid metabolism and systemic elimination [120]. To improve the bioavailability of curcumin, Laha et al. encapsulated the molecule inside an isoreticular nMOF (c), functionalized with folic acid (denoted IRMOF-3@CCM@FA) [121]. Compared to the drug-free IRMOF-3, IRMOF-3@CCM@FA exhibited an enhanced cytotoxicity towards MDA-MB-468 and $4 \mathrm{~T} 1$ cancer cells by decreasing the cell viability below $20 \%$ for concentrations over $80 \mu \mathrm{g} / \mathrm{mL}$. When treated with half-maximal inhibitory concentration (IC50) of IRMOF-3@CCM@FA (45.0 $\mu \mathrm{g} /$ $\mathrm{mL}$ ), annexin-V FITC staining revealed that $91 \%$ of MBAMB-468 cells underwent apoptosis after $24 \mathrm{~h}$. Furthermore, the apoptotic protein expression (Bax, Bcl2, p53, pBAD) was investigated by western blot analysis. Indeed, the cells incubated with IRMOF-3@CCM@FA showed reduced levels of Bcl2 and pBAD (anti-apoptotic) while those of Bax, p53 (pro-apoptotic) increased and the cell apoptosis was further induced by disrupting the mitochondrial membrane potential. Notch1 signaling pathways, known to promote cell proliferation and communication [122], were suppressed in IRMOF-3@CCM@FA treated MDA-MB-468 cells compared to empty IRMOF-3. Mice bearing TNBC tumors were injected with the MOF solutions and monitored for 30 days. The tumor weights of untreated and treated mice with IRMOF-3@CCM@FA/IRMOF-3 were 451.3, 278.1 and $67.2 \mathrm{mg}$, respectively, confirming their efficiency in in vivo tumor inhibition.

\subsubsection{DNA Damage Repair Inhibitors}

As the name suggests, DNA damage repair (DDR) inhibitors prevent the DNA of the cancer cell from repairing itself, thus effectively leading to cell apoptosis. Neufeld et al. designed a PEG functionalized hafnium-based MOF using terephtalic acid as a ligand, containing two DDR inhibitors [denoted TB@Hf-BDC-PEG, (d)] [123]. In this work, radiotherapy was combined with targeted therapy for an optimal anticancer treatment. While intense X-rays triggered DNA damage in cancer cells, talazoparib and buparlisib [Appendix 1. (entry 9-10)] respectively suppressed the DDR proteins poly(ADP-ribose) polymerase and phosphoinositide 3-kinase. In this case, Hf-BDC-PEG showed negligible cytotoxicity towards NIH3T3 normal cells and 4T1 cancer cells, while drug loading caused 4T1 cell viability to drop below $60 \%$ for $\mathrm{nMOF}$ concentrations over $1 \mu \mathrm{g} / \mathrm{mL}$. In order to assess the amount of DNA damage after irradiation and the subsequent amount of DDR, 4T1 cells were also incubated in the presence of the nMOFs and a DNA doublestrand biomarker histone $\mathrm{H} 2 \mathrm{AX}$, which is phosphorylated 


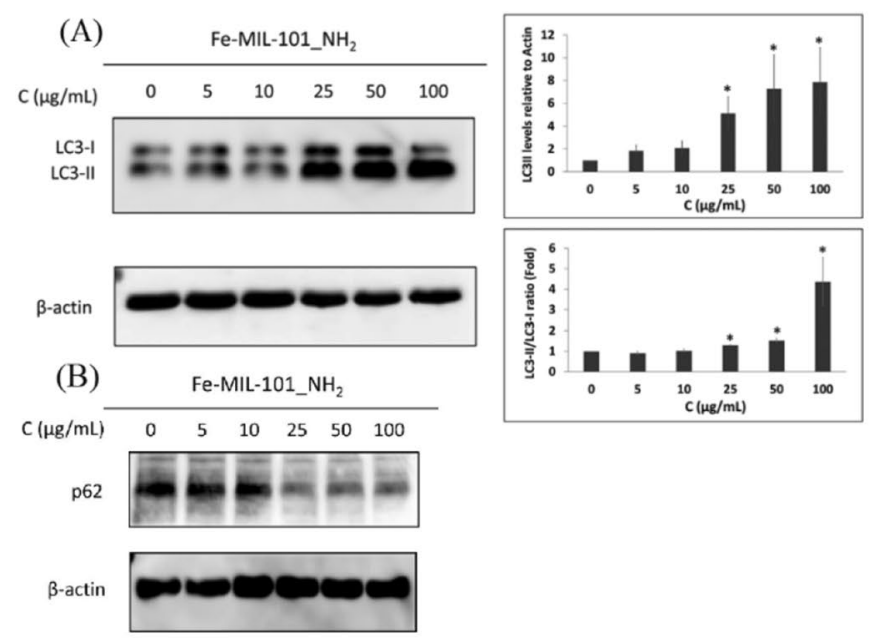

Fig. 24 a Expression levels of LC3-I and LC3-II in MEFs after exposure to Fe-MIL-101-NH2 at different concentrations for $24 \mathrm{~h}$. b Expression levels of p62 in MEFs treated with Fe-MIL-101-NH2 at different concentrations. c Expression levels of mTOR, Becline1 and

into $\mathrm{YH} 2 \mathrm{AX}$ in response to the DNA damage. Indeed, the number of microscopically visible $\mathrm{YH} 2 \mathrm{AX}$ foci per nucleus is a direct indication of the number of DNA double-strands [124]. Irradiated free TB and TB@Hf-BDC-PEG had the largest amount of foci per cell (16 foci/cell compared to 14.6 foci/cell for the drug-free MOF). After 24 h, TB@Hf-BDCPEG caused a significant increase in $\mathrm{YH} 2 \mathrm{AX}$ foci per cell ( 25 foci/cell, compared to 16 foci/per for free talazoparib and buparlisib). Concurrently, mice bearing 4T1 tumors were treated with a control phosphate-buffered saline solution, TB@Hf-BDC-PEG and Hf-BDC-PEG. Without radiotherapy, the antitumor activity turned out to be almost non-existent. Radiotherapy also allowed for a reduction in tumor growth in the case of both Hf-BDC-PEG and TB@ Hf-BDC-PEG compared to the control group. Since in vitro results do not take into account the immune response, the difference between in vitro and in vivo data can easily be explained. The Hf-BDC-PEG response was similar to that of hafnium oxide NPs, which generated an immune response, thus enhancing the effect of radiotherapy [125]. Unsurprisingly, H\&E staining revealed that the extent of apoptosis was higher for the radiotherapy treated groups, with mice treated with TB@Hf-BDC-PEG exhibiting apoptosis throughout the entire tumor.

\subsection{Angiogenesis Inhibitors}

Angiogenesis is the formation of new blood vessels from a pre-existing vascular network. As it provides oxygen and nutrients to tumors, inhibiting this process could prove effective in limiting cancer cell proliferation and metastasis. Matrix metalloproteinases (MMP) are zinc binding proteins
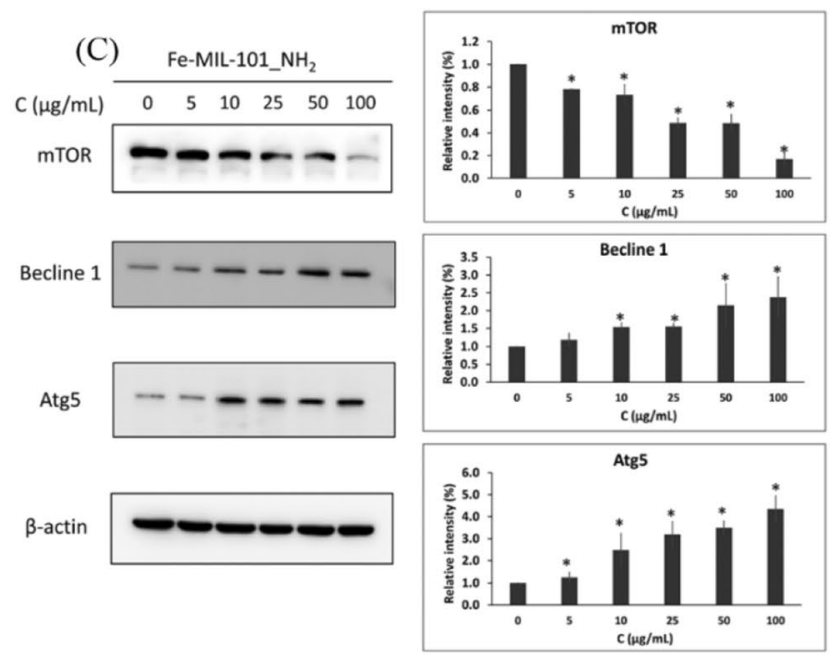

Atg5 in MEFs after exposure to Fe-MIL-101-NH2 at different concentrations for $24 \mathrm{~h} . * \mathrm{p}<0.05$ compared with control group. Data are expressed as mean \pm S.D. $n=3$ [134]. Reproduced with permission from The Royal Society of Chemistry

that degrade the extracellular matrix and as such their inhibition would reduce angiogenesis [126]. Different NPs have been used to that effect, namely iron oxide NPs, fullerenebased $\mathrm{Gd} @ \mathrm{C}_{82}(\mathrm{OH})_{22}$ [127], hollow mesoporous carbon NPs [128] and polysaccharide-based hydrogels [129]. Wang et al. investigated the inhibitory properties of a Fe-MIL-101 MOF [Appendix 2. (entry a)] on MMP-2/9 expression in human umbilical vein endothelial cells (HUVECs), SKOV3, $\mathrm{HeLa}$ and A549 cancer cells [130]. The in vitro cytotoxicity of the empty MOF was tested against each of the aforementioned cell lines and the MTT assay results showed IC50s of $33.5,56.5,41.9$ and $74.6 \mu \mathrm{g} / \mathrm{mL}$, respectively, compared to $91.2 \mu \mathrm{g} / \mathrm{mL}$ for normal mice BABL-3T3 cells after $24 \mathrm{~h}$. Fe-MIL-101 showed selective cytotoxicity, which increased with the incubation time and MOF concentration. Other types of MIL MOFs including MIL-100, MIL-101-NH (Appendix 2. (entry a), MIL-88B (Fig. 19), demonstrated much higher IC50 values, ranging from 690 to $2500 \mu \mathrm{g} /$ $\mathrm{mL}$ when tested against HeLa cells. Since both terephthalic acid and iron(III) chloride are non-toxic (IC50>1000 $\mu \mathrm{g} / \mathrm{mL}$ for all cell lines), therefore the cytotoxicity of Fe-MIL-101 is inherent to the MOF itself. After these general observations, the study focused on HUVECs, as the endothelial cells are crucial to the formation of new blood vessels. Treating HUVECs with Fe-MIL-101 MOFs for 24, 36, 48 and $72 \mathrm{~h}$ resulted in inhibitory rates of $40.6 \pm 1.5 \%, 50.1 \pm 3.2 \%$, $68.4 \pm 4.4 \%$ and $89.4 \pm 1.6 \%$ for $25 \mu \mathrm{g} / \mathrm{mL}$, respectively. Furthermore, an FITC-AnnexinV/PI assay as well as mitochondrial potential and G0/G1 phase cell cycle measurements confirmed that Fe-MIL-101 induced HUVEC apoptosis through a mitochondrial pathway and G0/G1 cell cycle arrest. The MOF also had an effect on the HUVEC migration 
Table 4 In vitro cytotoxicity of different MOFs in targeted therapy

\begin{tabular}{|c|c|c|c|c|c|}
\hline & \multirow[t]{2}{*}{$\mathrm{nMOF}$} & \multicolumn{3}{|l|}{ In vitro cytotoxicity } & \multirow[t]{2}{*}{ References } \\
\hline & & Cell type & $\begin{array}{l}\text { nMOF con- } \\
\text { centration }(\mu \mathrm{g} / \\
\mathrm{mL})\end{array}$ & Cell viability $(\%)$ & \\
\hline \multirow[t]{4}{*}{ ROS generation } & rMOF-FA & HeLa & 40 & 54 & [93] \\
\hline & G-BHM & SGC-7901 & 200 & 55 & {$[95]$} \\
\hline & (1) & A549 & $>5$ & $<10$ & [97] \\
\hline & GOx\&Hb@ZIF-8 & $\begin{array}{l}\text { HeLa } \\
\text { MCF-7 }\end{array}$ & 2 & $\begin{array}{l}62 \\
32\end{array}$ & [100] \\
\hline \multirow[t]{2}{*}{ Protein delivery } & ZIF-90/RNase A-NBC & HeLa & 135 & 15 & {$[102]$} \\
\hline & RNase A@ZIF-8 & A549 & 10 & 52.2 & [103] \\
\hline \multirow[t]{2}{*}{ Glycolysis inhibition } & DCA@UiO-66-FA; DCA@UiO-66-PEG2000 & HeLa; MCF-7 & $250-1000$ & $14-50$ & [107] \\
\hline & DCA@Zr-fum-FA; DCA@Zr-fum-L1-PEG2000 & HeLa; MCF-7 & $\begin{array}{l}>500 \\
1000\end{array}$ & $\begin{array}{l}<20-100 \\
<45\end{array}$ & {$[108]$} \\
\hline \multirow[t]{2}{*}{ Gene dysregulation } & Se/Ru@MIL-101-(V+P)siRNA & MCF-7; MCF-7/T & 10 & $<40$ & {$[112]$} \\
\hline & IRMOF-3@CCM@FA & MDA-MB-231; 4T1 & $>80$ & $<20$ & [122] \\
\hline DDR inhibitor & TB@Hf-BDC-PEG & $4 \mathrm{~T} 1$ & $>1$ & $<60$ & [124] \\
\hline Angiogenesis inhibitor & Fe-MIL-101 & $\begin{array}{c}\text { HeLa; A549; } \\
\text { SKOV3; } \\
\text { HUVECS }\end{array}$ & 50 & $20-60$ & [131] \\
\hline Autophagy inhibitor & FA-PEG/CQ@ZIF-8 & $\mathrm{HeLa}$ & 5 & 49.4 & {$[140]$} \\
\hline
\end{tabular}

and vessels tube-like formation. Scratching the cell surface normally triggers the migration of endothelial cells but the presence of Fe-MIL-101 successfully inhibited 50\% of cell migration after $24 \mathrm{~h}$ of incubation. In addition, the HUVECs formed a dense tube network $12 \mathrm{~h}$ after the post-seeding under VEGF, which is known to induce the proliferation and differentiation of HUVECs. However, introducing the MOF $(12.5-25 \mu \mathrm{g} / \mathrm{mL})$ reduced the tube length by between 60 and $90 \%$. The inhibition effects are superior to those observed for the silver NPs $(80 \mu \mathrm{g} / \mathrm{mL})$ [131] and SU5416 [132], the latter one being a selective inhibitor of VEGF tyrosine kinase activity. Finally, western blot analysis showed that Fe-MIL-101 reduced the expression of MMP-2/9 in both SKOV3 cells and HUVECs in a dose-dependent manner, which successfully suppressed the angiogenesis in vitro. Compared to the $\mathrm{Gd} @ \mathrm{C}_{82}(\mathrm{OH})_{22}$ NPs [124] and hollow mesoporous carbon NPs [125], the Fe-MIL-101 s are far easier to synthesize (Fig. 1) and hold promise for in vivo applications.

\subsection{Autophagy in Cancer Cells}

Autophagy is a cellular mechanism designed to degrade and recycle dysfunctional proteins or organelles, by engulfing them in autophagosomes. Autophagosomes merge with the lysosome and their contents and are degraded by lysosomal acid proteases. The level of autophagy actually determines whether it promotes cell survival or cell death [133]. As MOFs are becoming increasingly popular in the medical field, Shen et al. decided to investigate the effect of a FeMIL-101- $\mathrm{NH}_{2}$ MOF [Appendix 2. (entry a)] on autophagy in mouse embryonic fibroblast (MEFs) cells [134]. The cellular morphology, viability and apoptosis characterizations showed that the MOF was non-toxic. A CCK-8 assay proved that the cell viability remained at $90 \%$ for concentrations as high as $100 \mu \mathrm{g} / \mathrm{mL}$ while Hoechst/PI staining [135] and flow cytometry confirmed that a mere $2 \%$ of the cells underwent apoptosis. To evaluate the level of autophagy, western blot was used to estimate the level of protein light chain 3 (LC3). LC3 is an essential protein for autophagosome biogenesis and maturation, while pG2 is a multifunctional adaptor protein that is specifically degraded by autophagy in normal cells [136]. During autophagy activation, the pG2 levels are normally low and LC3 is converted from LC3-I to LC3-II through phosphatidylethanolamine conjugation. The level of LC3-II correlates with the number of completed autophagosomes [137]. After incubation with the nMOFs, the conversion rates of LC3-I to LC3-II increased with the concentration (Fig. 24a) while the pG2 levels gradually decreased (Fig. 24b), indicating successful autophagy. In addition, the mTOR, Beclin1 and Atg5-Agt12 protein levels were examined as mTOR inhibits autophagy while the other proteins also assist in the formation of autophagosomes [133]. Since the expression of mTOR was decreased, while that of Beclin1 and Agt5 increased (Fig. 24c), the synthesized nMOF proved to be an effective autophagy inducer in MEF cells.

Induced autophagy can also supply cancer cells with energy and nutrients, reduce cellular stress and promote 


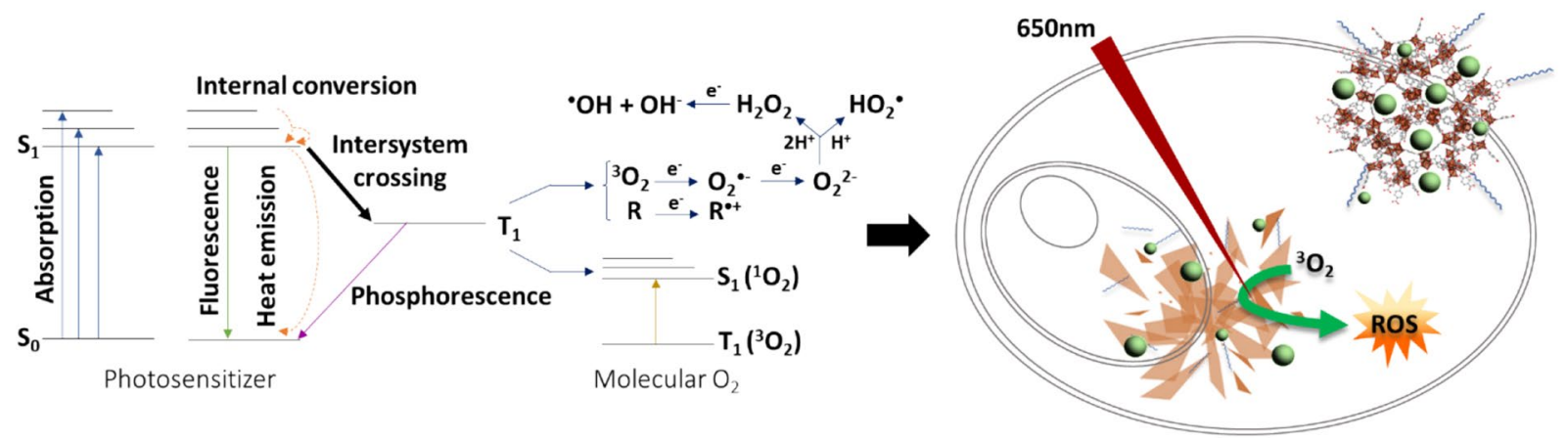

Fig. 25 Photophysical processes and nMOF-mediated PDT. Green circle Photosensitizers (Color figure online)

overall cellular survival through the release of ATP, for example. To counter this, Shi et al. designed a ZIF-8 MOF [Appendix 2. (entry c)] containing an autophagy inhibitor, chloroquine diphosphate, and coated with PEG conjugated targeting folic acid (denoted FA-PEG/CQ@ZIF-8) [138]. The HeLa cell viability dropped to $49.4 \%$ after a $24 \mathrm{~h}$ incubation in the presence of the nMOFs, compared to $75.8 \%$ when incubated with CQ@ZIF-8, proving the targeting ability of the folic acid. The effects on autophagy of the HeLa cancer cells and HEK293 normal cells were assessed by examining western blot data and protein levels of LC3-I, LC3-II, pG2, Atg5 and Beclin1. Compared to HEK293 and HeLa cells incubated with free chloroquine diphosphate, the HeLa cells containing FA-PEG/CQ@ZIF-8 nMOFs showed elevated levels of pG2 and LC3-I while the Beclin1 and Atg5 expressions decreased, indicating a successful autophagy inhibition via the targeted release of chloroquine diphosphate. To confirm the lack of autophagosome formation, the cells were stained with monodansylcadaverine, a fluorescent marker of autophagosome formation. The HeLa cells incubated with FA-PEG/CQ@ZIF-8 showed weaker fluorescence intensity than those incubated with chloroquine diphosphate alone, which suggests that the nMOF enhances the inhibition properties of chloroquine diphosphate autophagy.

The use of nMOFs as targeted therapy agents is still new and because of this, it is difficult to draw broad conclusions with such a small sample of investigations. Since tumors are complex entities, made up of various types of cells and reliant on the tumor micro-environment to supply nutrients and signal molecules, the efficiency of the different targeted therapies will vary from one tumor to the next. For example, even though Song et al.'s nMOF caused high A549 cell cytotoxicity at very low concentrations [93], the same results may not be achieved for HeLa or MCF-7 cells. Combining different therapies could potentially increase the antitumor activity. Indeed, encapsulating both DCA and RNase A inside Ranji-Burachaloo et al.'s rMOF-FA [92] could lead to a three-sided attack on Hela cells via ROS generation, cytotoxic protein and glycolysis inhibitor deliveries (Table 4). Moreover, intra-cellular mechanisms, such as angiogenesis and autophagy, have only been studied using one or two types of nMOFs, which significantly limits the scopes. Future research should focus on understanding the interactions between different types of nMOFs and cancer cells to better target specific mechanisms.

\section{Photodynamic therapy (PDT)}

Phototherapy utilizing MOFs in general as photosensitizer has become a subject of increasing interest over the past five years [139]. Photodynamic therapy involves the production of cytotoxic ROS when a photosensitizer is irradiated at around $650 \mathrm{~nm}$ in the presence of oxygen. When a photosensitizer in its ground state $\left(\mathrm{S}_{0}\right)$ absorbs a photon, it is promoted to its first excited singlet state, $S_{1}$. Then this energy is released almost instantly by emitting fluorescent light or the photosensitizer relaxes through a non-radiative internal conversion and the energy is lost into heat. However, this $S_{1}$ species, ${ }^{1}$ photosensitizer*, can also undergo an intersystem crossing to populate a first excited triplet state, $\mathrm{T}_{1}$. A second intersystem crossing results in the decay from $T_{1}$ to $S_{0}$ via phosphorescence or internal conversion. The forbidden nature of these processes makes the $T_{1}$ lifetime conveniently longer than that of $\mathrm{S}_{1}$ (Fig. 25) [140].

A $T_{1}$ species can further undergo two types of photochemical reactions. A type 1 reaction involves the photosensitizer directly reacting with intracellular molecules to form radicals or superoxide anions $\left(\mathrm{O}_{2}{ }^{--}\right) \cdot \mathrm{O}_{2}{ }^{\bullet-}$ subsequently generates $\mathrm{H}_{2} \mathrm{O}_{2}$ and $\mathrm{HO}_{2}{ }^{\bullet}$ via dismutation, while also participating in the production of hydroxyl radicals $\left({ }^{\circ} \mathrm{OH}\right)$ by reducing metal ions that are used to convert $\mathrm{H}_{2} \mathrm{O}_{2}$ into ${ }^{\circ} \mathrm{OH}$ (Fenton reaction). In a type 2 reaction, the excited photosensitizer transfers its electron to intracellular $\mathrm{O}_{2}$, forming excited state singlet oxygen $\left({ }^{1} \mathrm{O}_{2}\right)$ (Fig. 25) [141]. These oxidizing agents then attack the cellular components such as DNA or amino acids, but their effective surface area is ultimately limited by 


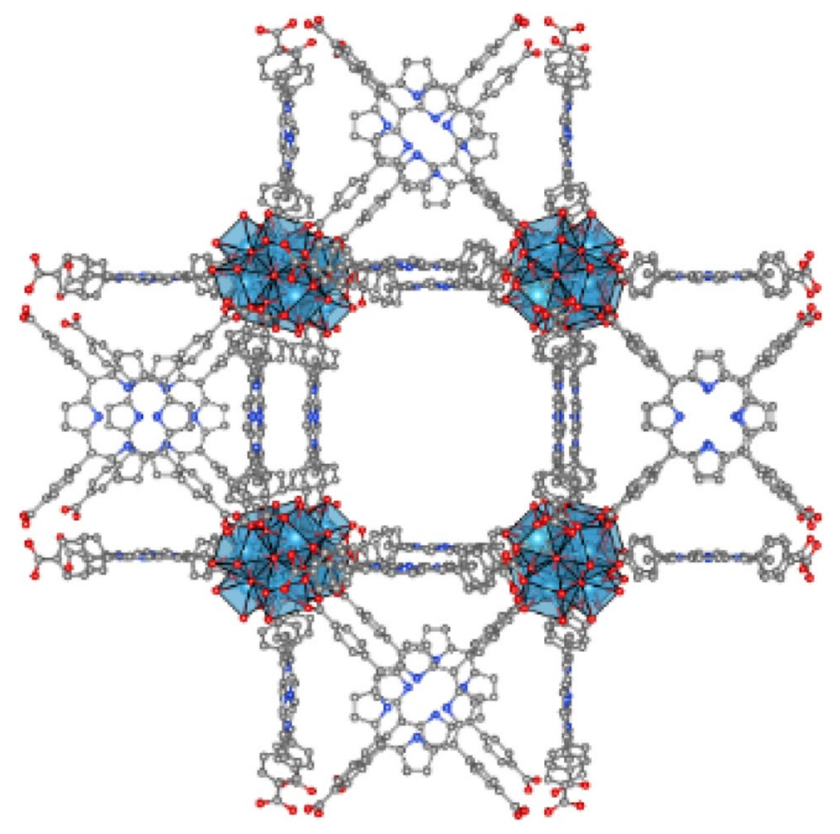

Fig. 26 Hafnium-porphyrin nMOF structure (Color figure online)

their high reactivity and short half-life. Hence the need for nMOFs, which offer localized and improved photodynamic therapy. Photosensitizers can either be directly incorporated into the framework, which is the case for porphyrin-based nMOFs; encapsulated inside the pores, or simply attached to the surface.

\subsection{Photosensitizers as nMOF Structure Components}

\subsubsection{Choice of Metal Centers or Ligands}

Due to the presence of a repetitive $\pi$-bonding structure and semi-conductive properties, certain nMOFs can be used to generate cytotoxic intracellular ROS for photodynamic therapy. Their capacity to do so depends on the choice of metallic centers and ligands. Liu et al. studied isoreticular MIL-53 s (Fig. 3a), specifically MIL-53(Fe), MIL-53(Cr) and MIL-53(Al) [142]. Aqueous suspensions of the nMOFs were irradiated at $365 \mathrm{~nm}$ and different scavengers were used to probe the generation of ${ }^{1} \mathrm{O}_{2}, \mathrm{O}_{2}{ }^{\bullet-},{ }^{\bullet} \mathrm{OH}$. Firstly, furfuryl alcohol was used to assess the amount of singlet oxygen generated at a specific irradiation time, its decrease indicating the formation of ${ }^{1} \mathrm{O}_{2}$. HPLC results showed that the furfuryl alcohol loss reached $90 \%$ for MIL-53(Fe), compared to $20 \%$ for MIL-53(Cr) and MIL-53(Al) within $40 \mathrm{~h}$. In contrast, furfuryl alcohol levels remained unchanged for nMOFs kept in the dark. Secondly, the superoxide output was monitored using nito blue terazolium salt, which is reduced to a purple monoformazan product in the presence of $\mathrm{O}_{2}{ }^{\bullet-}$.
The absorbance at $530 \mathrm{~nm}$ indicated that the amount of nito blue terazolium salt reduction varied as MIL-53(Cr) $>$ MIL$53(\mathrm{Fe})>$ MIL-53(Al). Finally, the generation of ${ }^{\bullet} \mathrm{OH}$ in nMOFs suspensions was monitored using pCBA. No pCBA decay was observed in the dark while the amount of ${ }^{\bullet} \mathrm{OH}$ followed the order MIL-53(Fe) $>$ MIL-53(Cr) = MIL-53(Al) for irradiated suspensions. When incubated with HepG2 cancer cells in vitro for $72 \mathrm{~h}$, the cytotoxicity of MIL-53 nMOFs varied as MIL-53(Al) > MIL-53(Fe) > MIL-53(Cr), due to increased ROS generation in Fe and Cr MIL-53 nMOFs.

Besides metal nodes, the choice of ligand can also significantly affect the PDT efficiency of a nanostructure. The ligand tertrakis(4-carboxyphenyl)porphyrin (TCPP, Appendix 1, entry 30) is commonly used for its photosensitizing properties, belonging to the vast family of porphyrinic compounds. Generally, porphyrins are intensely colored dyes consisting of a porphin core onto which various functional groups, such as carboxylic acids, sugars, carbon chains or phenyl groups, are attached. For example, Li et al. studied the photophysical and cellular properties of 5,10,15,20-tetrakis[(5-diethylamino)pentyl]porphyrin. Upon irradiation with a $630 \mathrm{~nm}$ laser, the dye effectively produced ${ }^{1} \mathrm{O}_{2}$, causing Eca-109 cancer cells apoptosis in vitro, while greatly inhibiting the growth of Eca-109 xenograft tumors in mice. Porphyrins have a tendency to aggregate resulting in both reduced triplet state lifetimes and decreased ${ }^{1} \mathrm{O}_{2}$ generation during PDT [143]. In addition, combining porphyrins with electron-rich donors such as transition metals can improve their ability to absorb red light, thus enhance light penetration in biological tissues.

Consequently, nMOFs are increasingly attractive as they increase the porphyrin stability and efficiency. To that effect, Chen et al. synthesized a PEG covered hafnium porphyrin nMOF (Fig. 26; denoted NMOF-PEG) for combined photodynamic and radiation therapy [144]. The ${ }^{1} \mathrm{O}_{2}$ generation efficiency of both free TCPP and the PEG-NMOF were estimated using singlet oxygen sensor green (SOSG, Appendix 1. entry 28), a highly selective reagent exhibiting bright green fluorescence in the presence of ${ }^{1} \mathrm{O}_{2}$. After a $1 \mathrm{~h}$ exposure to a $661 \mathrm{~nm}$ laser $\left(5 \mathrm{~mW} / \mathrm{cm}^{2}\right)$, the PEG-NMOF showed a 2.45 -fold increase in ${ }^{1} \mathrm{O}_{2}$ generation compared to free TCPP $(1 \mu \mathrm{M})$, due in part to the nMOF structure itself, where the ligands are isolated in the framework thus avoiding self-quenching of the excited states. Cytotoxicity assays were then carried out against 4T1, HeLa cancer cells and NIH3T3 normal cells. For TCPP in the dark with a concentration of $80 \mathrm{mg} / \mathrm{mL}$, cell viability remained $>80 \%$ for all cell types. However, a 30-min laser irradiation caused $4 \mathrm{~T} 1$ cell viability to drop below $20 \%$, compared to $40 \%$ for free TCPP. Finally, the combined treatment was evaluated in vivo on mice bearing 4T1 tumors. It is worth noting that the photodynamic treatment was carried out $8 \mathrm{~h}$ post radiation therapy in order to recover tumor oxygenation. For mice 


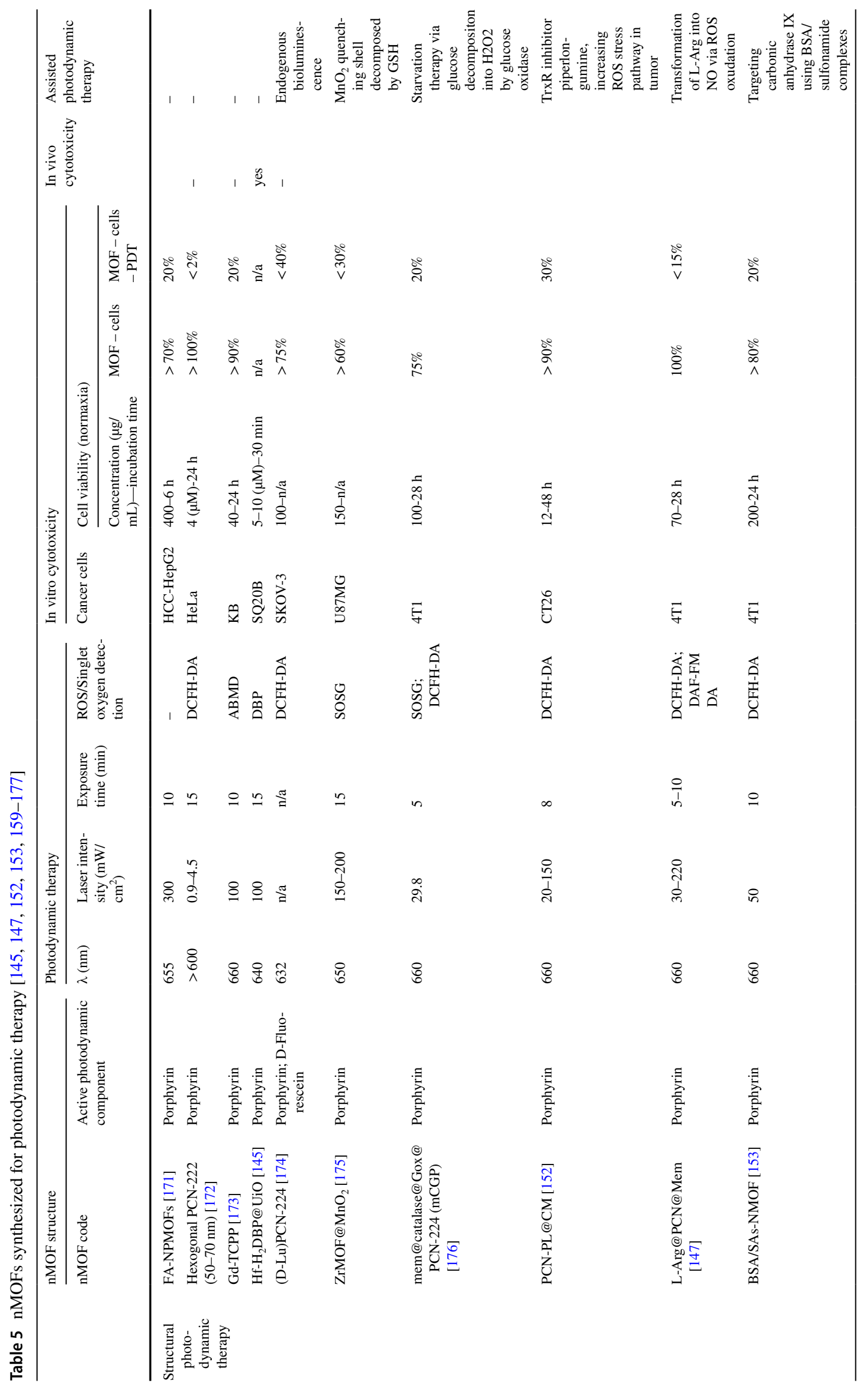




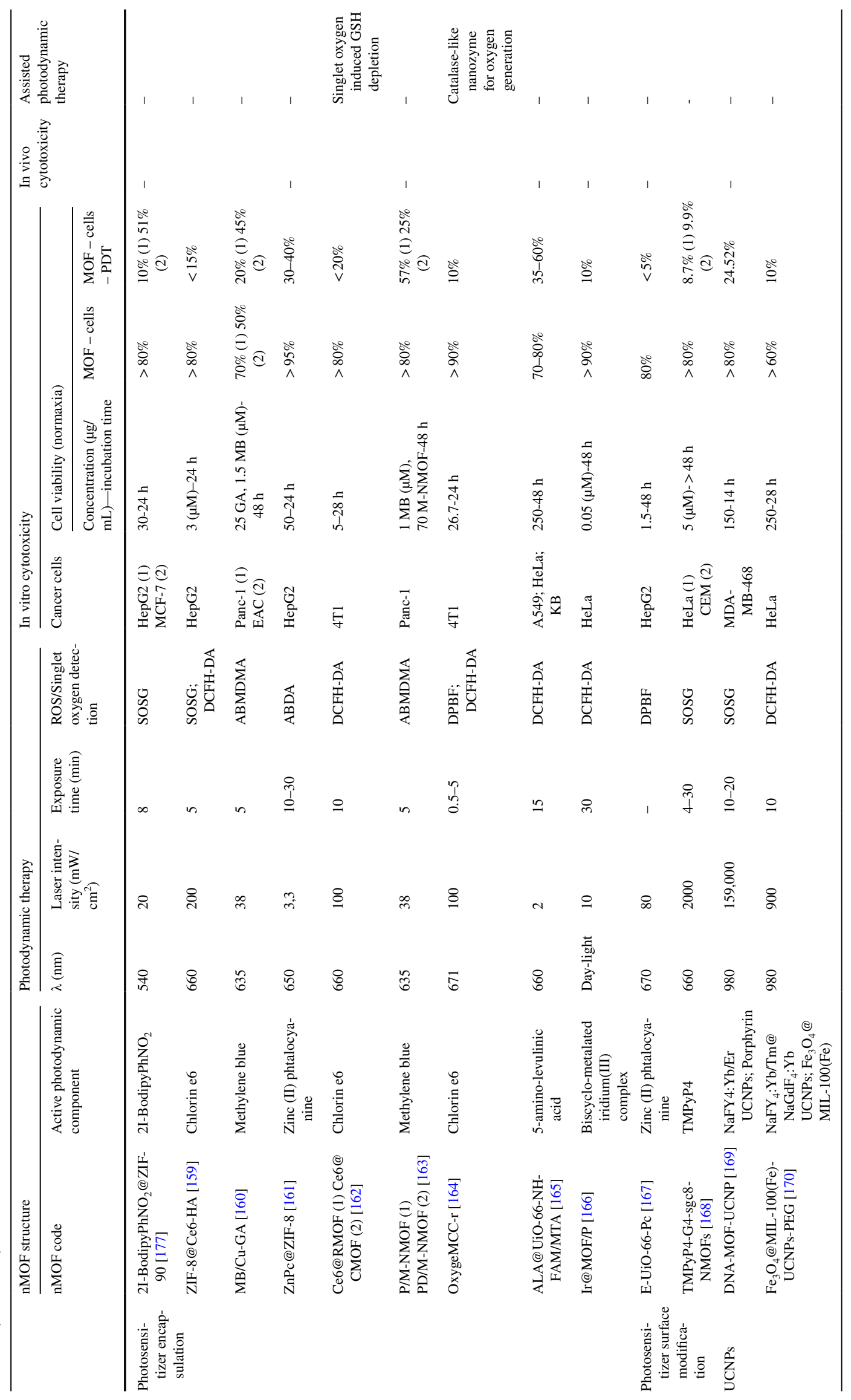


treated only with PDT, the tumor growth was delayed but not inhibited whereas the combined treatment successfully suppressed tumor growth after 14 days. H\&E staining of major organs showed no toxic side effects while a serum biochemistry assay and a complete blood panel test proved that all measured parameters were normal.

Other examples of porphyrin-based nMOFs are presented in Table 5 [145]. All of them achieve efficient in vitro cytotoxicity, with cell viability dropping to $20 \%$ or less after irradiation. However, no definite comparison can be made as the nMOF concentration, type of targeted cancer cells, irradiation time and laser power intensity, differ.

\subsubsection{Improving Porphyrin-Based Photodynamic Therapy}

PDT can be enhanced by combining the photosensitizing properties of porphyrin ligands with other chemicals. Notably, Chen et al. encapsulated $\alpha$-cyano-4-hydroxycinnamate (CHC) into a porous, hyaluronic acid-coated, $\mathrm{Zr}(\mathrm{IV})$-based porphyrin nMOF (CHC-PZM@HA, Fig. 17 b) in order to inhibit the expression of monocarboxylate transporter 1 (MCT1), a protein responsible for lactate uptake in tumors [146]. Lactate has been reported as vital in maintaining tumor microenvironment by promoting metastasis and stimulation angiogenesis. The inhibition of MCT1 would suppress lactate oxidation into ATP, necessary for cellular growth, thus increasing the intratumoral $\mathrm{O}_{2}$ levels for more efficient photodynamic therapy [147]. The capacity of the PZM NPs to generate ROS was first evaluated by DCFH-DA, where an intense green fluorescence was observed after a $30 \mathrm{~s} 660 \mathrm{~nm}$ irradiation, in the normaxic environment $\left(21 \% \mathrm{O}_{2}\right)$. The intensity decreased somewhat in the hypoxic environment $\left(5 \% \mathrm{O}_{2}\right)$ which proved that $\mathrm{ROS}$ generation was inherently dependent on the amount of surrounding oxygen. CT26 cancer cells were then incubated in Lactate-1640 medium with $\mathrm{CHC}$ and intracellular hypoxia was monitored using ROS-ID as a fluorogenic probe. Confocal laser scanning microscopy images exhibited weaker red fluorescence compared to the control cells, proving that $\mathrm{CHC}$ effectively reduced hypoxia. Based on these results, the intracellular ROS production of CHC-PZM@HA in CT26 cells was investigated. Compared to PZM or CHC, the nanostructures exhibited stronger ROS generation in both normoxic and hypoxic conditions after incubation and subsequent irradiation. For a nMOF concentration of $66 \mu \mathrm{g} / \mathrm{mL}$, cell viability decreased to 30 and $17 \%$ in hypoxic and normoxic environments, respectively. In the dark, cell viability remained at $80 \%$, indicating the non-toxic nature of the nMOFs. In vivo tests were finally carried out on mice bearing CT26 tumors. Following injection and irradiation, mice treated with CHC-PZM@HA showed successful tumor growth inhibition after 16 days, attributed to the targeting ability of hyaluronic acid and increased ROS generation.

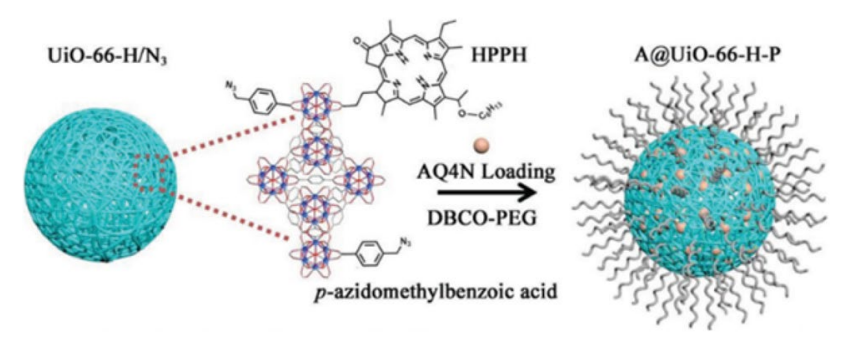

Fig. 27 Preparation of A@UiO-66-H-P. Reproduced with permission from WILEY (Color figure online)

The results were corroborated by a TUNEL assay and H\&E staining, showing increased apoptosis of CT26 tumor cells compared to the controls.

Another example of enhanced porphyrin-based PDT was put forward by Zhang et al., in which they decorated a $\mathrm{Zr}$ (IV) porphyrinic nMOF (Fig. 17b) with PEG-coated Pt nanozymes (denoted PCN-224-Pt) [148]. Pt nanozymes are metallic NPs possessing enzyme mimetic properties such as the ability to scavenge ${ }^{1} \mathrm{O}_{2}$ and $\mathrm{O}_{2}{ }^{\bullet-}$ thereby producing intracellular $\mathrm{O}_{2}$ and $\mathrm{H}_{2} \mathrm{O}_{2}$ [149]. The nanostructure increased the stability of the Pt nanozymes while showing excellent biocompatibility. After showing the catalyse-like activity of the nMOF for inducing $\mathrm{H}_{2} \mathrm{O}_{2}$ decomposition into $\mathrm{O}_{2}$, the ROS generation capacity was evaluated using DCFH-DA and ${ }^{1} \mathrm{O}_{2}$ specific 1,3-diphenylisobenzofuran (DPBF, Appendix 1. entry 29) probe molecules. Under $638 \mathrm{~nm}$ irradiation $\left(1 \mathrm{~W} / \mathrm{cm}^{2}\right)$ in normoxic conditions, PCN-224-Pt generated a similar amount of ROS and ${ }^{1} \mathrm{O}_{2}$ to that of PCN-224, in the presence of $\mathrm{H}_{2} \mathrm{O}_{2}$. In hypoxic conditions, the amount of ${ }^{1} \mathrm{O}_{2}$ generated by PCN-224-Pt without $\mathrm{H}_{2} \mathrm{O}_{2}$ was identical to that of PCN-224 with and without $\mathrm{H}_{2} \mathrm{O}_{2}$. However, the addition of $\mathrm{H}_{2} \mathrm{O}_{2}$ caused a significant rise in ${ }^{1} \mathrm{O}_{2}$ production for the PCN-224-Pt nMOF, illustrating its capacity for enhanced PDT. Next, in vitro experiments were carried out against HeLa cancer cells. Without irradiation, cell viability remained over $80 \%$ at $25 \mu \mathrm{g} / \mathrm{mL}$ and weak DCFH-DA fluorescence was observed confirming the absence of ROS. In contrast, irradiated cells showed bright green fluorescence and cell viability dropped below $20 \%$. In vivo tests were then carried out on mice bearing H22 tumors. After 14 days, only those injected with PCN-224-Pt and subsequently irradiated exhibited complete tumor growth inhibition and extensive damage to tumor cells as the TUNEL assay and H\&E staining attest.

Table 5 shows six other types of assisted porphyrinbased PDT. The synthesized nMOFs have the added value of having been tested in vivo, which is not the case for most other porphyrin-based nMOFs. Wan et al. seem to have the most promising nMOF, causing 4T1 cell viability to drop below 15\%, while exhibiting no dark cytotoxicity [150]. Indeed, upon irradiation, the nMOF produces ROS capable 
Fig. 28 Schematic illustration of TPZ/UCSs nMOFs (Color figure online)
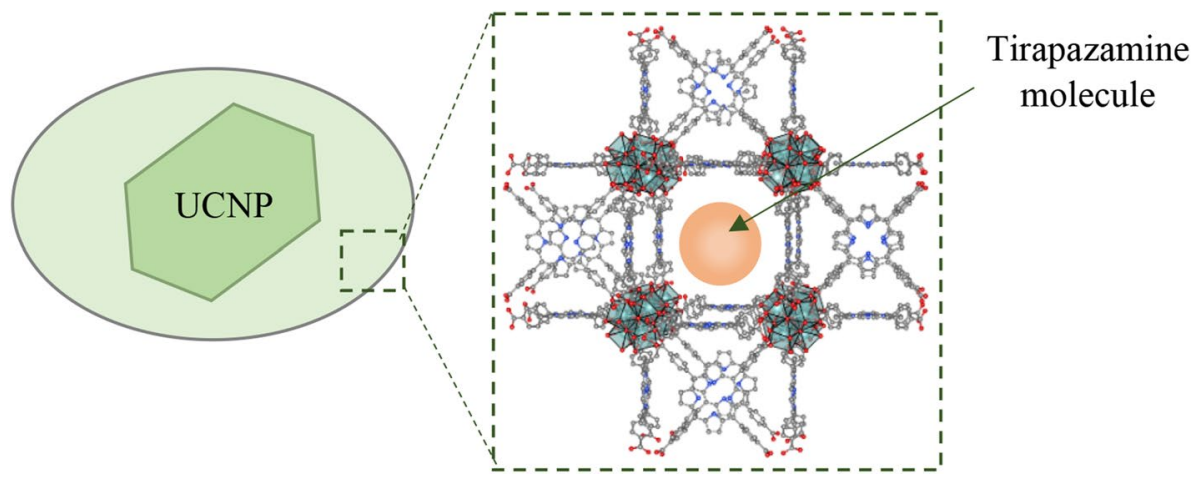

of oxidizing L-Arg into nitric oxide, an efficient cancer cell killer at high concentrations. Further research should be carried out towards combining these assistive therapies in order to improve the overall photodynamic efficiency of nMOFs.

\subsection{External Photosensitizers}

Notwithstanding their popularity, porphyrins are not the sole type of photosensitizer for PDT used today. nMOFs offer the distinct possibility of either encapsulating photosentitizers inside their pores or simply post-synthetically modifying their surface (Table 5). Among the encapsulated photosensitizers, chlorin e6 (Ce6, Appendix 1. entry 11) is a popular choice, closely followed by methylene blue and zinc(II) phtalocyanine. Wang et al. developed a mesoporous nanoenzyme able to catalyse intracellular $\mathrm{H}_{2} \mathrm{O}_{2}$ decomposition for $\mathrm{O}_{2}$ generation [151], much like Zhang et al.'s PCN224-Pt NPs. However, their nanostructure was made with mesoporous cobalt oxide, further modified with PEG and PDA and loaded with the photosensitizer Ce6 (MCOPP$\mathrm{Ce} 6$ ). ${ }^{1} \mathrm{O}_{2}$ production was assessed using electron spin resonance with 2,2,6,6-tetramethylpiperidine as the scavenger under a $671 \mathrm{~nm}$ irradiation. In the presence of $\mathrm{H}_{2} \mathrm{O}_{2}$, MCOPP-Ce6 showed enhanced ${ }^{1} \mathrm{O}_{2}$ generation owing to the mesoporous structure which provides numerous catalytic sites and reduces the diffusion distance between the generated $\mathrm{O}_{2}$ and the photosensitizer. The nMOF cytotoxicity was then tested against 4T1, HeLa and A549 cancer cells. In the dark, cell viabilities remained over $90 \%$ for concentrations as high as $200 \mu \mathrm{g} / \mathrm{mL}$. The phototoxicity under normoxic and hypoxic conditions was also investigated in 4T1 cells. Results showed similar phototoxicity between cells treated with free $\mathrm{Ce} 6$ and MCOPP-Ce6 under normoxic conditions, cell viability dropping below $40 \%$. Owing to the insufficient $\mathrm{O}_{2}$ supply, hypoxic conditions hindered phototoxicity (cell viability $>50 \%$ ) and it was only after the addition of $\mathrm{H}_{2} \mathrm{O}_{2}$ that the nMOF achieved a $95.2 \%$ killing efficiency at $57 \mu \mathrm{g} / \mathrm{mL}$ of MCOPP-Ce6. The $4 \mathrm{~T} 1$ cells also showed an increase in intracellular ROS generation. Mice bearing 4T1 tumors were next injected with MCOPP-Ce6 or free
Ce6 and underwent a 5-min irradiation $\left(100 \mathrm{~mW} / \mathrm{cm}^{2}\right)$. Tumor growth was only partially inhibited in mice treated with free Ce6 while those treated with MCOPP-Ce6 showed suppressed tumor growth after 15 days. Histological analysis on the main organs presented no sign of tissue damage or lesion.

Enhanced PDT via nMOF surface modification was achieved by $\mathrm{He}$ et al. Indeed, they designed a AQ4N-loaded UiO-66 NPs unto which they attached PEGylated photosensitizer photochlor (A@UiO-66-H-P; Fig. 27) [152]. AQ4N is a hypoxia activated prodrug, enabling chemotherapy once PDT is no longer efficient due to lack of endogenous $\mathrm{O}_{2}$. When incubated with U87MG cancer cells, weak DCF fluorescence was observed in both AQ4N and A@UiO66-H-P treated cells in the dark, indicating the absence of ROS. However, a 6-min $671 \mathrm{~nm}$ irradiation $(100 \mathrm{~mW} /$ $\mathrm{cm}^{2}$ ) resulted in an intense green fluorescence suggesting a significant increase in ROS generation levels, confirmed by flow cytometry analysis. Cell viability dropped below $25 \%$ as a result while negligible cytotoxicity was recorded in the absence of irradiation. Finally, in vivo experiments were carried out on mice bearing U87MG tumors. Without laser irradiation, the relative tumor volume of mice treated with A@UiO-66-H-P NPs was double that of mice having undergone a 10-min irradiation. This result was confirmed by H\&E staining of tumor slices, which showed significant necrosis compared to the other groups. Mice treated with only a mixture of photochlor and AQN4 presented limited tumor suppression after laser exposure, presumably owing to mediocre tumor accumulation and rapid excretion of both substances, hence the need for porous, modifiable structures such as nMOFs.

\subsection{Up-Conversion Nanoparticles (UCNPs)}

Since most MOF-based PDT are activated by visible light, the depth of tissue penetration is limited. Lanthanide-doped up-conversion NPs offer an alternative, as they can convert low-energy NIR photons into high-energy UV/visible light, subsequently exciting the nMOF structure and 
producing cytotoxic ROS [153]. With this in mind, Shao et al. developed a core-shell structure, in which a single $\mathrm{NaGdF}_{4}: \mathrm{Yb}, \mathrm{Er} @ \mathrm{NaGdF}_{4} \mathrm{UCNP}$ and prodrug tirapazamine were encapsulated inside each porphyrinic nMOFs (TPZ/ UCSs, Fig. 28) [154].

Upon NIR irradiation, the UCNP core transfers the incoming energy to the outer nMOF shell, which then converts tissue $\mathrm{O}_{2}$ into ROS. As the nMOF degrades, hypoxiaactivated tirapazamine is released, allowing combined chemo- and photodynamic therapy. After verifying that the up-conversion luminescence peaks of $\mathrm{Er}^{3+}$ overlapped with the absorption spectrum of the porphyrinic nMOF under a $980 \mathrm{~nm}$ irradiation $\left(1200 \mathrm{~mW} / \mathrm{cm}^{2}, 10 \mathrm{~min}\right)$, Shao et al. studied the ${ }^{1} \mathrm{O}_{2}$ generation capabilities of UCSs. The fluorescence intensity of SOSG in the UCS dispersions, a direct indicator of ROS production, dramatically increased with irradiation time. The capacity of UCSs to generate ROS in CT26 cancer cells was evaluated with DCFH-DA. As the CLSM images attest, NIR irradiation induced 0.3-foldhigher DCF fluorescence in cells treated with UCSs. A CCK-8 assay was then used to assess the in vitro phototoxicity in CT26 cells. In the absence of irradiation, cell viability remained over $80 \%$ even at high concentrations $(200 \mu \mathrm{g} / \mathrm{mL})$. In normoxic conditions, NIR irradiation caused cell viability to decrease to $40 \%$, while hypoxic conditions triggered the release of tirapazamine ( $3 \mu \mathrm{g} / \mathrm{mL}$ ), causing cell viability to drop below $25 \%$. The in vivo efficiency of the synthesized NPs was investigated in mice bearing CT26 tumors. After a 20-min irradiation, UCSs effectively delayed tumor growth and only TPZ/UCSs successfully inhibited tumor growth due to the combined effect of chemo- and photodynamic therapy. Finally, the combined therapy was able to induce antitumor immunity, specifically a PD-L1 checkpoint blockade. The primary tumors in mice were treated with TPZ/UCSs and irradiated while the distant tumor was left untreated. After several alpha-PD-L1 injections, the growth of both the primary and distant tumors was inhibited indicating the abscopal effects of the treatment. In addition, the amount of infiltrating CD4 +, CD8 + T cells, natural killer cells and $\mathrm{B}$ cells increased in both tumor sites compared to the PBS control group, thus proving the immunotherapeutic ability of the NPs.

Table 5 shows two other examples of UNCP-mediated PDT achieving similar cytotoxic results, although the laser intensity used in the case of He et al.'s nMOF is significantly higher than those used in the other two articles, raising the question of possible damage to surrounding tissue. Indeed, no in vivo experiments were carried out to ascertain this.

More generally, PDT is becoming an increasingly recognized treatment option for specific types of localized cancers. Unlike chemotherapy, it has no long-term side effects and can be precisely targeted. In addition, the treatment is relatively fast and can be repeated on the same site if needed without causing scarring. However, since light is unable to reach deep-seeded areas, PDT is limited to localized, near-surface cancers [155]. Among the FDA approved photosensitizers, Photofrin is a popular choice, used today to treat certain kinds of esophageal and lung cancers [156]. As yet, no treatments relying on the use of nMOFs have been approved for clinical use due to the lack of rigorous in vitro and in vivo assessments of their properties. A variety of nMOFs have been synthesized recently and show promise in improving the bio-distribution and stability of ordinary photosensitizers such as porphyrins or chlorins, but no evident comparisons or conclusions can be drawn between them as the experimental parameters are different. Based on the performance of the most promising nMOFs, a standardized panel of tests should be elaborated, using the same laser wavelength, power intensity, irradiation time and nMOF concentration to ascertain their performance towards various cancer cells. Future research should focus on nMOFs able to carry out effective PDT while countering hypoxia. Indeed, the unavoidable depletion in endogenous $\mathrm{O}_{2}$ causes the production of anti-oxidants, promoting tumor growth. Chen et al. [144], Cheng et al. [157] and Zhu et al. [158]. have successfully addressed this issue by combining their nMOFs with adjuvant agents, able to disrupt the survival mechanisms and hypoxia inducible factors of cancer cells. Therefore, instead of developing new nanoplatforms, research should turn to reproducing and building on existing results, in order to move towards possible clinical trials. Table 5 summarizes the nMOFs synthesized for photodynamic therapy [147, 152, 153, 159-177].

\section{Conclusions and Outlook}

nMOFs are continuously attracting attention in the medical field, specifically in oncology. Due to their high porosity, diverse pore shapes, large surface areas, nanoscale size, relative stability in the blood stream and tunable structures, they can be designed to fit the requirements of various cancer therapies. nMOFs have exhibited a high loading capacity for various molecules such as drugs, proteins, genes and photosensitizers. Coupled with surface functionalization, controlled and targeted release of the loaded therapeutic agents have been achieved for all therapy types. The variety of ligands and metal centers offer a wide range of synthesizable nMOFs. However, the toxicity of the raw materials should be systematically analyzed for all $\mathrm{nMOFs}$, especially for those constructed with less common compounds. Iron, zinc and zirconium have oral lethal doses of $50 \%$ of $30 \mathrm{~g} / \mathrm{kg}$, $350 \mu \mathrm{g} / \mathrm{kg}$ and $4.1 \mathrm{~g} / \mathrm{kg}$, respectively, while those of popular ligands, such as terephtalic acid, trimesic acid or 2-methylimidazole, and remain between 1 and $10 \mathrm{~g} / \mathrm{kg}$ [178]. Future research should focus on using endogenous and biological 
molecules as ligands, in order to increase biocompatibility while reducing side effects after structural decomposition.

Furthermore, in vitro studies produce limited results and as such, more effort should be devoted to in vivo studies to examine biocompatibility, stability, degradability, blood circulation half-time and cancer cell selectivity of nMOFs. Despite histological studies, showing various accumulations of nMOFs in the kidneys or liver, no clear information is given about nMOF elimination. Clearance measurements need to be carried out in order to ascertain how long the nanostructures remain in the body. Pharmacokinetics, toxicity and bio-distribution studies are the basics of preclinical assessments but are so far severely inadequate. The questions of administration routes (oral, intravenous), subject age (embryos, neonatal, adult) and physiological status (pregnancy) also need to be addressed in the future after extensive in vivo studies. In addition, the repeatability and comparison of different nMOF treatments are lacking and need to be carried out if these emerging materials are to have a future in cancer therapy.

Out of all five cancer therapies, immunotherapy holds greatest promise despite being in its infancy. It has the benefit of using the body's own defense system to fight the cancer, thus limiting side effects, which is a significant improvement over chemotherapy for example. nMOFs can easily infiltrate the tumor microenvironment and activate a rapid immune response. In addition, the systemic antitumor immunity can spread to distant tumors via abscopal effects, whereas photothermal or photodynamic therapies are limited to a localized tumor.

The combination of immunotherapy with one or more therapies in vitro and especially in vivo is the next logical step in the fight against cancer [179].

The recent COVID-19 pandemic has shown that nMOFs can also have a significant impact in the fight against diseases other than cancer. Efficient personal protective equipment is in high demand and nMOFs with antimicrobial properties, coupled with dense fibrous materials, could actively help in reducing virus propagation. As such, $\mathrm{Li}$ et al. have synthesized a series of photoactive MOFs able to produce bactericidal ROS driven by sunlight, which could then be integrated into a nano-fiber membrane [180]. Research has also gone into using nMOFs as virus detectors. The interaction between the pathogen and gold or silver NPs adsorbed onto nMOFs can trigger Off-On or On-Off optical mechanisms, allowing the subsequent quantification of the virus. In addition, cysteine-sensitive molecules, the active component of the SARS-CoV-2 proteins, can adsorb onto all types of nMOFs, which facilitates their detection via different physiochemical methods [181]. 


\section{Appendix 1: Various Molecules Mentioned Throughout the Article}

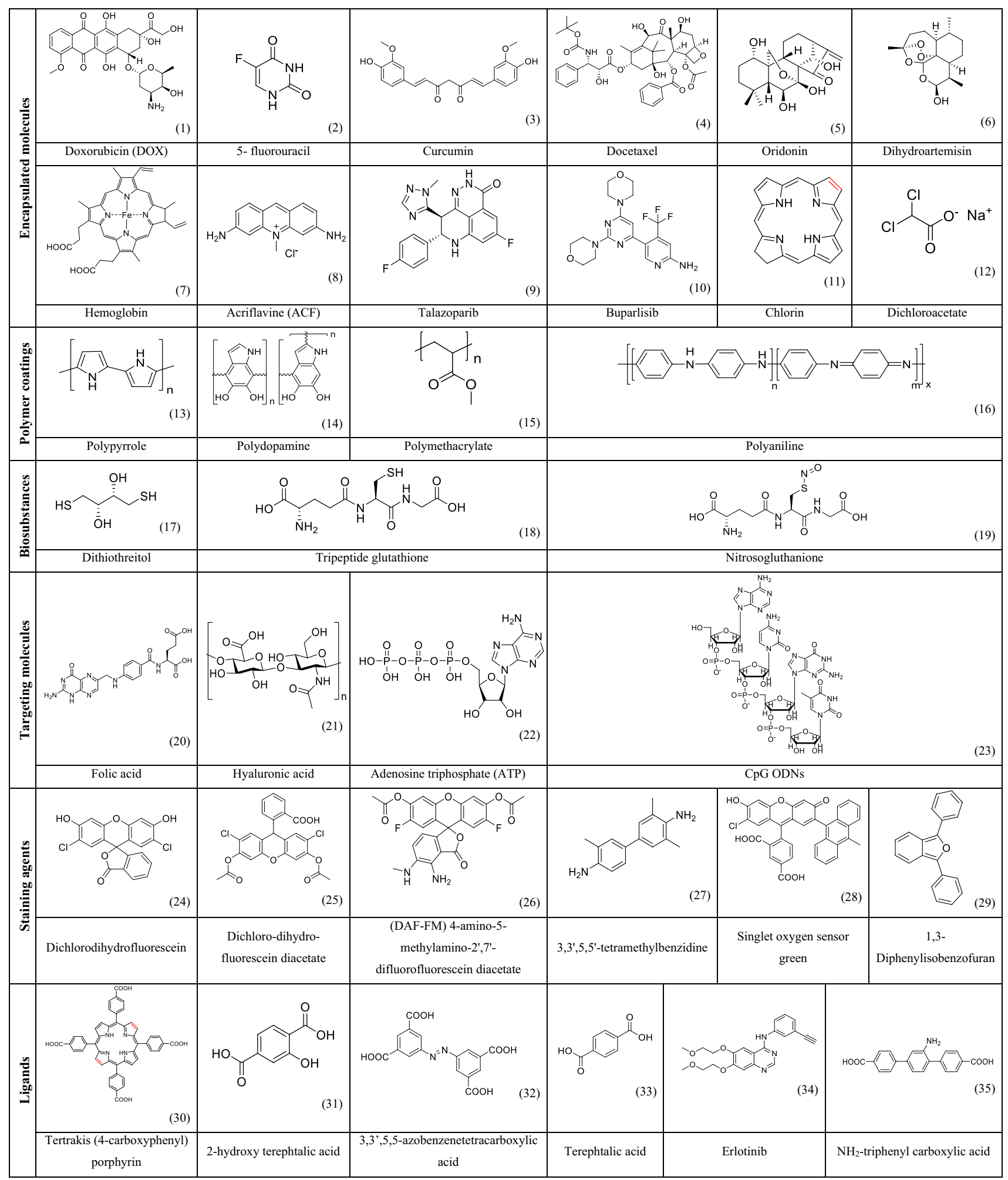




\section{Appendix 2: Frequently Synthesized nMOFs}

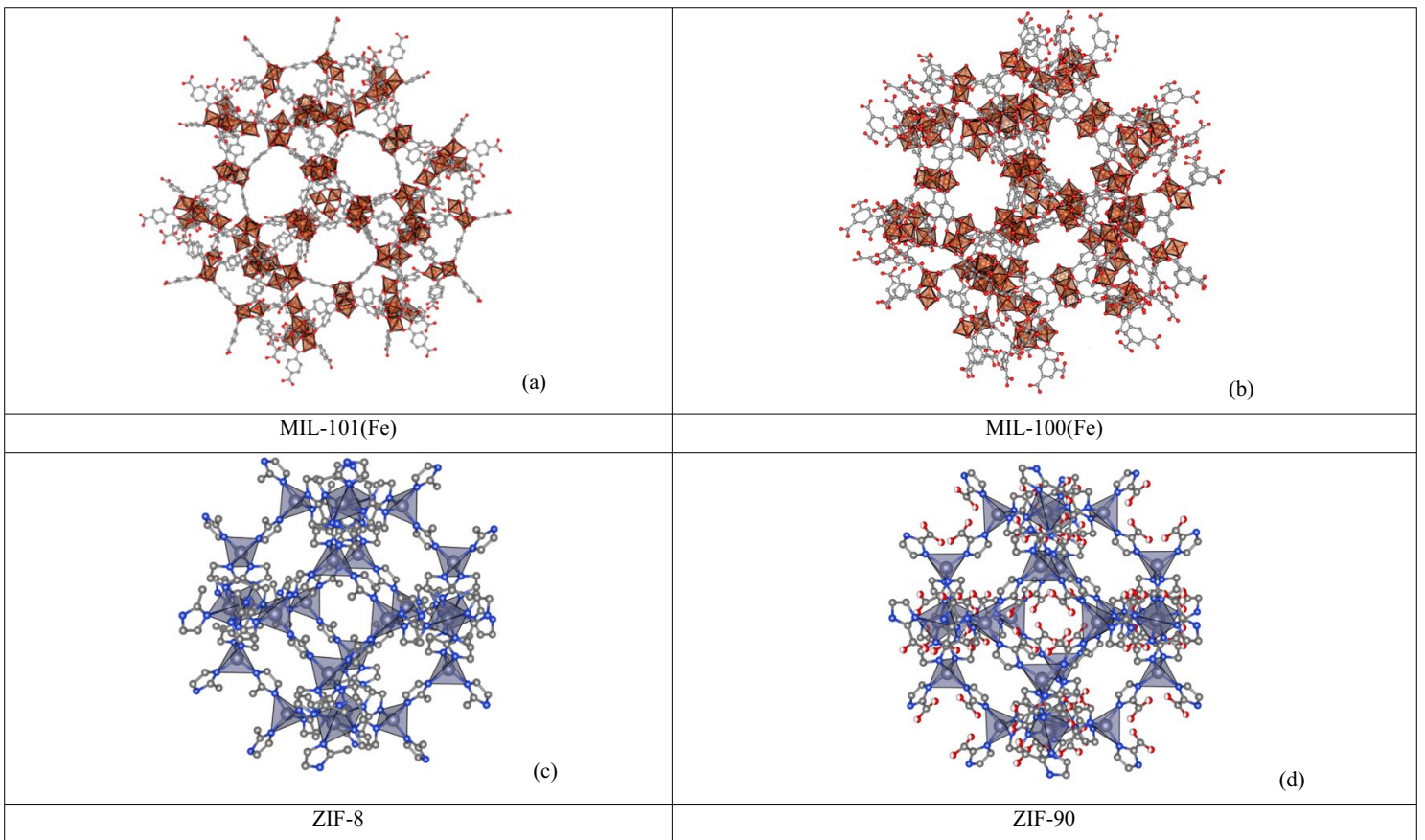

Acknowledgements This work was supported by the Natural Sciences and Engineering Research Council of Canada, the Fonds de Recherche du Québec-Nature et Technologies, Compute Canada and Calcul Québec, the Centre Quebecois sur les Matériaux Fonctionnels.

Author Contributions The manuscript was written through contributions of both authors. Both authors have given approval to the final version of the manuscript.

\section{Declarations}

Conflict of interest The authors declare no competing financial interest.

\section{References}

1. M.G. Krukemeyer, V. Krenn, F. Huebner, W. Wagner, R. Resch, J. Nanomed. Nanotechnol. 06, 336 (2015).

2. G.R. Rudramurthy, M.K. Swamy, J. Biol. Inorg. Chem. 23, 1185 (2018)

3. C.M. Magdalane, K. Kaviyarasu, A. Raja, M.V. Arularasu, G.T. Mola, A.B. Isaev, N.A. Al-Dhabi, M.V. Arasu, B. Jeyaraj, J. Kennedy, M. Maaza, J. Photochem. Photobiol. B Biol. 185, 275 (2018)

4. K. Kaviyarasu, K. Kanimozhi, N. Matinise, C.M. Magdalane, G.T. Mola, J. Kennedy, M. Maaza, Mater. Sci. Eng. C 76, 1012 (2017)
5. K. Kaviyarasu, N. Geetha, K. Kanimozhi, C.M. Magdalane, S. Sivaranjani, A. Ayeshamariam, J. Kennedy, M. Maaza, Mater. Sci. Eng. C 74, 325 (2017)

6. A.C. Anselmo, S. Mitragotri, Bioeng. Transl. Med. 4, e10143 (2019)

7. C. Martinelli, C. Pucci, G. Ciofani, APL Bioeng. 3, 11502 (2019)

8. Y. Liu, Y. Zhao, X. Chen, Theranostics 9, 3122 (2019)

9. Y. Yang, X. Wu, C. He, J. Huang, S. Yin, M. Zhou, L. Ma, W. Zhao, L. Qiu, C. Cheng, C. Zhao, A.C.S. Appl, Mater. Interfaces 12, 13698 (2020)

10. J. Xiao, S. Chen, J. Yi, H.F. Zhang, G.A. Ameer, Adv. Funct. Mater. 27, 1604872 (2017)

11. X. Zhang, L. Fang, K. Jiang, H. He, Y. Yang, Y. Cui, B. Li, G. Qian, Biosens. Bioelectron. 130, 65 (2019)

12. T. Baati, L. Njim, F. Neffati, A. Kerkeni, M. Bouttemi, R. Gref, M.F. Najjar, A. Zakhama, P. Couvreur, C. Serre, P. Horcajada, Chem. Sci. 4, 1597 (2013)

13. C. Arcuri, L. Monarca, F. Ragonese, C. Mecca, S. Bruscoli, S. Giovagnoli, R. Donato, O. Bereshchenko, B. Fioretti, F. Costantino, Nanomaterials 8, 867 (2018)

14. M. Hoop, C.F. Walde, R. Riccò, F. Mushtaq, A. Terzopoulou, X.Z. Chen, A.J. deMello, C.J. Doonan, P. Falcaro, B.J. Nelson, J. Puigmartí-Luis, S. Pané, Appl. Mater. Today 11, 13 (2018)

15. C.Y. Huang, D.T. Ju, C.F. Chang, P.M. Reddy, B.K. Velmurugan, Biomed. 7, 12 (2017)

16. A. Giordano, G. Tommonaro, Nutrients 11, 2376 (2019)

17. M. Vasaturo, R. Cotugno, L. Fiengo, C. Vinegoni, F. Dal Piaz, N. De Tommasi, Sci. Rep. 8, 16735 (2018)

18. W. Cai, J. Wang, C. Chu, W. Chen, C. Wu, G. Liu, Adv. Sci. 6, 1801526 (2019)

19. S.Y.C. Choi, C.C. Collins, P.W. Gout, Y. Wang, J. Pathol. 230, $350(2013)$ 
20. R.K. Alavijeh, K. Akhbari, Inorg. Chem. 59, 3570 (2020)

21. T.L. Riss, R.A. Moravec, A.L. Niles, S. Duellman, H.A. Benink, T.J. Worzella, L. Minor. Cell Viability Assays. 2013 Assay Guidance Manual [Internet]. Bethesda (MD): Eli Lilly \& Company and the National Center for Advancing Translational Sciences (2004)

22. X. Leng, X. Dong, W. Wang, N. Sai, C. Yang, L. You, H. Huang, X. Yin, J. Ni, Molecules 23, 2490 (2018)

23. L.L. Sun, Y.H. Li, H. Shi, J. Clust. Sci. 30, 251 (2019)

24. Y. Guo, B. Yan, Y. Cheng, L. Mu, J. Coord. Chem. 72, 262 (2019)

25. S.Z. Ren, D. Zhu, X.H. Zhu, B. Wang, Y.S. Yang, W.X. Sun, X.M. Wang, P.C. Lv, Z.C. Wang, H.L. Zhu, A.C.S. Appl, Mater. Interfaces 11, 20678 (2019)

26. M. Oancea, S. Mazumder, M.E. Crosby, A. Almasan, Methods Mol. Med. 129, 279 (2006)

27. H.A. Alturkistani, F.M. Tashkandi, Z.M. Mohammedsaleh, Glob. J. Health Sci. 8, 72 (2015)

28. Z. Jin, P. Zhao, J. Zhang, T. Yang, G. Zhou, D. Zhang, T. Wang, Q. He, Chem. A Eur. J. 24, 11667 (2018)

29. S. Wuttke, M. Lismont, A. Escudero, B. Rungtaweevoranit, W.J. Parak, Biomaterials 123, 172 (2017)

30. M. Zhang, J. Zhu, Y. Zheng, R. Guo, S. Wang, S. Mignani, A.M. Caminade, J.P. Majoral, X. Shi, Pharmaceutics 10, 162 (2018)

31. K.N. Yang, C.Q. Zhang, W. Wang, P.C. Wang, J.P. Zhou, X.J. Liang, Cancer. Biol. Med. 11, 34 (2014)

32. A. Liberman, N. Mendez, W.C. Trogler, A.C. Kummel, Surf. Sci. Rep. 69, 132 (2014)

33. W.H. Chen, X. Yu, A. Cecconello, Y.S. Sohn, R. Nechushtai, I. Willner, Chem. Sci. 8, 5769 (2017)

34. X. Cao, J. Xia, X. Meng, J. Xu, Q. Liu, Z. Wang, Adv. Funct. Mater. 29, 1902237 (2019)

35. P. Zhang, F. Cheng, R. Zhou, J. Cao, J. Li, C. Burda, Q. Min, J.-J. Zhu, Angew. Chemie 126, 2403 (2014)

36. F.F. Zheng, P.H. Zhang, Y. Xi, J.J. Chen, L.L. Li, J.J. Zhu, Anal. Chem. 87, 11739 (2015)

37. W.H. Chen, G.F. Luo, Y.S. Sohn, R. Nechushtai, I. Willner, Small 15, 1900935 (2019)

38. W.H. Chen, S.Y. Sung, M. Fadeev, A. Cecconello, R. Nechushtai, I. Willner, Nanoscale 10, 4650 (2018)

39. D. Giliopoulos, A. Zamboulis, D. Giannakoudakis, D. Bikiaris, K. Triantafyllidis, Molecules 25, 185 (2020)

40. J.V. Jokerst, T. Lobovkina, R.N. Zare, S.S. Gambhir, Nanomedicine 6, 715 (2011)

41. X.G. Wang, Z.Y. Dong, H. Cheng, S.S. Wan, W.H. Chen, M.Z. Zou, J.W. Huo, H.X. Deng, X.Z. Zhang, Nanoscale 7, 16061 (2015)

42. Y. Miao, X. Zhao, Y. Qiu, Z. Liu, W. Yang, X. Jia, A.C.S. Appl, Bio Mater. 2, 895 (2019)

43. D. Wang, J. Zhou, R. Chen, R. Shi, G. Xia, S. Zhou, Z. Liu, N.Q. Zhang, H. Wang, Z. Guo, Q. Chen, Biomaterials 107, 88 (2016)

44. Z. Li, Q. Li, J. Wu, M. Wang, J. Yu, Molecules 21, 1331 (2016)

45. Y. Zuguang, L. Zelin, Y. Shoujun, Z. Zhongming, L. Tao, Y. Weipeng, L. Guoqiao, Artemisinin-Based Other Antimalar. (Elsevier, New York, 2018), pp. 197-351.

46. P. Ma, H. Xiao, C. Yu, J. Liu, Z. Cheng, H. Song, X. Zhang, C. Li, J. Wang, Z. Gu, J. Lin, Nano Lett. 17, 928 (2017)

47. Y. Li, Z. Gao, F. Chen, C. You, H. Wu, K. Sun, P. An, K. Cheng, C. Sun, X. Zhu, B. Sun, A.C.S. Appl, Mater. Interfaces 10, 30930 (2018)

48. K. Sun, Z. Gao, Y. Zhang, H. Wu, C. You, S. Wang, P. An, C. Sun, B. Sun, J. Mater. Chem. B 6, 5876 (2018)

49. R. Prabhu, R. Anjali, G. Archunan, N.M. Prabhu, A. Pugazhendhi, N. Suganthy, Process. Biochem. 84, 39 (2019)

50. P. Kumar, A. Nagarajan, P.D. Uchil, Cold Spring Harb. Protoc. 2018, 469 (2018)
51. S. Sakamuru, M.S. Attene-Ramos, M. Xia, Methods Mol. Biol. 1473, 17 (2016)

52. K.M. McKinnon, Curr. Protoc. Immunol. 2018(120), 5-1 (2018)

53. G. Chen, J. Luo, M. Cai, L. Qin, Y. Wang, L. Gao, P. Huang, Y. Yu, Y. Ding, X. Dong, X. Yin, J. Ni, Molecules 24, 3369 (2019)

54. M. Arruebo, N. Vilaboa, B. Sáez-Gutierrez, J. Lambea, A. Tres, M. Valladares, Á. González-Fernández, Cancers (Basel). 3, 3279 (2011)

55. W. Ren, Y. Yan, L. Zeng, Z. Shi, A. Gong, P. Schaaf, D. Wang, J. Zhao, B. Zou, H. Yu, G. Chen, E.M.B. Brown, A. Wu, Adv. Healthc. Mater. 4, 1526 (2015)

56. H.S. Kim, D.Y. Lee, Polymers (Basel). 10, 961 (2018)

57. F.S. Majidi, E. Mohammadi, B. Mehravi, S. Nouri, K. Ashtari, A. Neshasteh-riz, Artif. Cells Nanomed. Biotechnol. 47, 2161 (2019)

58. S. Nouri, E. Mohammadi, B. Mehravi, F. Majidi, K. Ashtari, A. Neshasteh-Riz, S. Einali, Artif. Cells Nanomed. Biotechnol. 47, 2316 (2019)

59. H. Ghaznavi, S. Hosseini-Nami, S.K. Kamrava, R. Irajirad, S. Maleki, A. Shakeri-Zadeh, A. Montazerabadi, Artif. Cells Nanomed. Biotechnol. 46, 1594 (2018)

60. A. Mehdizadeh, S. Pandesh, A. Shakeri-Zadeh, S.K. Kamrava, M. Habib-Agahi, M. Farhadi, M. Pishghadam, A. Ahmadi, S. Arami, Y. Fedutik, Lasers Med. Sci. 29, 939 (2014)

61. Z. Bao, X. Liu, Y. Liu, H. Liu, K. Zhao, Asian. J. Pharm. Sci. 11, 349 (2016)

62. C. Liu, L. Luo, L. Zeng, J. Xing, Y. Xia, S. Sun, L. Zhang, Z. Yu, J. Yao, Z. Yu, O.U. Akakuru, M. Saeed, A. Wu, Small 14, 1801851 (2018)

63. L. Zhang, C. Liu, Y. Gao, Z. Li, J. Xing, W. Ren, L. Zhang, A. Li, G. Lu, A. Wu, L. Zeng, Adv. Healthc. Mater. 7, 1801144 (2018)

64. X.X. Ye, Y.Y. Zhao, Q. Wang, W. Xiao, J. Zhao, Y.J. Peng, D.H. Cao, W.J. Lin, M.Y. Si-Tu, M.Z. Li, X. Zhang, W.G. Zhang, Y.F. Xia, X. Yang, G.K. Feng, M.S. Zeng, ACS Omega 2, 2459 (2017)

65. J. Chen, J. Liu, Y. Hu, Z. Tian, Y. Zhu, Sci. Technol. Adv. Mater. 20, 1043 (2019)

66. E.A. Périgo, G. Hemery, O. Sandre, D. Ortega, E. Garaio, F. Plazaola, F.J. Teran, Appl. Phys. Rev. 2, 41302 (2015)

67. J.B. Vines, D.J. Lim, H. Park, Polymers (Basel). 10, 1357 (2018)

68. Z. Zha, X. Yue, Q. Ren, Z. Dai, Adv. Mater. 25, 777 (2013)

69. X. Cai, X. Deng, Z. Xie, Y. Shi, M. Pang, J. Lin, Chem. Eng. J. 358, 369 (2019)

70. L. Zhang, S. Li, X. Chen, T. Wang, L. Li, Z. Su, C. Wang, Adv. Funct. Mater. 28, 1803815 (2018)

71. H. Zhang, C. Hao, A. Qu, M. Sun, L. Xu, C. Xu, H. Kuang, Adv. Funct. Mater. 28, 1805320 (2018)

72. P.H. Pandya, M.E. Murray, K.E. Pollok, J.L. Renbarger, J. Immunol. Res. 2016, 1-13 (2016).

73. Cancer.net, Underst. Immunother. https://www.Cancer.Net/Navig ating-Cancer-Care/How-Cancer-Treated/Immunotherapy-andVaccines/Understanding-Immunotherapy (2016).

74. H. Shirota, D.M. Klinman, Immunopotentiators Mod. Vaccines (Elsevier, New York, 2017), pp. 163-198.

75. S. Behboudi, D. Chao, P. Klenerman, J. Austyn, Immunology 99 , $361(2000)$

76. H. Zhang, W. Chen, K. Gong, J. Chen, A.C.S. Appl, Mater. Interfaces 9, 31519 (2017)

77. K. Ni, T. Luo, G. Lan, A. Culbert, Y. Song, T. Wu, X. Jiang, W. Lin, Angew. Chemie Int. Ed. 59, 1108 (2020)

78. Z. Cai, F. Xin, Z. Wei, M. Wu, X. Lin, X. Du, G. Chen, D. Zhang, Z. Zhang, X. Liu, C. Yao, Adv. Healthc. Mater. 9, 1900996 (2020)

79. X. Zhao, S. Subramanian, Cancer Res. 77, 817 (2017)

80. G. Lan, K. Ni, Z. Xu, S.S. Veroneau, Y. Song, W. Lin, J. Am. Chem. Soc. 140, 5670 (2018) 
81. W. Park, Y.J. Heo, D.K. Han, Biomater. Res. 22, 24 (2018)

82. S.T. Reddy, A.J. Van Der Vlies, E. Simeoni, V. Angeli, G.J. Randolph, C.P. O’Neil, L.K. Lee, M.A. Swartz, J.A. Hubbell, Nat. Biotechnol. 25, 1159 (2007)

83. X. Zhong, Y. Zhang, L. Tan, T. Zheng, Y. Hou, X. Hong, G. Du, X. Chen, Y. Zhang, X. Sun, J. Control. Release 300, 81 (2019)

84. F. Duan, X. Feng, X. Yang, W. Sun, Y. Jin, H. Liu, K. Ge, Z. Li, J. Zhang, Biomaterials 122, 23 (2017)

85. Y. Zhang, F. Wang, E. Ju, Z. Liu, Z. Chen, J. Ren, X. Qu, Adv. Funct. Mater. 26, 6454 (2016)

86. J. Liu, J. Huang, L. Zhang, J. Lei, Chem. Soc. Rev. 50, 1188 (2021)

87. T. Baudino, Curr. Drug Discov. Technol. 12, 3 (2015)

88. Y. Yang, Q. Chen, J.P. Wu, T.B. Kirk, J. Xu, Z. Liu, W. Xue, A.C.S. Appl, Mater. Interfaces 10, 12463 (2018)

89. S. Gao, P. Zheng, Z. Li, X. Feng, W. Yan, S. Chen, W. Guo, D. Liu, X. Yang, S. Wang, X.J. Liang, J. Zhang, Biomaterials 178, $83(2018)$

90. B. Perillo, M. Di Donato, A. Pezone, E. Di Zazzo, P. Giovannelli, G. Galasso, G. Castoria, A. Migliaccio, Exp. Mol. Med. 52, 192 (2020)

91. Z. Chen, J.J. Yin, Y.T. Zhou, Y. Zhang, L. Song, M. Song, S. Hu, N. Gu, ACS Nano 6, 4001 (2012)

92. H. Ranji-Burachaloo, F. Karimi, K. Xie, Q. Fu, P.A. Gurr, D.E. Dunstan, G.G. Qiao, A.C.S. Appl, Mater. Interfaces 9, 33599 (2017)

93. G.A. Blaise, D. Gauvin, M. Gangal, S. Authier, Toxicology 208, 177 (2005)

94. T. Du, Z. Qin, Y. Zheng, H. Jiang, Y. Weizmann, X. Wang, Chem 5, 2942 (2019)

95. W. He, Y.T. Zhou, W.G. Wamer, M.D. Boudreau, J.J. Yin, Biomaterials 33, 7547 (2012)

96. C.Y. Song, J.Y. Zhang, Y. Qiu, H.P. Jin, H.M. Zhang, S. Liu, H. Liu, H.B. Qiu, G.G. Gao, Sci. China Chem. 62, 347 (2019)

97. C.I. Tsien, M.K. Nyati, A. Ahsan, S.G. Ramanand, D.B. Chepeha, F.P. Worden, J.I. Helman, N. D'Silva, C.R. Bradford, G.T. Wolf, T.S. Lawrence, A. Eisbruch, Head Neck 35, 1323 (2013)

98. S.B. Bankar, M.V. Bule, R.S. Singhal, L. Ananthanarayan, Biotechnol. Adv. 27, 489 (2009)

99. H. Ranji-Burachaloo, A. Reyhani, P.A. Gurr, D.E. Dunstan, G.G. Qiao, Nanoscale 11, 5705 (2019)

100. V.O. Shlyakhovenko, Exp. Oncol. 38, 2 (2016)

101. X. Yang, Q. Tang, Y. Jiang, M. Zhang, M. Wang, L. Mao, J. Am. Chem. Soc. 141, $3782(2019)$

102. J. Jia, S. Zhang, K. Wen, Q. Li, Int. J. Nanomedicine 14, 9971 (2019)

103. K.O. Alfarouk, D. Verduzco, C. Rauch, A.K. Muddathir, A.H.H. Bashir, G.O. Elhassan, M.E. Ibrahim, J.D.P. Orozco, R.A. Cardone, S.J. Reshkin, S. Harguindey, Oncoscience 1, 777 (2014)

104. M.I. Koukourakis, A. Giatromanolaki, E. Sivridis, K.C. Gatter, A.L. Harris, Neoplasia 7, 1 (2005)

105. P. W. Stacpoole, G. N. Henderson, Z. Yan, M. O. James, Environ. Health Perspect.106, 989 (1998)

106. I.A. Lázaro, S. Haddad, J.M. Rodrigo-Muñoz, C. Orellana-Tavra, V. Del Pozo, D. Fairen-Jimenez, R.S. Forgan, A.C.S. Appl, Mater. Interfaces 10, 5255 (2018)

107. I.A. Lázaro, S. Haddad, J.M. Rodrigo-Muñoz, R.J. Marshall, B. Sastre, V. Del Pozo, D. Fairen-Jimenez, R.S. Forgan, A.C.S. Appl, Mater. Interfaces 10, 31146 (2018)

108. Y. Ge, S. Li, S. Wang, R. Moore (eds.), Nanomedicine (Springer, New York, 2014)

109. A.K. Nanayakkara, C.A. Follit, G. Chen, N.S. Williams, P.D. Vogel, J.G. Wise, Sci. Rep. 8, 967 (2018)

110. M. Mariani, R. Karki, M. Spennato, D. Pandya, S. He, M. Andreoli, P. Fiedler, C. Ferlini, Gene 563, 109 (2015)
111. Q. Chen, M. Xu, W. Zheng, T. Xu, H. Deng, J. Liu, A.C.S. Appl, Mater. Interfaces 9, 6712 (2017)

112. H.W. Tan, H.Y. Mo, A.T.Y. Lau, Y.M. Xu, Int. J. Mol. Sci. 20, 75 (2019)

113. L. Zeng, P. Gupta, Y. Chen, E. Wang, L. Ji, H. Chao, Z.S. Chen, Chem. Soc. Rev. 46, 5771 (2017)

114. J.G. Donaldson, Curr. Protoc. Cell Biol. 1, 4 (1998)

115. T. Mahmood, P.C. Yang, N. Am, J. Med. Sci. 4, 429 (2012)

116. S. Yogosawa, K. Yoshida, Cancer Sci. 109, 3376 (2018)

117. F. Chang, J.T. Lee, P.M. Navolanic, L.S. Steelman, J.G. Shelton, W.L. Blalock, R.A. Franklin, J.A. McCubrey, Leukemia 17, 590 (2003)

118. G.M. Cooper, The Cell: A Molecular Approach, 2nd edn. (ASM Press, Washington, DC, 2000)

119. C. Ramachandran, S. Rodriguez, R. Ramachandran, P.K.R. Nair, H. Fonseca, Z. Khatib, E. Escalon, S.J. Melnick, Anticancer Res. 25, 3293 (2005)

120. P. Anand, A.B. Kunnumakkara, R.A. Newman, B.B. Aggarwal, Mol. Pharm. 4, 807 (2007)

121. D. Laha, K. Pal, A.R. Chowdhuri, P.K. Parida, S.K. Sahu, K. Jana, P. Karmakar, New J. Chem. 43, 217 (2019)

122. L. Li, P. Tang, S. Li, X. Qin, H. Yang, C. Wu, Y. Liu, Med. Oncol. 34, 1 (2017)

123. M.J. Neufeld, A.N. DuRoss, M.R. Landry, H. Winter, A.M. Goforth, C. Sun, Nano Res. 12, 3003 (2019)

124. A.N. Ivashkevich, O.A. Martin, A.J. Smith, C.E. Redon, W.M. Bonner, R.F. Martin, P.N. Lobachevsky, Mutat. Res. - Fundam. Mol. Mech. Mutagen. 711, 49 (2011)

125. J. Galon, M. Laé, J.O. Thariat, S. Carrere, Z. Papai, M. Delannes, P. Sargos, P. Rochaix, L.C. Mangel, Z. Sapi, T. Tornoczky, I. Peyrottes, R. Tetreau, M.C. Château, M.P. Sunyach, P. Agoston, H. Brisse, C. Llacer, A. Lecesne, S. Bonvalot, Int. J. Radiat. Oncol. 102, S204 (2018)

126. N. Nishida, H. Yano, T. Nishida, T. Kamura, M. Kojiro, Vasc. Health Risk Manag. 2, 213 (2006)

127. Y. Liu, C. Chen, P. Qian, X. Lu, B. Sun, X. Zhang, L. Wang, X. Gao, H. Li, Z. Chen, J. Tang, W. Zhang, J. Dong, R. Bai, P.E. Lobie, Q. Wu, S. Liu, H. Zhang, F. Zhao, M.S. Wicha, T. Zhu, Y. Zhao, Nat. Commun. 6, 1 (2015)

128. Y. Chen, P. Xu, M. Wu, Q. Meng, H. Chen, Z. Shu, J. Wang, L. Zhang, Y. Li, J. Shi, Adv. Mater. 26, 4294 (2014)

129. B.P. Purcell, D. Lobb, M.B. Charati, S.M. Dorsey, R.J. Wade, K.N. Zellars, H. Doviak, S. Pettaway, C.B. Logdon, J.A. Shuman, P.D. Freels, J.H. Gorman, R.C. Gorman, F.G. Spinale, J.A. Burdick, Nat. Mater. 13, 653 (2014)

130. J. Wang, D. Chen, B. Li, J. He, D. Duan, D. Shao, M. Nie, Sci. Rep. 6, 1 (2016)

131. S. Gurunathan, K.J. Lee, K. Kalishwaralal, S. Sheikpranbabu, R. Vaidyanathan, S.H. Eom, Biomaterials 30, 6341 (2009)

132. J. Litz, G.S. Warshamana-Greene, G. Sulanke, K.E. Lipson, G.W. Krystal, Lung Cancer 46, 283 (2004)

133. D. Glick, S. Barth, K.F. Macleod, J. Pathol. 221, 3 (2010)

134. S. Shen, L. Li, S. Li, Y. Bai, H. Liu, Nanoscale 10, 18161 (2018)

135. C. Lema, A. Varela-Ramirez, R.J. Aguilera, Curr. Cell. Biochem. 1, 1 (2008)

136. X. Li, S. He, B. Ma, Mol. Cancer 19, 1 (2020)

137. Y.K. Lee, J.A. Lee, BMB Rep. 49, 424 (2016)

138. Z. Shi, X. Chen, L. Zhang, S. Ding, X. Wang, Q. Lei, W. Fang, Biomater. Sci. 6, 2582 (2018)

139. Q. Zheng, X. Liu, Y. Zheng, K.W.K. Yeung, Z. Cui, Y. Liang, Z. Li, S. Zhu, X. Wang, S. Wu, Chem (Soc, Rev, 2021).

140. L. B. Josefsen, R.W. Boyle, Met. Based. Drugs 2008, 276109 (2008)

141. A.P. Castano, T.N. Demidova, M.R. Hamblin, Photodiagnosis Photodyn. Ther. 1, 279 (2004) 
142. K. Liu, Y. Gao, J. Liu, Y. Wen, Y. Zhao, K. Zhang, G. Yu, Environ. Sci. Technol. 50, 3634 (2016)

143. J. Zhang, C. Jiang, J.P.F. Longo, R.B. Azevedo, H. Zhang, L.A. Muehlmann, Acta Pharm. Sin. B 8, 137 (2018)

144. J. Liu, Y. Yang, W. Zhu, X. Yi, Z. Dong, X. Xu, M. Chen, K. Yang, G. Lu, L. Jiang, Z. Liu, Biomaterials 97, 1 (2016)

145. K. Lu, C. He, W. Lin, J. Am. Chem. Soc. 136, 16712 (2014)

146. Z.X. Chen, M.D. Liu, M.K. Zhang, S.B. Wang, L. Xu, C.X. Li, F. Gao, B.R. Xie, Z.L. Zhong, X.Z. Zhang, Adv. Funct. Mater. 28, 1803498 (2018)

147. J.R. Doherty, C. Yang, K.E.N. Scott, M.D. Cameron, M. Fallahi, W. Li, M.A. Hall, A.L. Amelio, J.K. Mishra, F. Li, M. Tortosa, H.M. Genau, R.J. Rounbehler, Y. Lu, C.V. Dang, K.G. Kumar, A.A. Butler, T.D. Bannister, A.T. Hooper, K. Unsal-Kacmaz, W.R. Roush, J.L. Cleveland, Cancer Res. 74, 908 (2014)

148. Y. Zhang, F. Wang, C. Liu, Z. Wang, L. Kang, Y. Huang, K. Dong, J. Ren, X. Qu, ACS Nano 12, 651 (2018)

149. Y. Liu, H. Wu, M. Li, J.J. Yin, Z. Nie, Nanoscale 6, 11904 (2014)

150. S.S. Wan, J.Y. Zeng, H. Cheng, X.Z. Zhang, Biomaterials 185, $51(2018)$

151. D. Wang, H. Wu, W.Q. Lim, S.Z.F. Phua, P. Xu, Q. Chen, Z. Guo, Y. Zhao, Adv. Mater. 31, 1901893 (2019)

152. Z. He, Y. Dai, X. Li, D. Guo, Y. Liu, X. Huang, J. Jiang, S. Wang, G. Zhu, F. Zhang, L. Lin, J.J. Zhu, G. Yu, X. Chen, Small 15, 1804131 (2019)

153. H. Dong, S.R. Du, X.Y. Zheng, G.M. Lyu, L.D. Sun, L.D. Li, P.Z. Zhang, C. Zhang, C.H. Yan, Chem. Rev. 115, 10725 (2015)

154. Y. Shao, B. Liu, Z. Di, G. Zhang, L.D. Sun, L. Li, C.H. Yan, J. Am. Chem. Soc. 142, 3939 (2020)

155. G.M.F. Calixto, J. Bernegossi, L.M. De Freitas, C.R. Fontana, M. Chorilli, A.M. Grumezescu, Molecules 21, 342 (2016)

156. T.J. Dougherty, C.J. Gomer, B.W. Henderson, G. Jori, D. Kessel, M. Korbelik, J. Moan, Q. Peng, J. Natl. Cancer Inst. 90, 889 (1998)

157. Q. Cheng, W. Yu, J. Ye, M. Liu, W. Liu, C. Zhang, C. Zhang, J. Feng, X.Z. Zhang, Biomaterials 224, 119500 (2019)

158. W. Zhu, Y. Liu, Z. Yang, L. Zhang, L. Xiao, P. Liu, J. Wang, C. Yi, Z. Xu, J. Ren, J. Mater. Chem. B 6, 265 (2018)

159. X. Fu, Z. Yang, T. Deng, J. Chen, Y. Wen, X. Fu, L. Zhou, C. Yu, Z. Zhu, J. Mater. Chem. B 8, 1481 (2020)

160. S. Sharma, D. Mittal, A.K. Verma, I. Roy, A.C.S. Appl, Bio Mater. 2, 2092 (2019)

161. D. Xu, Y. You, F. Zeng, Y. Wang, C. Liang, H. Feng, X. Ma, A.C.S. Appl, Mater. Interfaces 10, 15517 (2018)

162. X. Meng, J. Deng, F. Liu, T. Guo, M. Liu, P. Dai, A. Fan, Z. Wang, Y. Zhao, Nano Lett. 19, 7866 (2019)

163. S. Sharma, K. Sethi, I. Roy, New J. Chem. 41, 11860 (2017)

164. D. Wang, H. Wu, S.Z.F. Phua, G. Yang, W.Q. Lim, L. Gu, C. Qian, H. Wang, Z. Guo, H. Chen, Y. Zhao, Nat. Commun. 11, 1 (2020)

165. Y. Pan, Z. Luo, X. Wang, Q. Chen, J. Chen, Y. Guan, D. Liu, H. Xu, J. Liu, Dalt. Trans. 49, 5291 (2020)

166. Y. Zhang, H. Fu, S. Chen, B. Liu, W. Sun, H. Gao, Chem. Commun. 56, $762(2020)$

167. F. Nian, Y. Huang, M. Song, J.J. Chen, J. Xue, J. Mater. Chem. B 5, 6227 (2017)

168. H.M. Meng, X.X. Hu, G.Z. Kong, C. Yang, T. Fu, Z.H. Li, X.B. Zhang, Theranostics 8, 4332 (2018)

169. L. He, M. Brasino, C. Mao, S. Cho, W. Park, A.P. Goodwin, J.N. Cha, Small 13, 1700504 (2017)

170. X. Wang, J. Xu, D. Yang, C. Sun, Q. Sun, F. He, S. Gai, C. Zhong, C. Li, P. Yang, Chem. Eng. J. 354, 1141 (2018)

171. Y. Chen, W. Liu, Y. Shang, P. Cao, J. Cui, Z. Li, X. Yin, Y. Li, Int. J. Nanomed. 14, 57 (2019)
172. D. Bůžek, J. Zelenka, P. Ulbrich, T. Ruml, I. Křížová, J. Lang, P. Kubát, J. Demel, K. Kirakci, K. Lang, J. Mater. Chem. B 5, 1815 (2017)

173. Y. Zhao, Y. Kuang, M. Liu, J. Wang, R. Pei, Chem. Mater. 30 , $7511(2018)$

174. W. Lin, J. Gong, L. Fang, K. Jiang, Zeitschrift Fur Anorg. Und Allg. Chemie 645, 1161 (2019)

175. Y. Liu, C.S. Gong, L. Lin, Z. Zhou, Y. Liu, Z. Yang, Z. Shen, G. Yu, Z. Wang, S. Wang, Y. Ma, W. Fan, L. He, G. Niu, Y. Dai, X. Chen, Theranostics 9, 2791 (2019)

176. S.Y. Li, H. Cheng, B.R. Xie, W.X. Qiu, J.Y. Zeng, C.X. Li, S.S. Wan, L. Zhang, W.L. Liu, X.Z. Zhang, ACS Nano 11, 7006 (2017)

177. Q. Guan, L.L. Zhou, Y.A. Li, Y.B. Dong, Inorg. Chem. 57, 10137 (2018)

178. C. Tamames-Tabar, D. Cunha, E. Imbuluzqueta, F. Ragon, C. Serre, M.J. Blanco-Prieto, P. Horcajada, J. Mater. Chem. B 2, $262(2014)$

179. K. Ni, T. Luo, G.T. Nash, W. Lin, Acc. Chem. Res. 53, 1739 (2020)

180. P. Li, J. Li, X. Feng, J. Li, Y. Hao, J. Zhang, H. Wang, A. Yin, J. Zhou, X. Ma, B. Wang, Nat. Commun. 10, 1 (2019)

181. N. Rabiee, M. Bagherzadeh, A. Ghasemi, H. Zare, S. Ahmadi, Y. Fatahi, R. Dinarvand, M. Rabiee, S. Ramakrishna, M. Shokouhimehr, R.S. Varma, Int. J. Mol. Sci. 21, 1 (2020)

182. V. Gupta, S. Mohiyuddin, A. Sachdev, P.K. Soni, P. Gopinath, S. Tyagi, J. Drug Deliv. Sci. Technol. 52, 846 (2019)

183. F. Shu, D. Lv, X.L. Song, B. Huang, C. Wang, Y. Yu, S.C. Zhao, RSC Adv. 8, 6581 (2018)

184. C. Sang, L. Ma, D. Luo, H. Liu, D. Li, T. Chen, Chem. Eng. J. 371, 301 (2019)

185. B.H. Song, X. Ding, C. Li, G.F. An, Zeitschrift Fur Anorg. Und Allg. Chemie 644, 472 (2018)

186. A. Tiwari, A. Singh, N. Garg, J.K. Randhawa, Sci. Rep. 7, 1 (2017)

187. Z. Wu, N. Hao, H. Zhang, Z. Guo, R. Liu, B. He, S. Li, Biomater. Sci. 5, 1032 (2017)

188. C. Adhikari, A. Mishra, D. Nayak, A. Chakraborty, J. Drug Deliv. Sci. Technol. 47, 1 (2018)

189. F. Li, C. Gu, H. Li, J. Xu, J. Liu, J. Inorg. Organomet. Polym. Mater. 27, 334 (2017)

190. S. Javanbakht, M. Pooresmaeil, H. Namazi, Carbohydr. Polym. 208, 294 (2019)

191. R. Abazari, A.R. Mahjoub, F. Ataei, A. Morsali, C.L. CarpenterWarren, K. Mehdizadeh, A.M.Z. Slawin, Inorg. Chem. 57, 13364 (2018)

192. L. Fang, W. Wang, Y. Liu, Z. Xie, L. Chen, Dalt. Trans. 46, 8933 (2017)

193. J. Meng, X. Chen, Y. Tian, Z. Li, Q. Zheng, Chem. A Eur. J. 23, $17521(2017)$

194. Z. Tian, X. Yao, Y. Zhu, Microporous Mesoporous Mater. 237, 160 (2017)

195. X. Yang, L. Li, D. He, L. Hai, J. Tang, H. Li, X. He, K. Wang, J. Mater. Chem. B 5, 4648 (2017)

196. J. Feng, Z. Xu, P. Dong, W. Yu, F. Liu, Q. Jiang, F. Wang, X. Liu, J. Mater. Chem. B 7, 994 (2019)

197. Q. Wu, M. Niu, X. Chen, L. Tan, C. Fu, X. Ren, J. Ren, L. Li, K. Xu, H. Zhong, X. Meng, Biomaterials 162, 132 (2018)

198. H. Zhang, Q. Zhang, C. Liu, B. Han, Biomater. Sci. 7, 1696 (2019)

199. B. Li, X. Wang, L. Chen, Y. Zhou, W. Dang, J. Chang, C. Wu, Theranostics 8, 4086 (2018)

Publisher's Note Springer Nature remains neutral with regard to jurisdictional claims in published maps and institutional affiliations. 
Pierre D. Harvey obtained his MSc at the U. de Montréal (1982) and his $\mathrm{PhD}$ at McGill U. (1986). He was a NSERC postdoctoral fellow at CalTech (1986-88) and MIT (1988) under the supervisions of Profs H.B. Gray and M.S. Wrighton, respectively. He was appointed assistant professor (1989) and promoted to full professor (1998) at the U. de Sherbrooke (Canada). He awarded a Chaire d'Excellence de Recherche from the ANR (France) held at the U. de Bourgogne, Dijon (2008-10). He serves on the Editorial Boards of the Journal of Cluster Science and Journal of Inorganic and Organometallic Polymers. He published over 320 research papers and 8 book chapters, and he was awarded the Rio Tinto Alcan Award from the Canadian Society for Chemistry (2013), among many other prizes.
Jessica Plé obtained her MSc at the European school of Chemistry, Polymers and Materials (ECPM) in Strasbourg, majoring in material sciences. During her second year, she worked at Teijin Aramid (The Netherlands) as an intern, to study the thermostability of friction paper in automatic transmission systems and the mechanical properties of aramid-reinforced rubber. She spent her final year at the University of Sherbrooke at the end of which she obtained another MSc in nanomaterials. During this time, she also joined Prof. Harvey's research group to work on the synthesis and characterisation of MOFs. She was the recipient of an excellence grant provided by the University of Strasbourg to finance her year in Canada. 